\title{
Chapter
}

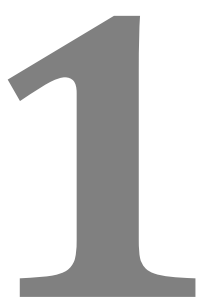

\section{PHYSICOCHEMICAL PROFILING IN DRUG RESEARCH AND DEVELOPMENT}

\author{
Krisztina Takács-Novák
}

\section{Contents}

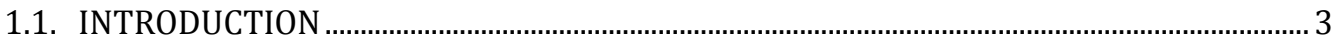

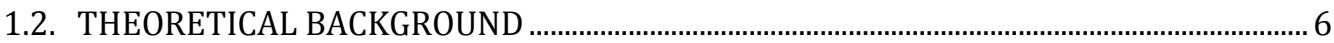

1.2.1. The physical-chemistry of drug action .................................................................. 6

1.2.2. Physicochemical parameters …………………………………………………….... 8

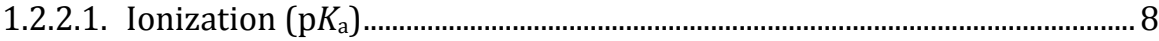

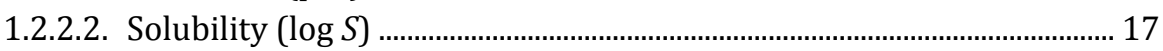

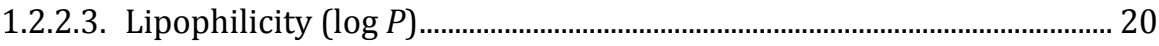

1. 3. METHODS FOR PHYSICOCHEMICAL PROFILING.................................................................. 25

1.3.1. $\mathrm{p} K_{\mathrm{a}}$ determination .................................................................................................. 25

1.3.1.1. Potentiometric method ........................................................................... 26

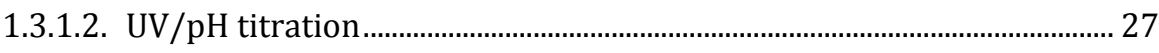

1.3.1.3. Other methods............................................................................................ 28

1.3.1.4. Co-solvent method........................................................................................... 30

1.3.1.5. Decision tree for method selection .......................................................... 31 


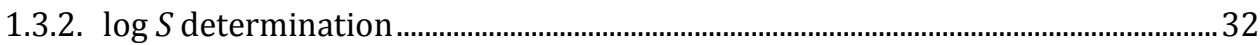

1.3.2.1. Methods for determination of kinetic solubility.......................................32

1.3.2.2. Methods for determination of equilibrium solubility ...............................33

1.3.2.2.1. Saturation shake-flask method (SSF) .......................................... 33

1.3.2.2.2. Potentiometric methods............................................................ 34

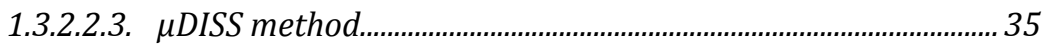

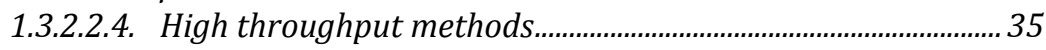

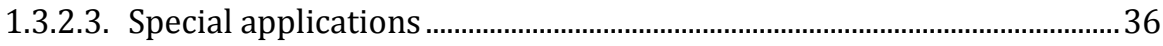

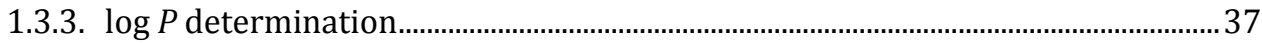

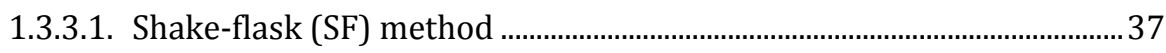

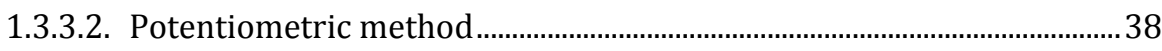

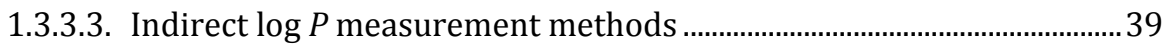

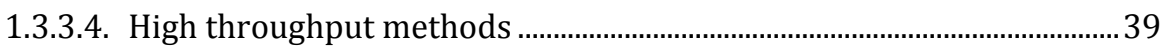

1.3.3.5. Decision tree for method selection............................................................. 40

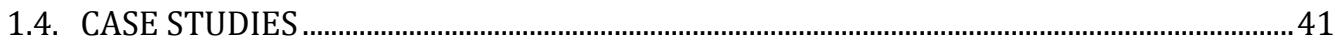

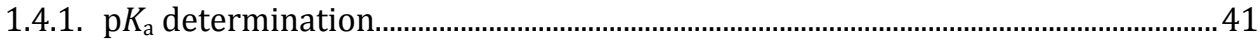

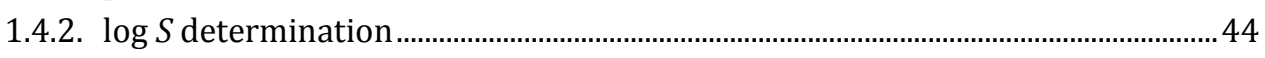

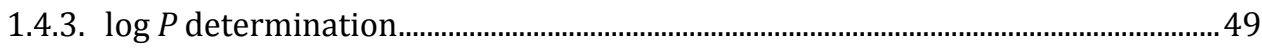

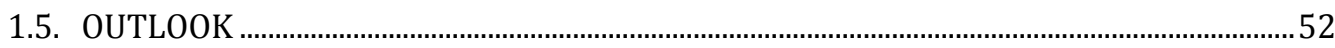

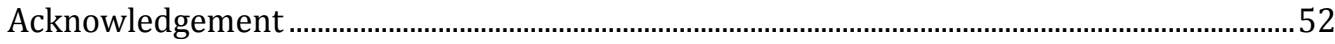

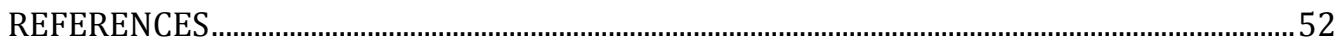




\subsection{INTRODUCTION}

The purpose of drug research is to develop effective, safe, and high quality new medicines to treat diseases where no drugs or otherwise nonoptimal ones are available. This activity is very complex, lengthy, expensive, and risky. Since drug research became industrialized, the highest level of scientific and technological knowledge has been applied during the given era. Fundamentally, the industry uses and puts into the practice the newest scientific results as early as possible thus drug research itself becomes the driving force for the development of new theories, technologies, and methods [1].

Taking a look back at the history of drug research, one can recognize on the long way of the evolution of the present system some milestones, paradigm-changes which resulted in considerable development in its age (Figure 1.1). In the '60s of the last century, the formerly used traditional methods (such as the extraction of active compounds from medicinal plants; random screening, trial-error method; side-effect observation; serendipity, etc.) more or less have been replaced or at least extended by the new strategy of rational drug design. Its first application was the Quantitative Structure-Activity Relationships (QSAR) analysis introduced by C. Hansch [2] and based on the accumulated knowledge of structure-activity relationships. The rational drug design was completed with the application of 3D molecular modeling, theoretical and computational chemistry (Computer Aided Drug Design, CADD) and proved to be a more effective tool than previous ones in the discovery and optimization of new active molecules. The appearance and fast expansion of high throughput screening (HTS) and combinatorial chemistry in the '90s have greatly enhanced the number of active compounds found [3]. The latest paradigm-change was provoked by the human genome project and the increased number of potential targets identified by genomics. However, these changes in the research strategy did not mean that former methods were completely neglected, indeed a majority of them are an inherent part of drug research. Each method has its appropriate use and importance in it.

Since the first recognitions of structure-activity relationships, medicinal chemists involved in drug research have been always paying outstanding attention to those properties of drugs which determine their pharmacological action. The knowledge of solubility, ionization ability and lipophilicity of drug candidates provides useful information about the expectable pharmacokinetic properties 
and gives synthetic chemists adequate tools to improve them by modifying the structural moieties of the molecule [4].

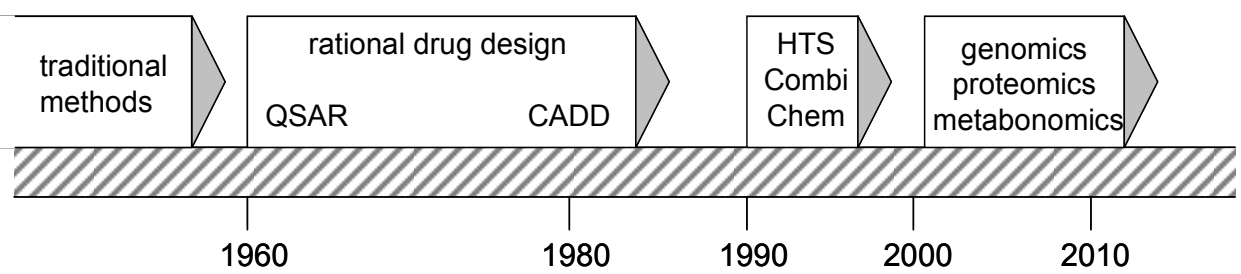

Figure 1.1. Strategies in drug research

In the past, however, the main focus of drug research was first devoted almost exclusively to the pharmacodynamic aspects of the biological activity and only later in the development phase were the pharmacokinetic properties examined. This has led to a high attrition rate of compounds. In the late '80s studies reported two prominent reasons of drug candidate failure: the poor biopharmaceutical properties (e.g. low bioavailability) and safety. Pharmaceutical companies have made initiatives to shift the physicochemical profiling of compounds earlier in the drug discovery process [5].

Currently, drug research is usually divided into two main phases: (1) discovery phase, which involves the target identification, hit discovery, lead selection and optimization; and (2) development phase in which preclinical and clinical studies are conducted (Figure 1.2). The role and timing of the physicochemical characterization has considerably changed. The new strategy applied since the ' 90 s is based on a parallel optimization of efficacy and prognostic profiling of drugability. This required a new mentality: to break down the wall between the discovery and development phases and to migrate from sequentially assessing efficacy and drugability to the parallel process; to evaluate the therapeutic and drug-like features together [6].

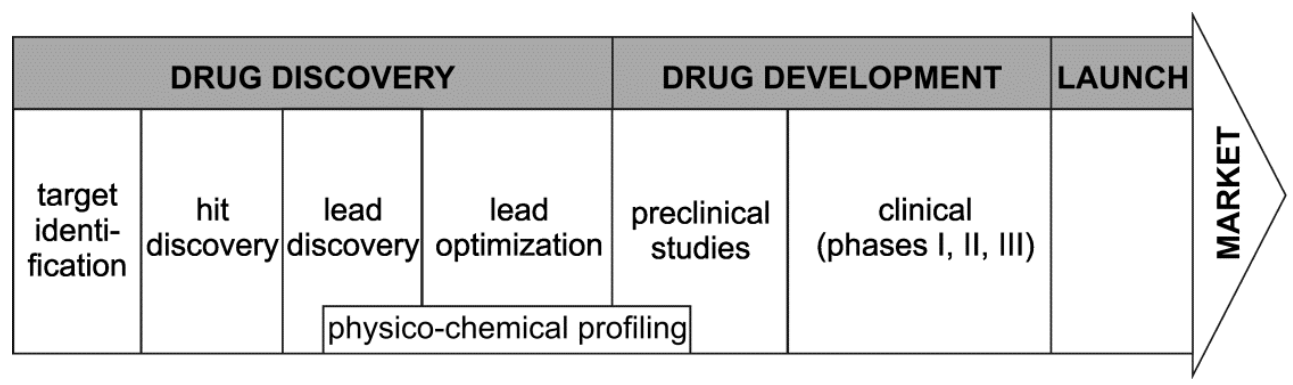

Figure 1.2. Drug research process

Good pharmaceutical properties, besides the efficacy, mean good absorption and distribution, chemical and metabolic stability (appropriate bioavailability) and low toxicity. 
For optimization of drug-like properties, physicochemical parameters are simple and cheap tools in the early phase of drug research. Determination of properties relevant to biological activity of drugs such as ionization, solubility, lipophilicity and permeability is called physicochemical profiling (Kerns et al. 2001.) [7].

It is distinguished from the more complex term pharmaceutical profiling which involves the investigation of integrity, stability, metabolic properties (e.g. CYP 450 inhibition), transporter effects and drug-drug interactions as well (Figure 1.3) [8].

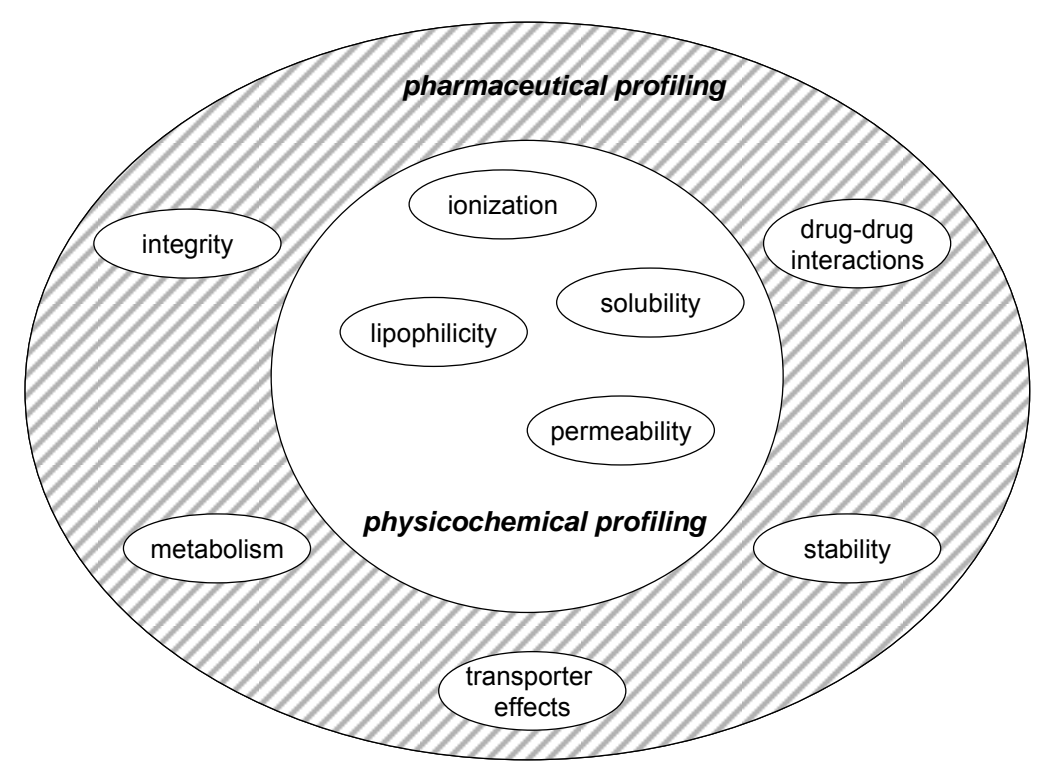

Figure 1.3. Pharmaceutical profiling $v s$. physicochemical profiling

The present chapter focuses on only three parameters of physicochemical profiling $\left(\mathrm{p} K_{\mathrm{a}}, \log S\right.$, and $\log P$ ) while Chapter 3 is dedicated to the role and determination of membrane permeability. The traditional non-automated, timeand material-consuming methods developed in the past for physicochemical profiling are not suitable in discovery for the measurement of the drastically increased number of new chemical entities (NCE). Nowadays, such early physicochemical determinations must be material-saving, HT, and reasonably reliable. Several excellent commercial instruments have been developed for this purpose, which are miniaturized, automated, and adapted to high-throughput technologies [9].

The first comprehensive overview of physicochemical profiling was reported by P. Taylor in 1990 [10]. The progressive development achieved in the next decade is surveyed in A. Avdeef's book: Absorption and Drug Development: Solubility, Permeability and Charge State [11]. This book can be considered as the most competent and detailed compilation of advanced knowledge required by physical chemists involved in drug development. Numerous reviews summarized the state-of-the-art of new HT experimental techniques [12-15], the most recent was 
published by Y. Henchoz et al. [16]. So, various literature sources are available for all who would expand their understanding of physicochemical profiling according to their need.

The aim of this chapter is to provide: (i) a concise summary of theoretical background; (ii) a comparison of different experimental methods and approaches; (iii) an introduction to ample, useful, and practical examples. The case studies taken from more than 30 years of experiences of the author are intended to provide help to physical chemists in the right method selection and measurement of difficult molecules.

\subsection{THEORETICAL BACKGROUND}

\subsubsection{The physical chemistry of drug action}

Drug action is a consequence of several chemical and biological processes in which binding to the receptor (pharmacodynamic phase) is essential. Besides this however, the pharmacokinetic processes have also fundamental importance in the biological activity. The active ingredient of a drug must separate from the applied pharmaceutical dosage form, must dissolve in body fluids and permeate through biological membranes to reach the receptor site. Following the receptor response, the active compound dissociating from the binding site generally undergoes metabolism and is excreted from the body. These liberation, absorption, distribution, metabolism, excretion (LADME) features are mainly determined by the physicochemical properties of drugs, namely by ionization, solubility and lipophilicity.

Biological membranes are the main physiological permeation barriers to be crossed by drugs. Structurally, they have a lipid bilayer resulting from the orientation of amphiprotic lipids (phospholipids, glycolipids, sphyngomyelin) and cholesterol in the aqueous medium. This bilayer has some of the properties of a two-dimensional fluid (fluid-mosaic membrane model) in which individual lipid molecules can diffuse rapidly in the plane of their monolayer (lateral mobility) but cannot easily pass to the other monolayer. An important observation is that phospholipids are asymmetrically distributed in the membrane. Generally, the outer (extracellular) half of the bilayer comprises mainly zwitterionic lipids (phosphatidylcholine and phosphatidylethanolamine), whereas the inner (intracellular) part contains negatively charged lipids (e.g., phosphatidylserine). Different proteins that induce transporter, signal transduction, or metabolic functions are integrated into the lipid bilayer $[17,18]$. The biological membranes are apolar barriers, where the relative permittivity inside is extremely low $(\varepsilon \sim 2)$. It has long been assumed that most drugs use transcellular transport and pass these barriers by passive diffusion which is favorable only for unionized, lipophilic compounds. There are several other mechanisms of permeation. Active transport is ligand-mediated by different transporters for compounds. Paracellular permeation exists between the cells for smaller, more polar compounds. 
Some compounds are transported by endocytosis, when the molecules are engulfed by the membrane and move through the cell in these membraneenclosed vesicles. For further detailed information, the reader is encouraged to review specialized resources $[18,19]$.

The pH-partition hypothesis [20] provides a good model for the passive transport of ionizable molecules with sufficient lipophilicity. Figure 1.4 shows a schematic representation of the transport of a basic (B) (e.g. papaverine, chlorpromazine, etc.) and an acidic (HA) (e.g. acetylsalicylic acid, ibuprofen, etc.) molecule. In the extracellular aqueous medium, the ratio of ionized $\left(\left[\mathrm{BH}^{+}\right]\right.$or $\left.\left[\mathrm{A}^{-}\right]\right)$and unionized ([B] or [HA]) forms is dependent on the actual $\mathrm{pH}$ of the given compartment and the $\mathrm{p} K_{\mathrm{a}}$ of the compound. The uncharged, neutral species has much higher lipophilicity than its charged (ionic) form, thus it can permeate through the lipid membrane even if being present as a minor component. In medicinal chemistry this species is called the "transport form". Entering into the intracellular aqueous phase, another ionization process takes place resulting in the ionized form again which generally interacts with the target and is referred to as the "receptor form". The amount of the transport form present at the membrane surface depends on its solubility. Molecules must be in solution in order to diffuse into the membranes, however low solubility can be a limiting factor of permeation. Permeability as a determinant kinetic parameter of transport is discussed in Chapter 3.

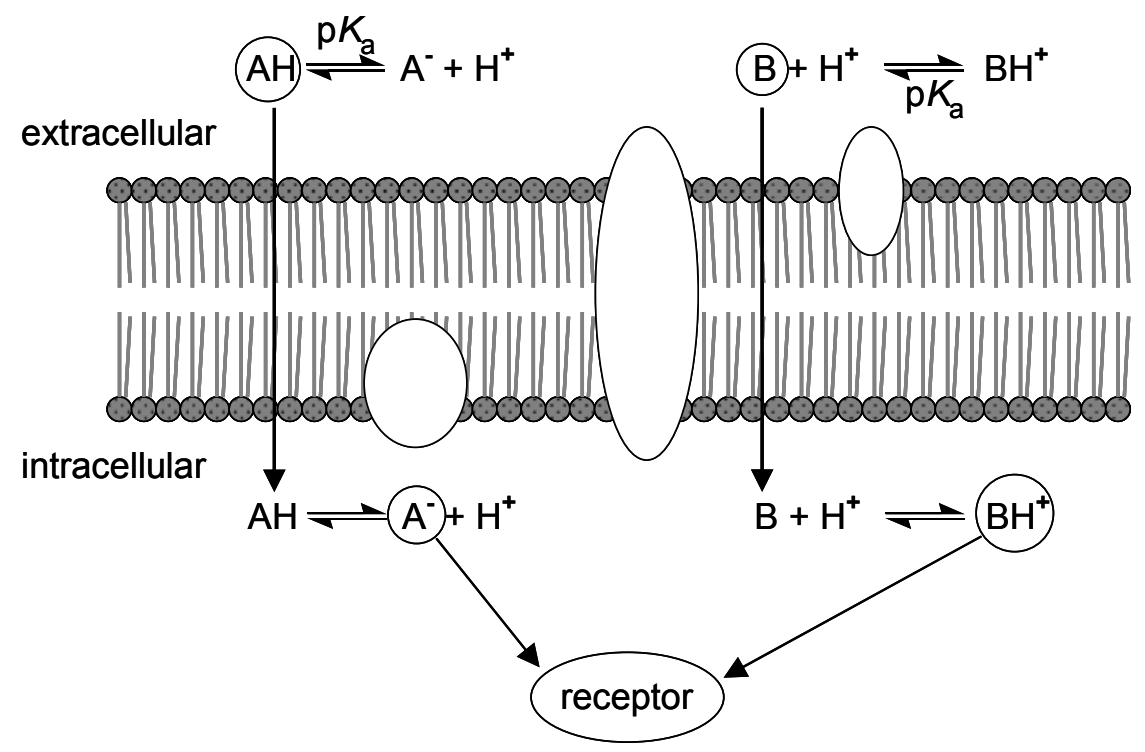

Figure 1.4. Transport and receptor forms of an acid and a base

The concept derived from the pH-partition theory that "only neutral molecules permeate membranes" started to be questioned from the mid "90s because of an increasing body of experimental evidence supporting ion-partitioning into artificial membranes like liposomes [21]. This was interpreted with electrostatic interactions and hydrogen bonding between the charged group of compounds 
and ionized polar head group of phospholipids in the "pH priston model" [22]. Recently, S. Krämer and coworkers [23] reviewed the mechanisms underlying lipid bilayer permeation. They proposed a kinetic "flip-flop model" based on a three-step mechanism, namely the partitioning into one lipid layer, translocation (flip-flop) to the opposite lipid layer and partitioning into the aqueous phase. According to this model, the permeation of a charged species could be the result of occasionally occurring trans-membrane translocation of charged compounds. It was concluded that membrane permeation is more complex than expected from a simple diffusion model and $\mathrm{pH}$-partition hypothesis.

Another possible mechanism of transport for ionized, hydrophilic compounds is carrier-mediated active transport. The increasing number of different uptake transporters discovered in the past 15 years highlights the importance of the role of active transport in membrane permeation of drugs which may be underestimated. Their physiological function is to deliver the necessary nutrients and other endogenous biochemical compounds having low lipophilicity for passive diffusion to the cell. Several drugs were found to be the substrate of different specific transporters like oligopeptide (PEPT1: captopril, enalapril, ampicillin, acyclovir), organic anion (OATP1: fexofenadine, enalapril, temocaprilat), organic cation (OCT1: metformin, famotidin), or nucleoside, etc. [18,24]. The efflux transporters (P-glycoprotein, P-gp; breast cancer resistance protein, BCRP; multidrug resistance protein, MRP2) assist in the movement of compounds out of the cell as they protect the cell from potentially toxic xenobiotics. This outward transport has a negative effect on the pharmacokinetics of some compounds. The activity of efflux transporters is very intensive in the blood-brain barrier and some tumor cells resulting in multidrug resistance. Binding to the transporters is determined by the chemical structure of compound. Similar moieties to the natural substrate, a large number of $\mathrm{H}$-bond acceptors ( $\mathrm{N}+\mathrm{O}$ atoms), and high molecular weight $\left(M_{\mathrm{w}}>400\right)$ appear to increase the likelihood of P-gp efflux [25].

Physicochemical properties influencing the fate of a drug in the body are described by the thermodynamic equilibrium constants. Below, we summarize the fundamentals of $\mathrm{p} K_{\mathrm{a}}, \log S$, and $\log P$ terms.

\subsubsection{Physicochemical parameters}

\subsubsection{Ionization $\left(\mathrm{p} K_{\mathrm{a}}\right)$}

Drugs are multifunctional compounds. A great majority of them contain one or more ionizable (acidic or basic) functional groups. In aqueous solutions, ionizable compounds exist in different ionization (charged or uncharged) states depending on their strength of acidity or basicity and the $\mathrm{pH}$ of the solution.

\section{Definitions, terms}

The ionization constant (or acid dissociation constant), $K_{\mathrm{a}}$, is used to characterize the acid-base chemistry of a molecule generally expressed as a negative logarithm: $-\log K_{\mathrm{a}}=\mathrm{p} K_{\mathrm{a}}$. In medicinal chemistry, it is common to use $\mathrm{p} K_{\mathrm{a}}$ for both acids 
and bases. In aqueous solutions, the $\mathrm{p} K_{\mathrm{a}}$ scale spans from 0 to 14 . The stronger the acid, the lower is its $\mathrm{p} K_{\mathrm{a}}$ value. The opposite is true for bases; a higher $\mathrm{p} K_{\mathrm{a}}$ value means stronger basicity [26].

\section{$\longleftarrow$ increasing acidity}
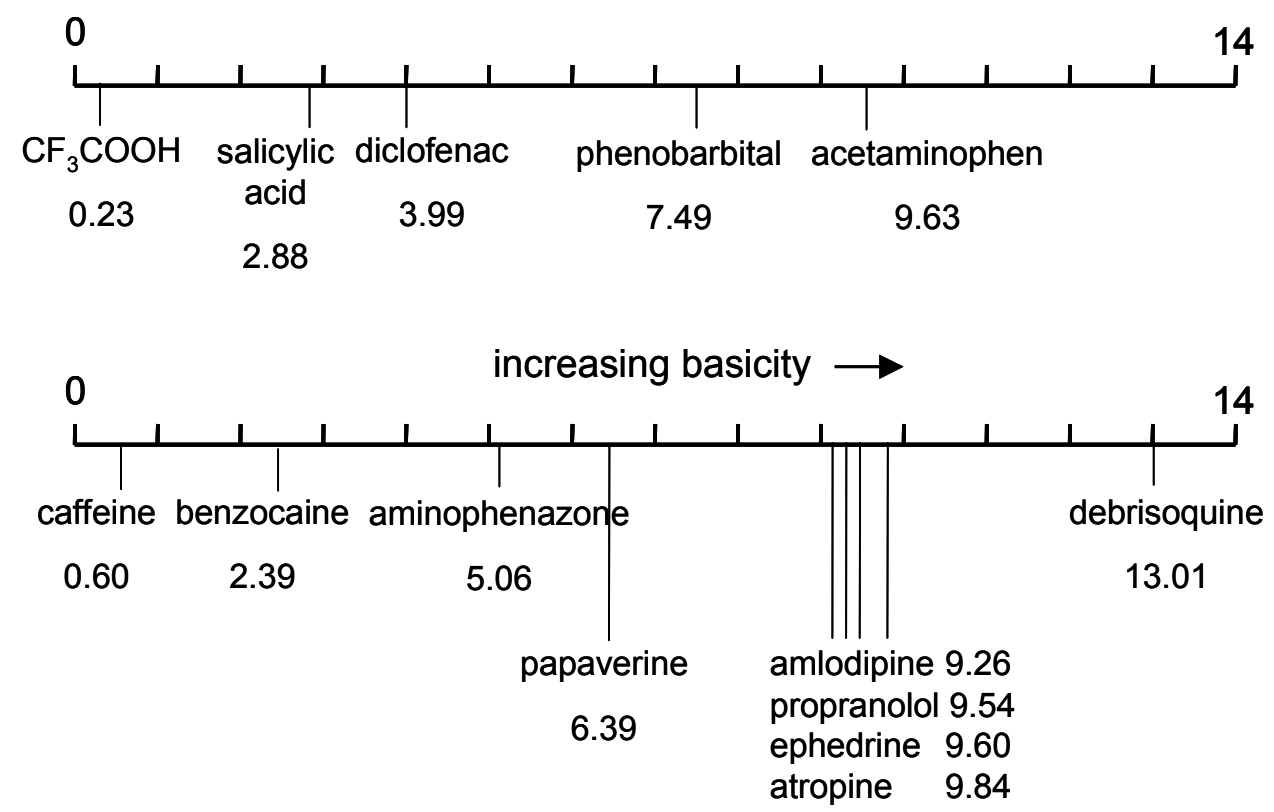

Figure 1.5. The $\mathrm{p} K_{\mathrm{a}}$ scale in aqueous medium

Some examples for the most frequently occurring acidic and basic functional groups in drugs are listed in Tables 1.1 and 1.2.

Equations 1.1-1.4 show the ionization equilibria and the relevant thermodynamic ionization constants using general symbols: HA for acid, B for base, XH for diprotic ampholyte molecule.

$$
\begin{aligned}
& \mathrm{HA} \rightleftharpoons \mathrm{A}^{-}+\mathrm{H}^{+} \quad K_{a}=\frac{\left[\mathrm{A}^{-}\right]\left[\mathrm{H}^{+}\right]}{[\mathrm{HA}]} \\
& \mathrm{p} K_{\mathrm{a}}=\mathrm{pH}+\log \frac{[\mathrm{HA}]}{\left[\mathrm{A}^{-}\right]} \\
& \mathrm{BH}^{+} \rightleftharpoons \mathrm{B}+\mathrm{H}^{+} \quad K_{\mathrm{a}}=\frac{[\mathrm{B}]\left[\mathrm{H}^{+}\right]}{\left[\mathrm{BH}^{+}\right]}
\end{aligned}
$$


Table 1.1. Some important acidic functional groups in drugs

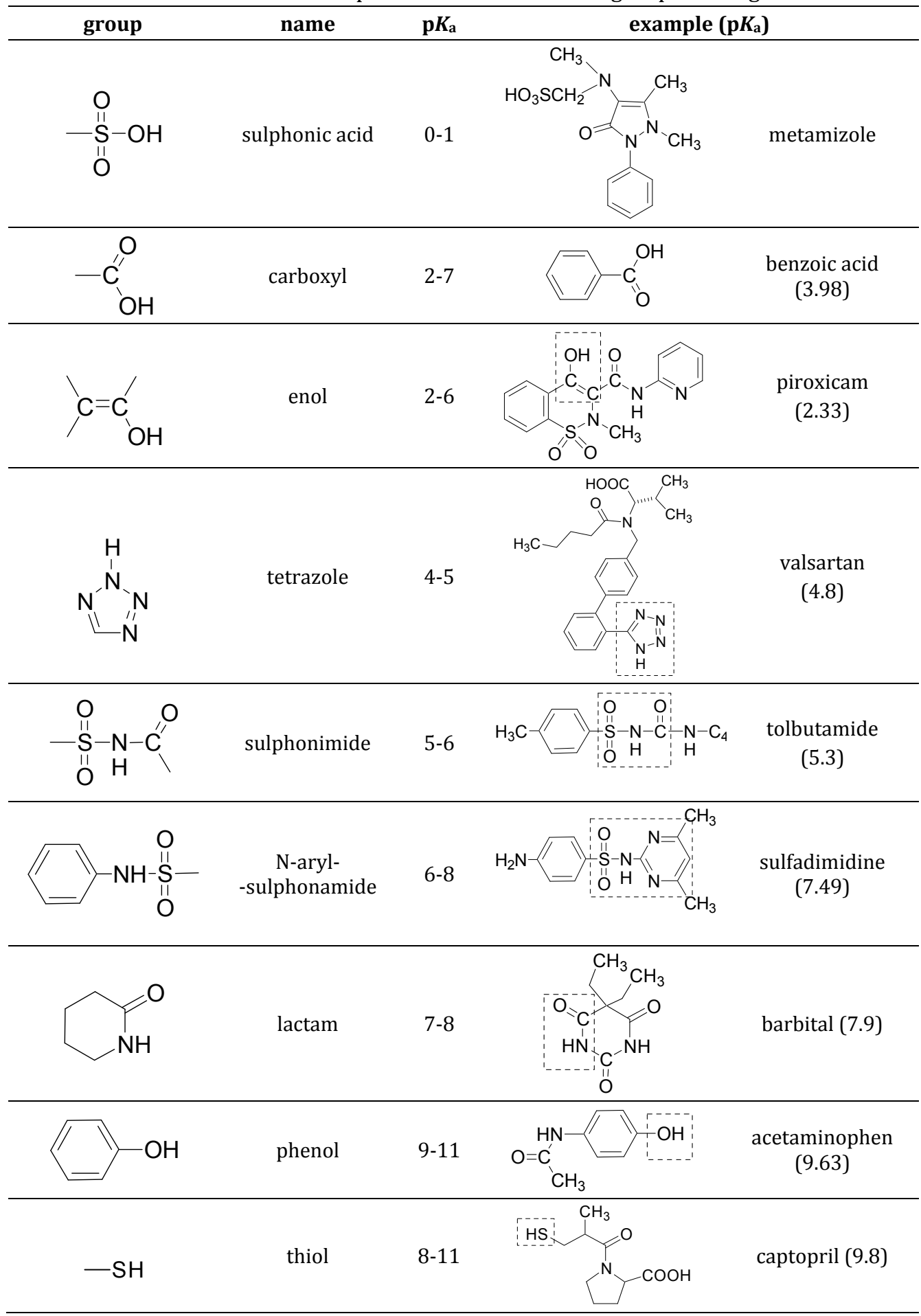


Table 1.2. Some important basic functional groups in drugs

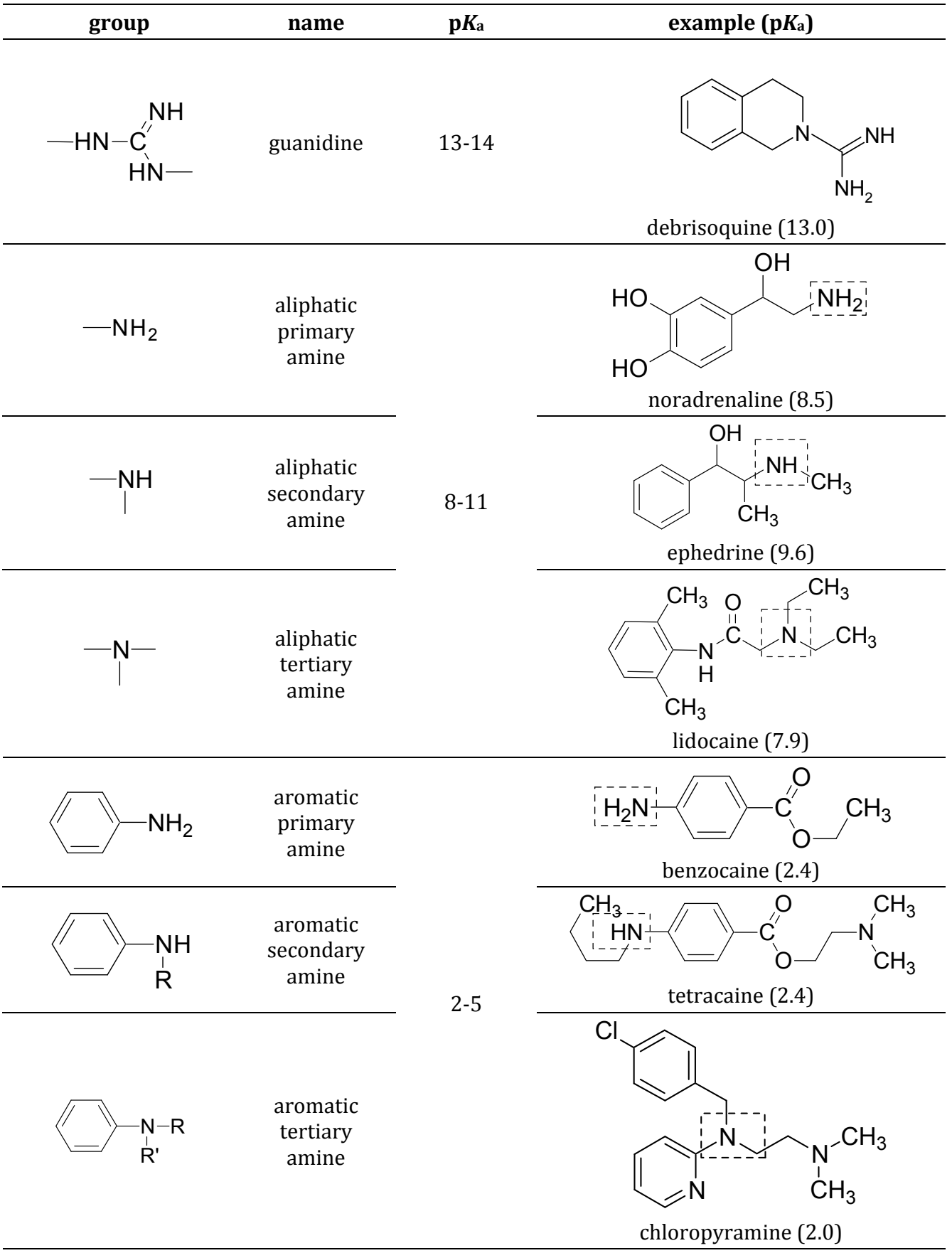




$$
\begin{aligned}
& \mathrm{p} K_{\mathrm{a}}=\mathrm{pH}+\log \frac{\left[\mathrm{BH}^{+}\right]}{[\mathrm{B}]} \\
& \mathrm{XH}_{2}^{+} \rightleftharpoons \mathrm{XH}+\mathrm{H}^{+} \quad K_{\mathrm{a} 1}=\frac{[\mathrm{XH}]\left[\mathrm{H}^{+}\right]}{\left[\mathrm{XH}_{2}^{+}\right]} \\
& \mathrm{XH} \rightleftharpoons \mathrm{X}^{-}+\mathrm{H}^{+} \quad K_{a 2}=\frac{\left[\mathrm{X}^{-}\right]\left[\mathrm{H}^{+}\right]}{[\mathrm{XH}]} \\
& \mathrm{p} K_{\mathrm{a} 1}=\mathrm{pH}+\log \frac{\left[\mathrm{XH}_{2}^{+}\right]}{[\mathrm{XH}]} \quad \mathrm{p} K_{\mathrm{a} 2}=\mathrm{pH}+\log \frac{[\mathrm{XH}]}{\left[\mathrm{X}^{-}\right]}
\end{aligned}
$$

In certain research articles, preference is given to the use of the ionization rather than the proton association process and the term protonation constant, $K_{\mathrm{p}}$, particularly in coordination chemistry [27]. The relationship between them is reciprocal where $K_{\mathrm{a}}=1 / K_{\mathrm{p}}$, or $\mathrm{p} K_{\mathrm{a}}=\log K_{\mathrm{p}}$. For a monoprotic compound this relationship is evident, but may not be clear regarding molecules with more than one ionizable group. Below, we describe the ionization processes of a triprotic compound (like amoxicillin) from both points of view: dissociation (molecule releases the proton) and association (molecule gains the proton).

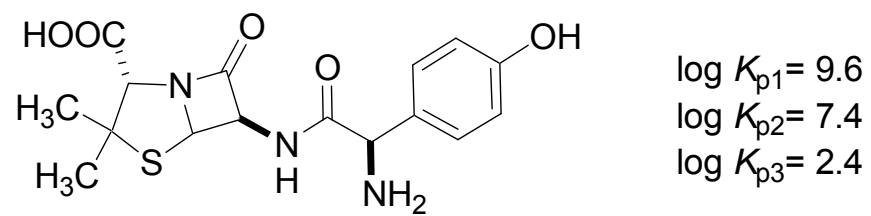

Dissociation

$$
\begin{aligned}
& \mathrm{XH}_{3}{ }^{+} \stackrel{\mathrm{K}_{\mathrm{a}} \rightleftharpoons}{\rightleftharpoons} \mathrm{XH}_{2}+\mathrm{H}^{+} \quad \mathrm{X}^{2-}+\mathrm{H}^{+} \stackrel{K_{\mathrm{p} 1}}{\rightleftharpoons} \mathrm{XH}^{-} \\
& \mathrm{XH}_{2} \stackrel{\mathrm{K}_{\mathrm{a} 2}}{\rightleftharpoons} \mathrm{XH}^{-}+\mathrm{H}^{+} \quad \mathrm{XH}^{-}+\mathrm{H}^{+} \stackrel{K_{\mathrm{p} 2}}{\rightleftharpoons} \mathrm{XH}_{2} \\
& \mathrm{XH}^{-} \stackrel{\mathrm{K}_{03}}{\rightleftharpoons} \mathrm{X}^{2-}+\mathrm{H}^{+} \quad \mathrm{XH}_{2}+\mathrm{H}^{+} \stackrel{K_{\mathrm{p} 3}}{\rightleftharpoons} \mathrm{XH}_{3}^{+} \\
& K_{\mathrm{a} 1}=\frac{1}{K_{\mathrm{p} 3}} \quad K_{\mathrm{a} 2}=\frac{1}{K_{\mathrm{p} 2}} \quad K_{\mathrm{a} 3}=\frac{1}{K_{\mathrm{p} 1}} \\
& \mathrm{p} K_{\mathrm{a} 1}=\log K_{\mathrm{p} 3} \quad \mathrm{p} K_{\mathrm{a} 2}=\log K_{\mathrm{p} 2} \quad \mathrm{p} K_{\mathrm{a} 3}=\log K_{\mathrm{p} 1}
\end{aligned}
$$




\section{Ionization microconstants}

The equilibria above characterize the dissociation/protonation of the molecule at the molecular level, so called macroscopic level, using ionization macroconstants. Ionization macroconstants quantitate the overall acidity/basicity of the molecule, but cannot be assigned to individual proton binding sites of multiprotic molecules. Ionization microconstants are the terms which describe the proton binding ability of the individual functional groups and are useful in calculating the $\mathrm{pH}$-dependent concentrations of microspecies (named microspeciation) [28]. In the past decade, the microspeciation of several drug molecules was published [e.g. 29-31].

The macroscopic and microscopic protonation scheme of a diprotic molecule using norfloxacin as a model is shown in Figure 1.6. For simplicity, $K$ denotes the protonation macroconstants and $k$ is used for microconstants. The superscript denotes the functional group is protonating in a given process, the subscript (if any) shows the already protonated group and $\mathrm{N}$ and $\mathrm{C}$ refer to the piperazine nitrogen and the carboxylate group, respectively. There are two possible alternative routes of protonation. From the most basic anionic form (X) the carboxylate group first accepts a proton resulting in the chargeless $\left(\mathrm{XH}^{\circ}\right)$ form, then a secondary amine group protonates producing the cation $\left(\mathrm{XH}_{2}{ }^{+}\right)$(lower route). The other pathway of protonation is conducted through the formation of a zwitterion $\left(\mathrm{XH}^{ \pm}\right)$due to the protonation of an amino group first. The chargeless and zwitterionic forms are chemically different microspecies (they bear the proton on different binding sites) having the same stochiometric composition (one proton is accepted), so they are protonation isomers.

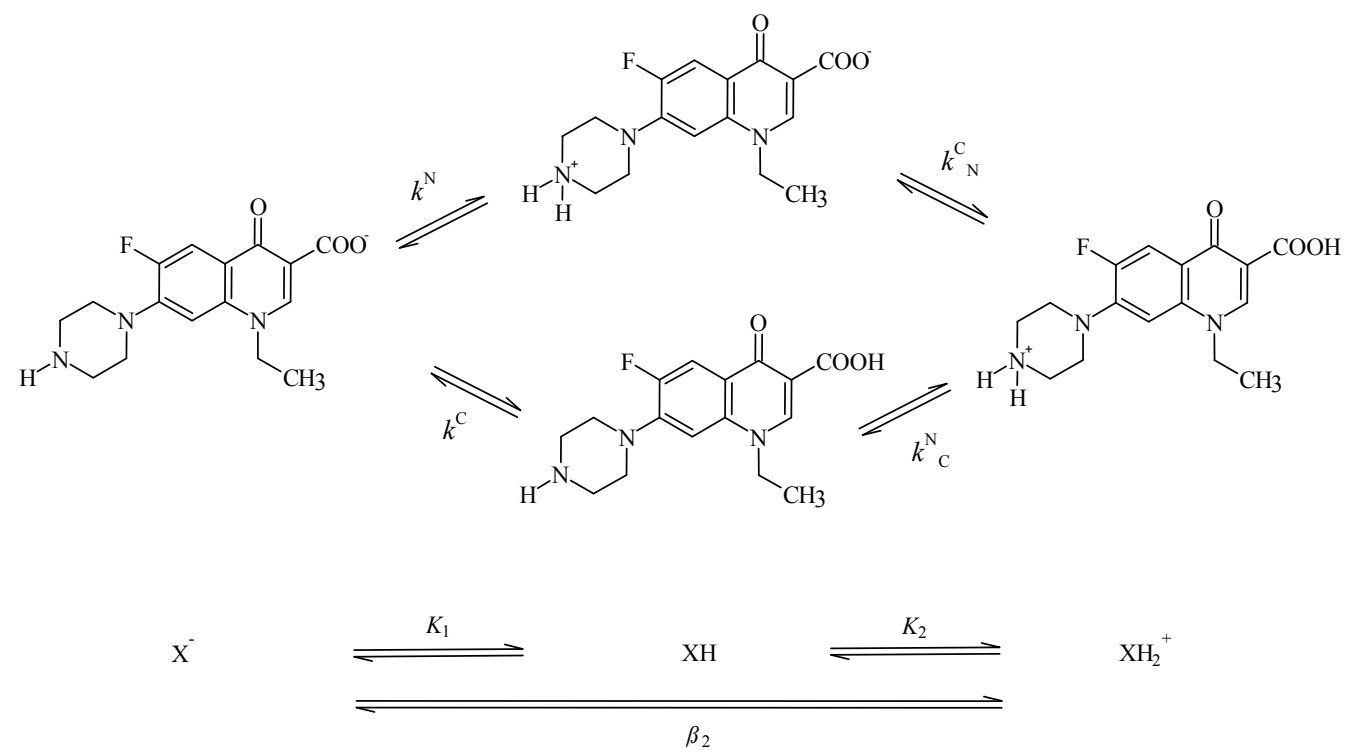

Figure 1.6. The protonation macro- and micro-equilibria of norfloxacin 
The relationships between the macro- and microconstants are the following:

$$
\begin{aligned}
& K_{1}=k^{\mathrm{C}}+k^{\mathrm{N}} \quad K_{1} K_{2}=k^{\mathrm{C}} k_{\mathrm{C}}^{\mathrm{N}}=k^{\mathrm{N}} k_{\mathrm{N}}^{\mathrm{C}} \\
& \frac{1}{K_{2}}=\frac{1}{k_{\mathrm{C}}^{\mathrm{N}}}+\frac{1}{k_{\mathrm{N}}^{\mathrm{C}}}
\end{aligned}
$$

Once macro- and microconstants are known, the mole fraction of each species can readily be calculated and the pH-dependent distribution of macro- and microspecies can be constructed. Figure 1.7 shows the distribution of different protonation forms of norfloxacin against the $\mathrm{pH}$ and indicates the predominance of the zwitterionic form over the chargeless microspecies. However, it is also visible that their concentration at the iso-electric point $\mathrm{pH}$ is commensurable and both forms are present in a significant amount.

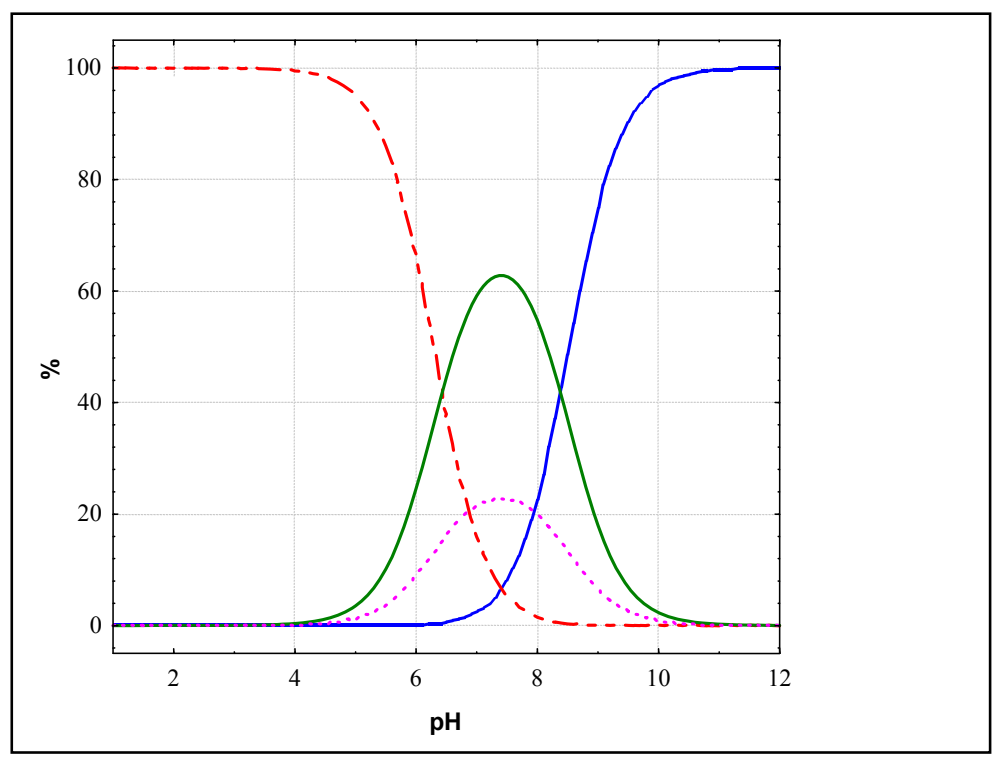

Figure 1.7. Distribution curve of the 4 microspecies of norfloxacin as a function of $\mathrm{pH}$

The microspeciation of a triprotic molecule $[32,33]$ is more complicated, containing 8 microspecies. The total protonation process can be depicted by 12 microconstants as demonstrated in case of amoxicillin in Figure 1.8. The O, N, C sub- or superscripts of the $k$ microconstant refer to the three proton binding sites, namely phenolate, amino, and carboxylate groups, respectively. The relationships between the macro- and microconstants are the following:

$$
\begin{aligned}
& K_{1}=k^{0}+k^{\mathrm{N}}+k^{C} \\
& K_{1} K_{2}=k^{0} k_{0}^{\mathrm{N}}+k^{0} k_{0}^{\mathrm{C}}+k^{\mathrm{N}} k_{\mathrm{N}}^{\mathrm{C}}=k^{\mathrm{N}} k_{\mathrm{N}}^{\mathrm{O}}+k^{\mathrm{C}} k_{\mathrm{C}}^{\mathrm{O}}+k^{\mathrm{C}} k_{\mathrm{C}}^{\mathrm{N}} \\
& K_{1} K_{2} K_{3}=k^{0} k_{0}^{\mathrm{N}} k_{0, \mathrm{~N}}^{\mathrm{C}}=k^{\mathrm{N}} k_{\mathrm{N}}^{\mathrm{O}} k_{0, \mathrm{~N}}^{\mathrm{C}}=\ldots \ldots . .
\end{aligned}
$$


The theory and practice of proton microspeciation based on NMR-pH titration and data in the literature on complete microspeciation of small ligands including drugs have recently been surveyed [34].

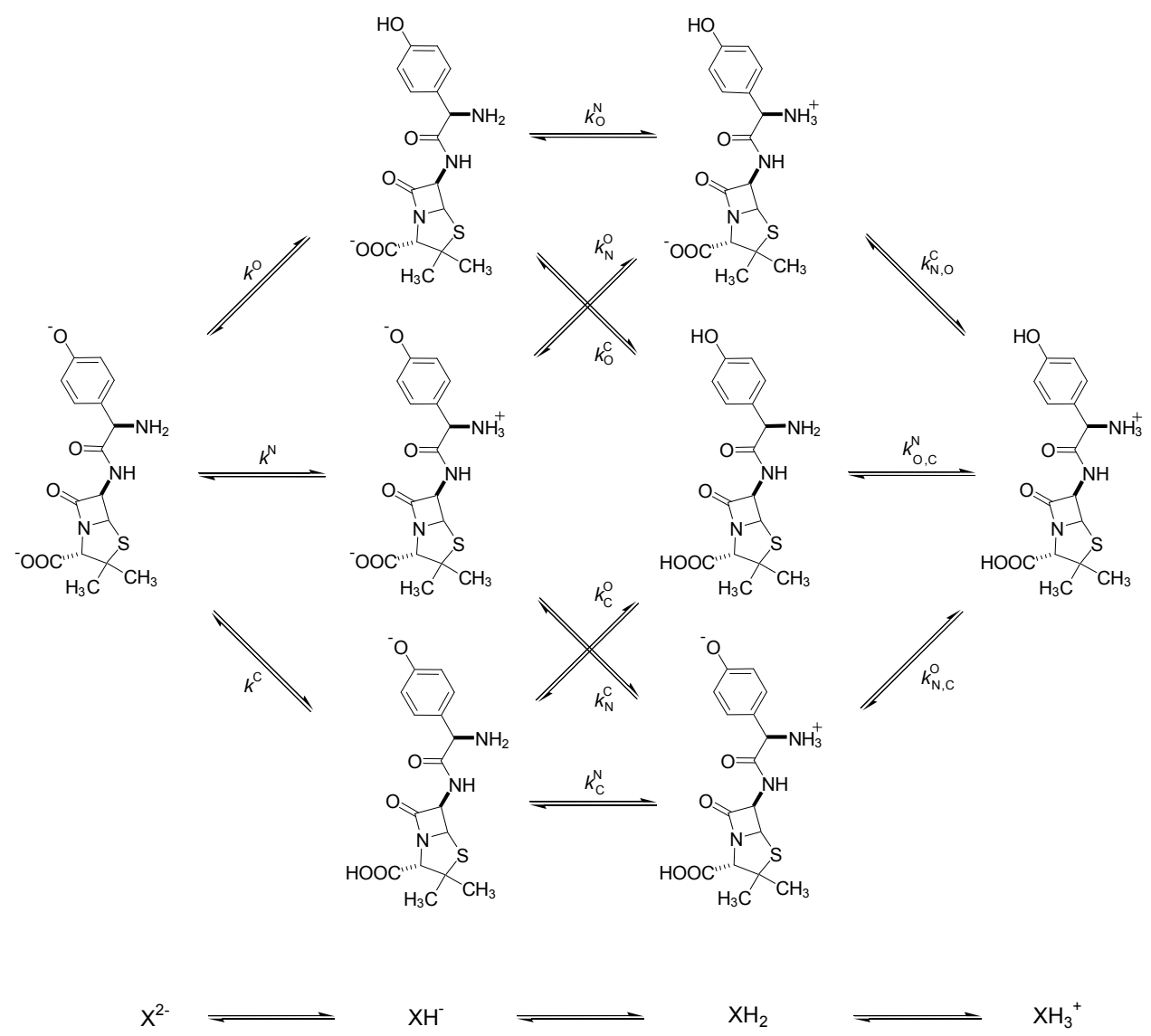

Figure 1.8. Protonation macro- and micro-equilibria of triprotic amoxicillin

\section{Temperature and ionic strength}

The ionization constant as a thermodynamic parameter is temperaturedependent. For the precise determination of $\mathrm{p} K_{\mathrm{a}}$, experiments must be conducted under controlled constant temperature. In practice, the common reference value is $25{ }^{\circ} \mathrm{C}$ and only few data are available measured at $37^{\circ} \mathrm{C}$. The change in $\mathrm{p} K_{\mathrm{a}}$ upon an increase of temperature from $25^{\circ} \mathrm{C}$ up to the physiological temperature of $37^{\circ} \mathrm{C}$ is dependent on the given molecule. Generally the change in the $\mathrm{p} K_{\mathrm{a}}$ of acids is less, while bases are more sensitive to temperature change [26]. The approximate average value of temperature dependence is known as $\delta \mathrm{p} K_{\mathrm{a}} / \delta T$ : 0.02-0.03, which means $0.24-0.36 \Delta \mathrm{p} K_{\mathrm{a}}$ values between 25 and $37^{\circ} \mathrm{C}$. If the $\mathrm{p} K_{\mathrm{a}}$ of a compound falls into the $\mathrm{pH}$ range 1.5-8 (the $\mathrm{pH}$ gradient present in the human gastrointestinal tract), then even a relatively small difference may lead to poor in 
vitro-in vivo correlations. For a better interpretation of the cellular transport mechanism of such molecules, the biorelevant $\mathrm{p} K_{\mathrm{a}}$ value is particularly useful. A prediction method for this value based on a $2 \mathrm{D}$ structure and $\mathrm{p} K_{\mathrm{a}}$ at $25{ }^{\circ} \mathrm{C}$ was proposed very recently [35].

The ionic strength of the medium also affects the $\mathrm{p} K_{\mathrm{a}}$ value. It is common to measure at constant ionic medium, generally at $I=0.15 \mathrm{M}$ adjusted by $\mathrm{KCl}$ or $\mathrm{NaCl}$ corresponding to the physiological level. Frequently, a different ionic medium is used or data calculated to zero ionic strength using the Debye-Hückel theory are also published, thus it is always necessary to report the ionic strength and temperature of a $\mathrm{p} K_{\mathrm{a}}$ measurement.

Importance of $p K_{a}$ in medicinal chemistry

The degree of ionization at a given $\mathrm{pH}$ can be calculated once the $\mathrm{p} K_{\mathrm{a}}$ is known. As a rule of thumb, at $\mathrm{pH}=\mathrm{p} K_{\mathrm{a}} 50 \%$ of the compound is ionized and $50 \%$ is in the unionized form, while at $\mathrm{pH}=\mathrm{p} K_{\mathrm{a}} \pm 2$ predominance of one species becomes 99 $\%$. For example, an acid is present in $99 \%$ at $\mathrm{pH}=\mathrm{p} K_{\mathrm{a}}-2$ as unionized (HA) and at $\mathrm{pH}=\mathrm{p} K_{\mathrm{a}}+2$ as ionized $\left(\mathrm{A}^{-}\right)$(the opposite case applies to a base).

The ionization state determines the transport properties, thus its precise calculation allows the estimation of ADME features. With the knowledge of the $\mathrm{p} K_{\mathrm{a}}$ value, the proportion of the transport form can be calculated at any physiologically important $\mathrm{pH}$ values. Regarding ampholyte compounds, the $\mathrm{p} K_{\mathrm{a}}$ values are useful to calculate the iso-electric point or the $\mathrm{pH}$ at which a molecule has the lowest solubility and highest lipophilicity. Since solubility, lipophilicity, and permeability are $\mathrm{pH}$-dependent properties, the $\mathrm{p} K_{\mathrm{a}}$ value of a new molecule must be determined in advance to the $\log S, \log P$ and permeability measurement.

Ionic interactions play a fundamental role in the receptor binding of ionizable molecules. An ionic bond is the strongest non-covalent binding type. The electrostatic attraction of opposite charges directs the molecule to the receptor surface and electrostatic complementarity with the receptor is a prerequisite of any drug action.

Antiarrhythmic drugs (class I: $\mathrm{Na}^{+}-$channel antagonists) serve as a good example of how $\mathrm{p} K_{\mathrm{a}}$ affects drug action. These drugs are weak bases with most having $\mathrm{p} K_{\mathrm{a}}$ values ranging from 7.5 - 9.5. At the physiological $\mathrm{pH}$ of 7.4 they exist in an equilibrium mixture consisting of both the free base (B) and protonated $\left(\mathrm{BH}^{+}\right)$ cationic form. In compounds with the $\mathrm{p} K_{\mathrm{a}}>9$ (like procainamide, mexiletine, propafenone), the presence of the receptor form exceeds $90 \%$ which is favorable for the binding to the sodium-channel. However, for compounds in which the $\mathrm{p} K_{\mathrm{a}}<8$ (like quinidine, lidocaine) this ratio is much less favorable (Table 1.3). Lidocaine $\left(\mathrm{p} K_{\mathrm{a}}=7.96\right)$ has a stronger electrophysiologic effect in ischemic than normal myocardial tissue. This potentiation has, in part, been attributed to the increase in $\mathrm{H}^{+}$concentration (lower $\mathrm{pH}$ ) within the ischemic areas of the heart. Acidosis increases the portion of receptor form of the drug (Table 1.3) and consequently the proportion of $\mathrm{Na}^{+}$-channels occupied by the $\mathrm{BH}^{+}$of lidocaine [36]. 
Table 1.3. Ionization state of antiarrhythmic class I drugs at normal and ischemic tissue

\begin{tabular}{ccccc}
\hline \multirow{2}{*}{ compound } & \multicolumn{2}{c}{$\mathbf{~ H ~} \mathbf{7 . 4}$ (normal tissue) } & \multicolumn{2}{c}{$\mathbf{p H}=\mathbf{6 . 4}$ (ischemic tissue) } \\
\cline { 2 - 5 } & $\mathbf{\mathbf { B H } ^ { + } , \mathbf { \% }}$ & $\mathbf{B , ~ \%}$ & $\mathbf{B H}^{+}, \mathbf{\%}$ & $\mathbf{B}, \mathbf{\%}$ \\
\hline procainamide & 98.4 & 1.6 & 99.9 & 0.1 \\
\hline mexiletin & 98.2 & 1.8 & 99.8 & 0.2 \\
\hline quinidine & 76.0 & 24.0 & 99.0 & 1.0 \\
\hline lidocaine & 78.4 & 21.6 & 97.3 & 2.7 \\
\hline
\end{tabular}

\subsubsection{Solubility $(\log S)$}

Solubility is a molecular property which determines the maximal concentration of a solute in a given solvent. The aqueous solubility depends on the polarity of a molecule and varies with the $\mathrm{pH}$ for ionizable compounds. Solubility can be described by different parameters and a vast variety of terms and symbols are used to express the solubility data of compounds, hence below we summarize the most common basic definitions.

\section{Definitions, terms}

Equilibrium (or thermodynamic) solubility $(S)$ is the concentration of a compound in a saturated solution when a solid is present and the solution and solid are at equilibrium. This value is constant at a given pressure and temperature and characteristic for a given compound.

For ionizable molecules, further terms are distinguished. Intrinsic solubility $\left(S_{0}\right)$ is the equilibrium solubility of a free acid (HA) or free base (B) form of an ionizable compound at a pH where it is fully unionized. With respect to ampholytes, this refers to the neutral (chargeless) form (XH) which exists at the iso-electric (i.e.) point $\mathrm{pH}$. Effective solubility $\left(S_{\mathrm{pH}}\right)$ is the equilibrium solubility of an ionizable compound at a $\mathrm{pH}$ where both unionized and ionized forms are present. It is also denoted as apparent (or total) solubility and defined at a particular $\mathrm{pH}$ as the sum of the concentrations of all compound species dissolved in an aqueous solution.

The solubility of salt form of an ionizable compound $\left(S_{\text {salt }}\right)$ can be derived from the solubility product $\left(K_{\mathrm{sp}}\right)$. For a monoprotic acid or base:

$$
S_{\text {salt }}=\sqrt{K_{\text {sp }}}
$$

where, $K_{\mathrm{sp}}=\left[\mathrm{A}^{-}\right]\left[\mathrm{Y}^{+}\right]$for an acid and $K_{\mathrm{sp}}=\left[\mathrm{BH}^{+}\right]\left[\mathrm{X}^{-}\right]$for a base, $\mathrm{Y}^{+}$and $\mathrm{X}^{-}$ represent the counter-ion in the salt.

Recently, a new term called kinetic solubility ( $S^{\mathrm{APP}}$ ) was introduced in early drug discovery. It is the concentration of a solution of an examined compound at the moment when the first precipitation of the solid is observed in an experiment where a small volume of 10-20 $\mu \mathrm{g} / \mathrm{ml}$ dimethyl sulfoxide (DMSO) stock solution is added to aqueous buffer. This parameter is not a thermodynamic physicochemical constant because the system does not reach an equilibrium state. Generally, $S^{\mathrm{APP}}$ is higher than the equilibrium solubility since there is no need to overcome the crystal lattice forces by aqueous solvent once the compound has 
been dissolved in DMSO. Kinetic solubility data are mainly used for ranking the molecules in the early stages of discovery and cannot replace the determination of the true equilibrium constant later in the development phase.

The above solubility parameters can be expressed in various concentration terms like: $\mathrm{g} / 100 \mathrm{ml} ; \mathrm{g} / \mathrm{ml} ; \mathrm{mg} / \mathrm{ml} ; \mu \mathrm{g} / \mathrm{ml}$ or $\mathrm{mol} / \mathrm{L}(\mathrm{M}) ; \mathrm{mmol} / \mathrm{L}(\mathrm{mM}) ; \mu \mathrm{mol} / \mathrm{L}(\mu \mathrm{M})$, etc. For better comparability, the logarithm of solubility term $(\log S)$ is frequently used and can be obtained from $\mathrm{M}$ or $\mu \mathrm{M}$ concentration. Preference for the $-\log S$ term is found in the literature in order to avoid negative numbers for low solubility compounds. However, it may be somewhat confusing because the aforementioned term yields higher values meaning lower solubility.

Solubility is affected by many factors, such as temperature, pressure, $\mathrm{pH}$, ionic strength of aqueous media, purity of a sample, crystal form, particle size, polymorphism, etc. The effect of these factors have been comprehensively discussed in classic $[37,38]$ and new books $[11,18]$. Here, we focus only on the $\mathrm{pH}$ dependency of solubility.

\section{Solubility-pH profile}

The solubility of ionizable compounds varies with the $\mathrm{pH}$. They are more soluble in the charged than in the unionized form. When a molecule exists only in the monomer state, its pH-dependent equilibrium solubility is derived from the Henderson-Hasselbalch ( $\mathrm{HH}$ ) equations (Equations 1.1c-1.4c). The HH relationship for a monovalent acid, base, and (diprotic) ampholyte molecule can be derived from solubility and ionization equilibria as follows where, by convention $[\mathrm{HA}(\mathrm{s})]=[\mathrm{B}(\mathrm{s})]=[\mathrm{XH}(\mathrm{s})]=1$, and $\left[\mathrm{A}^{-}\right],\left[\mathrm{BH}^{+}\right],\left[\mathrm{X}^{-}\right],\left[\mathrm{XH}_{2}+\right]$ are expressed using Equations 1.1b, 1.2b, 1.3b.

acid:

$$
\begin{aligned}
& \mathrm{HA}(\mathrm{s}) \rightleftharpoons \mathrm{HA} \\
& S_{0}=\frac{[\mathrm{HA}]}{[\mathrm{HA}(\mathrm{s})]}=[\mathrm{HA}] \\
& S_{\mathrm{pH}}=\left[\mathrm{A}^{-}\right]+[\mathrm{HA}] \\
& S_{\mathrm{pH}}=\frac{\mathrm{K}_{\mathrm{a}}[\mathrm{HA}]}{\left[\mathrm{H}^{+}\right]}+[\mathrm{HA}] \\
& S_{\mathrm{pH}}=[\mathrm{HA}]\left(\frac{K_{\mathrm{a}}}{\left[\mathrm{H}^{+}\right]}+1\right) \\
& S_{\mathrm{pH}}=S_{0}\left(10^{\left(-\mathrm{p} K_{\mathrm{a}}+\mathrm{pH}\right)}+1\right) \\
& \log S_{\mathrm{pH}}=\log S_{0}+\log \left(1+10^{\left(\mathrm{pH}-\mathrm{p} K_{\mathrm{a}}\right)}\right)
\end{aligned}
$$


base:

$\mathrm{B}_{(\mathrm{S})} \rightleftharpoons \mathrm{B}$

$S_{0}=\frac{[\mathrm{B}]}{[\mathrm{B}(\mathrm{s})]}=[\mathrm{B}]$

$\log S_{\mathrm{pH}}=\log S_{0}+\log \left(1+10^{\left(\mathrm{p} K_{\mathrm{a}}-\mathrm{pH}\right)}\right)$

\section{diprotic ampholyte:}

$$
\begin{aligned}
& \mathrm{HX}(\mathrm{s}) \rightleftharpoons \mathrm{HX} \\
& S_{0}=\frac{[\mathrm{XH}]}{[\mathrm{XH}(\mathrm{s})]}=[\mathrm{XH}] \\
& S_{\mathrm{pH}}=\left[\mathrm{X}^{-}\right]+[\mathrm{XH}]+\left[\mathrm{XH}_{2}^{+}\right] \\
& \cdots \\
& \log S_{\mathrm{pH}}=\log S_{0}+\log \left(1+10^{\left(\mathrm{p} K_{\mathrm{a} 1}-\mathrm{pH}\right)}+10^{\left(\mathrm{pH}-\mathrm{p} K_{\mathrm{a} 2}\right)}\right)
\end{aligned}
$$

Figure 1.9 shows the characteristic solubility-pH profile (a plot of $\log S_{\mathrm{pH}} v s . \mathrm{pH}$ ) for an acid (a), base (b), and diprotic ampholyte (c).
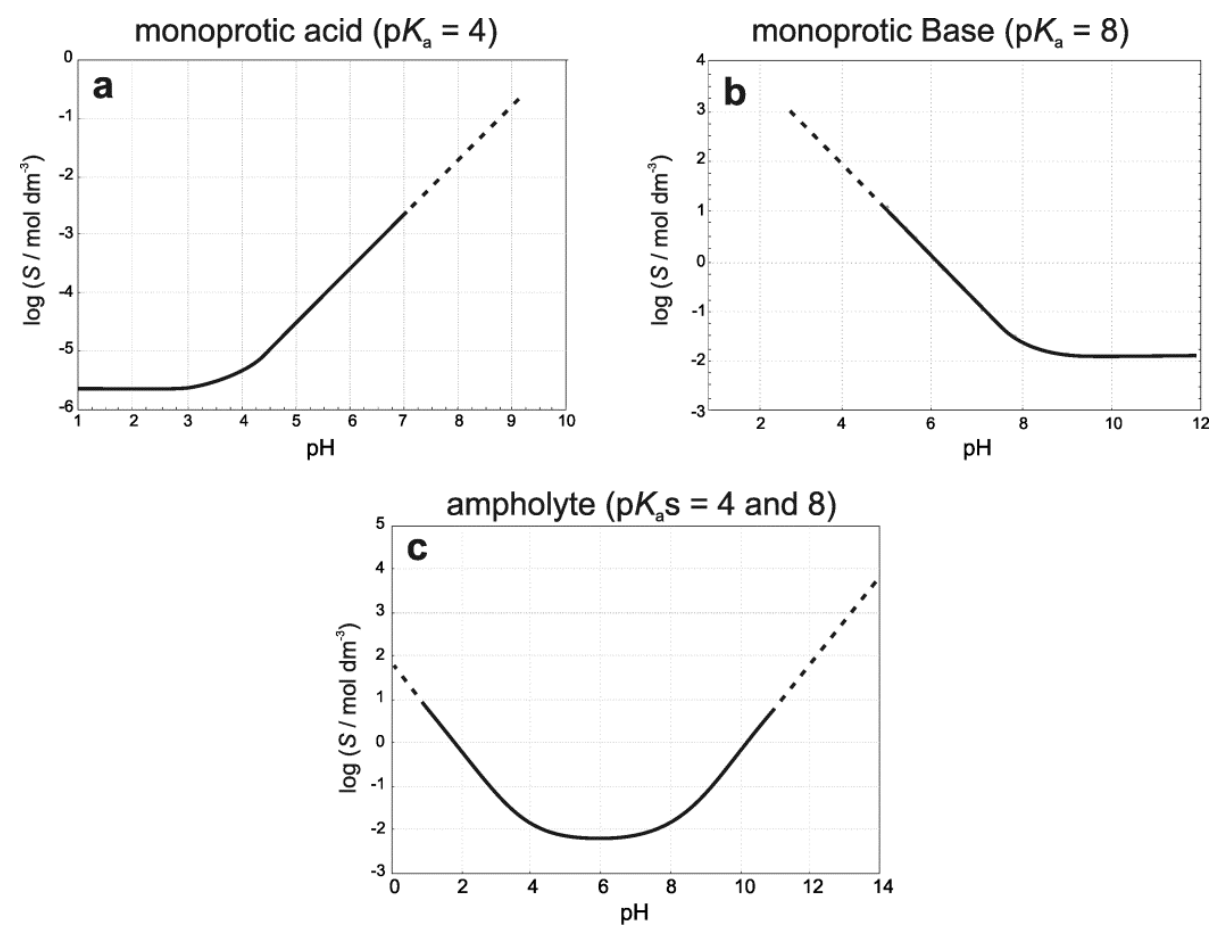

Figure 1.9. Solubility-pH profile of (a) an acid, (b) a base and c) a diprotic ampholyte 
The $\mathrm{HH}$ relationship can be used to predict the $\mathrm{pH}$-dependent equilibrium solubility of drugs when the $\mathrm{p} K_{\mathrm{a}}$ and $\log S_{0}$ values of a compound are known. It is a frequent practice in drug research to convert the experimentally measured intrinsic solubility value to equilibrium solubility at a physiological relevant $\mathrm{pH}$ in order to estimate its expected behavior.

The validity of the HH relationship has been widely investigated and certain deviations were found $[39,40]$. They were interpreted with the influence of different molecular interactions such as aggregation and micelle formation $[39,41]$. Recently, a revisit of the $\mathrm{HH}$ relationship concerning organic bases confirmed the validity provided if highly precise $\mathrm{p} K_{\mathrm{a}}$ and $\log S_{0}$ values were used for its generation [42] (see also Section 1.4.2).

\section{Importance of $\log S$ in medicinal chemistry}

The aqueous solubility of compounds receives considerable attention in drug development, because this is a key molecular property for the gastrointestinal absorption of orally administered drugs. Further on, in biological activity tests compounds must be in solution otherwise false, erroneous data can be obtained. Low solubility is detrimental from both pharmacokinetic and pharmacodynamic points of view. Determination of aqueous solubility is an inevitable part of physicochemical profiling in drug research. Its importance has grown since the Biopharmaceutical Classification System (BCS) was first proposed by G. Amidon in 1995 [43]. This classification uses four classes to categorize drugs based on their solubility and intestinal permeability (class 1 : high solubility + high permeability; class 2: low solubility + high permeability; class 3 : high solubility + low permeability; class 4: low solubility + low permeability). For class 1 molecules, the rate-limiting factor of intestinal absorption is the rate of dissolution, low solubility in class 2 molecules, while low permeability in class 3 is rate-limiting. In class 4 , both properties are unfavorable for oral administration, and no in vitro-in vivo correlation can be expected.

To improve the in vitro-in vivo correlation, the measurement of solubility is recommended for biomimetic media as well. There is growing evidence that in the intestine, the presence of bile acids and other components such as lipids can alter (usually increase) the intrinsic solubility of (lipophilic) compounds. Two physiologically relevant media developed by Dressmann et al. [44] are used. These are the fasted-state simulated intestinal fluid (FaSSIF) and the fed-state simulated intestinal fluid (FeSSIF) having pH 6.5 and 5.0, respectively, and contain different amounts of sodium taurocholate, lecithine and salts [44].

\subsubsection{Lipophilicity $(\log P)$}

The more fundamental property governing the fate of a drug in the body is undoubtedly the lipophilicity. This molecular property represents the affinity of a molecule for a lipophilic environment. It is most commonly described by the logarithm of partition coefficient $(\log P)$ between two immiscible solvents, one is an organic apolar (e.g. octanol) and the other an aqueous polar (buffer solution) [45]. 
Besides $P$, other symbols have been used in the literature such as $P_{\mathrm{ow}}, K_{\mathrm{ow}}, K_{\mathrm{p}}, \mathrm{PC}$, etc., however, we use the terminology widely accepted in medicinal chemistry.

Two types of partition parameters are distinguished: the true partition coefficient $(P)$ and the distribution coefficient ( $D$ or in older literature $\left.P_{\text {app }}\right)$. Their definition and relationship are briefly summarized below.

\section{Definitions, terms}

The true partition coefficient (according to the Nernst law) refers to the partition of a single electrical species, and is expressed as an equilibrium concentration ratio of the same molecular form in both phases of the solvent system. This value is constant at a given temperature and pressure, independent of the $\mathrm{pH}$ and characteristic for the molecule. It can be derived for the neutral, monomeric form of a compound $\left(\log P^{\mathrm{N}}\right.$ ) (Equation 1.27) and theoretically can be also defined for the partition of an ionic form ( $\log P \mathrm{I}$ ) (Equation 1.28), but later the value has orders of magnitude lower and in most of cases can be practically neglected.

$$
\begin{aligned}
P^{\mathrm{N}} & =\frac{[\text { unionized form }]_{\text {octanol }}}{[\text { unionized form }]_{\text {water }}} \\
P^{\mathrm{N}} & =\frac{[\mathrm{HA}]_{\mathrm{o}}}{[\mathrm{HA}]_{\mathrm{w}}} \quad P^{\mathrm{N}}=\frac{[\mathrm{B}]_{\mathrm{o}}}{[\mathrm{B}]_{\mathrm{w}}} \quad P^{\mathrm{N}}=\frac{[\mathrm{XH}]_{\mathrm{o}}}{[\mathrm{XH}]_{\mathrm{w}}} \\
P^{\mathrm{I}} & =\frac{[\text { charged species }]_{\text {octanol }}}{[\text { charged species }]_{\text {water }}} \\
P^{\mathrm{I}} & =\frac{\left[\mathrm{A}^{-}\right]_{\mathrm{o}}}{\left[\mathrm{A}^{-}\right]_{\mathrm{w}}} \quad P^{\mathrm{I}}=\frac{\left[\mathrm{BH}^{+}\right]_{\mathrm{o}}}{\left[\mathrm{BH}^{+}\right]_{\mathrm{w}}} \quad P^{\mathrm{I}}=\frac{\left[\mathrm{X}^{-}\right]_{\mathrm{o}}}{\left[\mathrm{X}^{-}\right]_{\mathrm{w}}} \quad P^{\mathrm{I}}=\frac{\left[\mathrm{XH}_{2}^{+}\right]_{\mathrm{o}}}{\left[\mathrm{XH}_{2}^{+}\right]_{\mathrm{w}}}
\end{aligned}
$$

The distribution coefficient of an ionizable compound refers to all species that are present in the solution (Equation 1.29). Since it is a pH-dependent term, the $\mathrm{pH}$ must be specified as $\mathrm{DpH}$.

$$
D^{\mathrm{pH}}=\frac{[\text { unionized }+ \text { ionized species }]_{\mathrm{octanol}}}{[\text { unionized }+ \text { ionized species }]_{\text {water }}}
$$

For monoprotic acid and base:

$$
D^{\mathrm{pH}}=\frac{[\mathrm{HA}]_{\mathrm{o}}+\left[\mathrm{A}^{-}\right]_{\mathrm{o}}}{[\mathrm{HA}]_{\mathrm{w}}+\left[\mathrm{A}^{-}\right]_{\mathrm{w}}} \quad D^{\mathrm{pH}}=\frac{[\mathrm{B}]_{\mathrm{o}}+\left[\mathrm{BH}^{+}\right]_{\mathrm{o}}}{[\mathrm{B}]_{\mathrm{w}}+\left[\mathrm{BH}^{+}\right]_{\mathrm{w}}}
$$

For diprotic ampholyte:

$$
D^{\mathrm{pH}}=\frac{\left[\mathrm{X}^{-}\right]_{\mathrm{o}}+[\mathrm{XH}]_{\mathrm{o}}+\left[\mathrm{XH}_{2}^{+}\right]_{\mathrm{o}}}{\left[\mathrm{X}^{-}\right]_{\mathrm{w}}+[\mathrm{XH}]_{\mathrm{w}}+\left[\mathrm{XH}_{2}^{+}\right]_{\mathrm{w}}}
$$


with the assumption that the concentration of the ionic forms in the organic phase is much less than that of the neutral forms (e.g., $\left[\mathrm{A}^{-}\right]_{\mathrm{o}} \ll[\mathrm{HA}]_{\mathrm{o}}$ and $\left[\mathrm{BH}^{+}\right]_{0}<<[\mathrm{B}]_{\mathrm{o}}$, etc. $)$ and upon substituting the aqueous equilibrium concentrations from Equations 1.1b, 1.2b, and 1.3b, the relationships between $\mathrm{P}$ and $\mathrm{D}$ can be obtained. For simple molecules, these relationships are given below (Equations $1.30 \mathrm{a}-\mathrm{c}$ ) while interactions between more complicated multiprotic compounds can be found in the literature [46].

For monoprotic acid:

$$
\log P^{\mathrm{N}}=\log D^{\mathrm{pH}}+\log \left(1+10^{\left(\mathrm{pH}-\mathrm{p} K_{\mathrm{a}}\right)}\right)
$$

For monoprotic base:

$$
\log P^{\mathrm{N}}=\log D^{\mathrm{pH}}+\log \left(1+10^{\left(\mathrm{p} K_{\mathrm{a}}-\mathrm{pH}\right)}\right)
$$

For diprotic ampholyte:

$$
\log P^{\mathrm{N}}=\log D^{\mathrm{pH}}+\log \left(1+10^{\left(\mathrm{p} K_{\mathrm{a} 1}-\mathrm{pH}\right)}+10^{\left(\mathrm{pH}-\mathrm{p} K_{\mathrm{a} 2}\right)}\right)
$$

\section{Partition microconstants}

Similarly to ionization microconstants, micro-log $P$ (denoted as $\log p$ ) of a given microspecies of multiprotic compounds can also be defined [46]. This has particular significance in the case of ampholyte compounds where the most lipophilic species, the neutral $(\mathrm{XH})$ form, is a composite from zwitterionic $\left(\mathrm{XH}^{ \pm}\right)$ and chargeless $\left(\mathrm{XH}^{0}\right)$ microspecies. If they are present in solution in a commensurable amount (e.g., norfloxacin in Figure 1.7) then the exclusive partitioning of the chargeless form can be expected into the lipophilic phase and micro-log $P$ of $\mathrm{XH}^{0}$ microspecies may be the relevant lipophilicity parameter. Its calculation requires knowledge of the $\log D$ at iso-electric $\mathrm{pH}$ value, $\log D^{\mathrm{i} . e . \mathrm{pH}}$, and the protonation microconstants $\left(k^{\mathrm{C}}, k_{\mathrm{C}}^{\mathrm{N}}, k_{\mathrm{N}}^{\mathrm{C}}\right)$ as previously published [47].

$$
\log p^{0}=\log D^{\mathrm{i} \text {.e.pH }}+\log \left(1+\frac{1}{k^{\mathrm{C}}\left[\mathrm{H}^{+}\right]}+\frac{k_{\mathrm{C}}^{\mathrm{N}}}{k_{\mathrm{N}}^{\mathrm{C}}}+k_{\mathrm{C}}^{\mathrm{N}}\left[\mathrm{H}^{+}\right]\right)
$$

\section{Lipophilicity-pH profile}

The plot of $\log D^{\mathrm{pH}}$ against the $\mathrm{pH}$ (lipophilicity-pH profile) of a compound (Equations 1.30a-c) can be derived from the HH relationships (Equations 1.1c1.4c), provided that there is no ion-pair partition involved in the process. If such ion-pair partition exists, the profiles show a plateau at $\log D$ of values 3-4 orders lower (for acids at high $\mathrm{pH}$, for bases at low $\mathrm{pH}$ ) than as indicated in Figure 1.10.

The lipophilicity-pH profiles are useful to estimate the effective lipophilicity of a compound at physiologically relevant $\mathrm{pH}$ values and widely used in medicinal chemistry. 


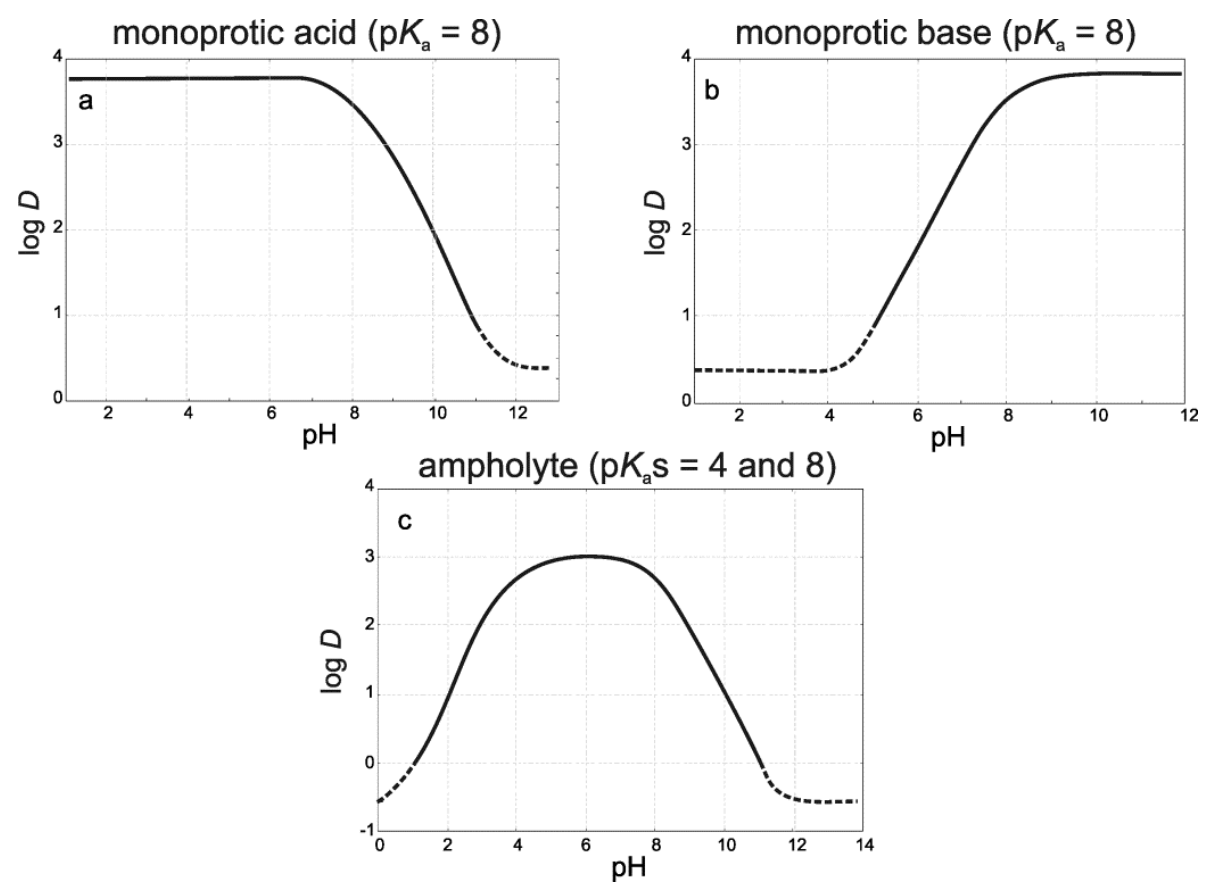

Figure 1.10. Lipophilicity-pH profile of (a) an acid, (b) a base, and (c) a diprotic ampholyte

Solvent systems for $\log P$

The widely accepted reference solvent system for $\log P$ measurement is octanol/water proposed first by Hansch [45]. In this system, the two phases are isotropic. A buffer solution serves as the aqueous phase and n-octanol is used as a typical H-bond donor and acceptor organic solvent. This system is thought to model the essential properties of general biological membranes. The structure of water-saturated octanol became better understood in the '90s [48]. Inverted micellar aggregates are formed where water clusters are surrounded by about 16 molecules of octanol, with the polar $\mathrm{OH}$ groups pointing to the clusters and intertwined in a hydrogen-bonding network. The aliphatic tails form a hydrocarbon region with properties not too different from the hydrocarbon core of bilayers. Obviously, the octanol/water system cannot be a universal model for all types of membranes. In the past two decades, partition solvents other than octanol have been explored. Leahy et al. [49] proposed the "critical quartet" system consisting of octanol/water, chloroform/water, alkane/water and propylene glycol dipelargonate (PGDP)/water for the general modeling of membranes. Later, 1,2-dichloroethane (DCE) and cyclohexane were found useful organic solvents. Once $\log P$ has been measured both in alkane/water and octanol/water systems, the $\Delta \log P\left(\log P_{\text {octanol }}-\log P_{\text {alkane }}\right)$ can be calculated, and used as a simple parameter for the $\mathrm{H}$-bond formation ability of a compound.

Recently, anisotropic systems such as liposomes (vesicles formed from phospholipid bilayers) were increasingly used to model membrane partitioning. 
Liposome/water $\log P$ values are considered as $\log P_{\text {mem }}$ (membrane partition). An accumulation of $\log P_{\text {mem }}$ data show a significantly higher partitioning of ionic forms. Generally, charged species partition into membranes about 100 times more strongly than into octanol. The theory and practice of liposome/water lipophilicity were reviewed $[5,50,51]$.

\section{Importance of $\log P$ in medicinal chemistry}

The $\log P$ is the oldest and most traditional physicochemical parameter used in medicinal chemistry. Lipophilicity is implicated in numerous biological events (such as transport, receptor binding via hydrophobic interactions, metabolic processes, storage in fat tissues, etc.). The $\log P$ value - concerning its information content - is much more than a simple number, because the same molecular interactions which exist between the compound and the biological environment results in this value. At the same time, $\log P$ is very easy to handle by chemists for comparison of molecules with different lipophilicity and estimating the expected transport behavior in the body.

Among the properties suggested by Lipinski, (known as "rule of 5 ") one of the criteria for drug-likeness is that $\log P$ should be below 5 [52]. It seems to be a reasonable concept since $90 \%$ of marketed drugs have a log $P$ value in the range of $0-5$ (see Figure 1.11). From hydrophilic compounds $(\log P<0$ ) good solubility, but poor absorption from the GI tract can be expected except for those which have active transport (such as for example ascorbic acid). Compounds with moderate lipophilicity ( $\log P$ between 0 and 3) are optimal for oral administration due to a good balance of solubility and permeability. For good blood-brain barrier (BBB) penetration, the optimal $\log P$ value is about 2 .

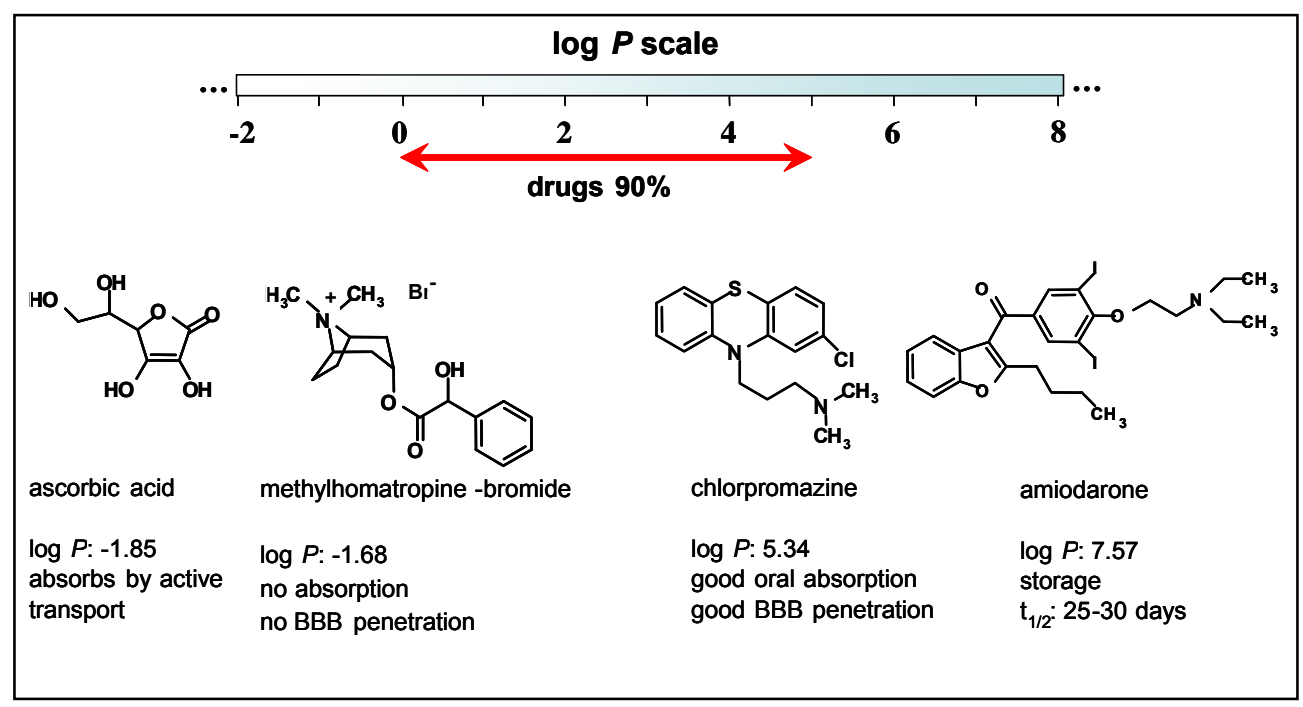

Figure 1.11. The $\log P$ scale of drugs

Highly lipophilic compounds $(\log P>5)$ are sparingly soluble in aqueous compartments, tend to accumulate in lipoidal parts and are also more sensitive to 
metabolism. Extremely high lipophilicity may lead to strange pharmacokinetics, for example, amiodarone has $\log P=7.37$ and half-life $t_{1 / 2}: 25-30$ days(!) (Figure 1.11). First, in 1987 Hansch called attention to the danger of exceedingly high lipophilic drug candidates and proposed the "minimal hydrophobicity" concept for the design of new compounds [53]. Since then, the unfavorable tendency of highly lipophilic drug production has not stopped, as new molecules in drug research are getting more lipophilic and less water-soluble [54].

\subsection{METHODS FOR PHYSICOCHEMICAL PROFILING}

Demands set up to the methods for physicochemical profiling are different in various phases of drug research. In the discovery phase, the drastically increased number of NCEs produced by combinatorial chemistry requires high throughput (HT), material saving, automated approaches, while less emphasis is placed on precision. A method for physicochemical profiling is considered HT when its capacity exceeds the measurement of 50 compounds/day [7]. Later, in the development phase reliable, precise data are needed which is why accuracy is more important and not the speed of the method.

This subchapter is dedicated to experimental methods used for the measurement of $\mathrm{p} K_{\mathrm{a}}, \log P$, and $\log S$ values and comparison of their capacity, accuracy, time, and material demand (see Tables 1.4-1.6). We focus here mainly on the practical aspects of their application, while the detailed theoretical background of the methods is out of the scope of this review. For this purpose, excellent basic books are recommended to readers $[11,18,26,37]$.

\subsection{1. $\mathrm{p} K_{\mathrm{a}}$ determination}

Potentiometry and UV spectroscopy are the commonly used standard methods of $\mathrm{p} K_{\mathrm{a}}$ determination. Due to its simplicity and precision, potentiometry is the method of choice once the aqueous solubility of a compound reaches a minimum of $0.5 \mathrm{mM}$ concentration in the entire $\mathrm{pH}$ range of the titration. For less soluble compounds, a good alternative tool is the $\mathrm{UV} / \mathrm{pH}$ titration provided that the molecule has a pH-dependent UV spectrum. In this method, it is generally enough if the compound dissolves in a concentration of 10-500 $\mu \mathrm{M}$ depending on its molar absorptivity, $\varepsilon$. Both potentiometric and $\mathrm{UV} / \mathrm{pH}$ titration methods are strongly supported commercially, and the available automated instruments such as the GLpKa and its follow up the Sirius T3 automated analyzers (Sirius UK) are widely used. In the recent years, capillary electrophoresis (CE) has proved to be a very powerful $\mathrm{p} K_{\mathrm{a}}$ determination method, being more sensitive and less sample consuming $[11,16]$. Some other methods such as NMR/pH titration [55], CD/pH titration [56], and chromatographic technique [57] have also been applied for special cases, but so far have not become routine techniques. 


\subsubsection{Potentiometric method}

Procedure. In potentiometric titration, the $\mathrm{pH}$ of a 1-5 mM solution of a sample is preciously measured with a carefully standardized combined glass electrode upon addition of small volumes of a strong acid $(e . g . \mathrm{HCl})$ or base $(e . g . \mathrm{KOH})$ volumetric solution. The measurement is performed in a stirring solution, under an inert gas atmosphere (argon or nitrogen) while the ionic strength of the solution is kept constant using an inorganic salt (e.g. $0.15 \mathrm{M} \mathrm{KCl}$ ), and the titration cell is thermostated usually at $25.0 \pm 0.1^{\circ} \mathrm{C}$. Typical sample volume for titration is $5-15 \mathrm{ml}$, but measurement in as less as $1 \mathrm{ml}$ solution has been reported [58]. The concentration of the titrant is generally $0.5 \mathrm{M}$ in order to avoid considerable dilution upon titration. The potentiometric titration can be used as a direct approach for $\mathrm{p} K_{\mathrm{a}}$ measurement, when the tested compound is a (relatively) strong acid/base to produce enough potential change (big jump) in the titration curve. Otherwise, the "Calvin- $\Delta m l$ " difference-titration is a useful and widely applied method. Here, the $\mathrm{p} K_{\mathrm{a}}$ value is obtained from the difference between the titration curve of a tested compound and a "blank" titration (see below). This approach is a built in function in $\mathrm{p} K_{\mathrm{a}}$ analyzers.

Calculation. The $\mathrm{p} K_{\mathrm{a}}$ value can be calculated according to the $\mathrm{HH}$ equations (Equations 1.1c-1.4c). The $\mathrm{pH}$ is measured and the term $\log ([$ protonated]/[nonprotonated]) is obtained from the mass balance of the titration data. In automated analyzers built in programs (e.g., Refinement-Pro $\left.{ }^{\mathrm{TM}}\right)$ calculate the $\mathrm{p} K_{\mathrm{a}}$. First, the titration curve is converted to the Bjerrum plot (the average number of bound protons/molecule, $\bar{n} v s . \mathrm{pH}$ ), where the $\mathrm{p} K_{\mathrm{a}}$ value is equal to the $\mathrm{pH}$ at $\bar{n}=$ 0.5 (for a multiprotic compound: second $\mathrm{p} K_{\mathrm{a}}$ at $\bar{n}=1.5$, third at $\bar{n}=2.5$, etc.). The obtained raw values are then further refined by a nonlinear least squares method. The adjustable parameters are the concentration of the material, acid/base error of $\mathrm{pH}$ measurement, carbon dioxide content, etc.

Accuracy. This method with the above experimental parameters allows the measurement of precise $\mathrm{p} K_{\mathrm{a}}$ values in a range from 2 to 12 with a standard deviation $S D= \pm 0.01-0.03$. By using a glass electrode of excellent quality, performing proper electrode calibration, excluding the presence of ambient carbon dioxide as much as possible, and accurately dispensing very small titrant volumes $(0.01 \mathrm{ml}$ or even smaller) potentiometry in aqueous solution can be applied to a concentration as low as $0.1 \mathrm{mM}$ (according to some authors as low as $0.01 \mathrm{mM}$ ). Of course, the accuracy and reproducibility of titrations in such diluted solutions is much less ( $S D= \pm 0.10-0.15)$. Similarly, the precision of the measurement decreases out of the $\mathrm{pH}$ range of 2-12.

Calibration. Electrode calibration is a fundamental step in $\mathrm{pH}-\mathrm{metric} \mathrm{p} K_{\mathrm{a}}$ determination. A standardized "Four-parameter procedure" developed by Avdeef et al. [59] is widely used. A known concentration of $\mathrm{HCl}$ is titrated with $\mathrm{KOH}$ (from $\mathrm{pH} 1.8$ to 12.2) under standard experimental conditions (see above). Data from this "blank" titration are used to convert the operational pH scale to the concentration scale $\left(\mathrm{p}_{\mathrm{c}} \mathrm{H}=-\log \left[\mathrm{H}^{+}\right]\right)$by a multi-parametric equation. 


$$
\mathrm{pH}=\alpha+S \mathrm{p}_{\mathrm{c}} \mathrm{H}+j_{\mathrm{H}}\left[\mathrm{H}^{+}\right]+j_{\mathrm{OH}} K_{\mathrm{w}} /\left[\mathrm{H}^{+}\right]
$$

The parameters are determined by a weighted nonlinear least-squares procedure. The intercept parameter $\alpha$ in aqueous solution mainly corresponds to the negative logarithm of the activity coefficient of $\mathrm{H}^{+}$at the working temperature and ionic strength. The $j_{\mathrm{H}}$ term corrects $\mathrm{pH}$ readings for the nonlinear $\mathrm{pH}$ response due to the liquid junction and asymmetric potentials in moderately acidic solutions, while the $j_{\mathrm{OH}}$ term corrects the high-pH nonlinear effect. Factor $S$ accounts for the fact that a particular electrode may not have 100\% Nernstianslope and $K_{\mathrm{w}}$ is the ionization constant of water. Typical aqueous values of the adjustable parameters at $25^{\circ} \mathrm{C}$ and $0.15 \mathrm{M}$ ionic strength are: $\alpha=0.08 \pm 0.01, S=$ $1.001 \pm 0.001, j_{\mathrm{H}}=1.0 \pm 0.2$, and $j_{\mathrm{OH}}=-0.6 \pm 0.2$.

Advantages/drawbacks. Potentiometry is a simple, fast, and precise method for $\mathrm{p} K_{\mathrm{a}}$ determination. The smallest practical volume of sample solution is about $5 \mathrm{ml}$. This requires $1.5 \mathrm{mg}$ of sample for a compound with $M_{\mathrm{w}} 300$ to achieve the $1 \mathrm{mM}$ concentration which is ideal for titration. For reliable $\mathrm{p} K_{\mathrm{a}}, 2-3$ parallel measurements are necessary, so the sample consumption reaches 3-4.5 mg. A titration between $\mathrm{pH}$ 2-12 typically takes 20-40 min to perform. With an automated instrument (e.g. GLpKa) 30-40 titrations could be performed during one 24-h day [60]. So, the maximum capacity is about 10-12 compounds/day. This is a relatively low throughput. The main limitation of the application of this technique is the poor solubility of compounds. In such cases, the co-solvent method can be applied (see Section 1.3.1.4). Further on, it is difficult to handle impure or unstable compounds (e.g., certain esters, diphenols, etc.).

\subsubsection{2. $\mathrm{UV} / \mathrm{pH}$ titration}

Procedure. In spectrophotometric $\mathrm{p} K_{\mathrm{a}}$ determination method the change in the UV spectrum upon ionization is registered. Such a pH dependent UV-spectrum is obtained if the ionizable group is near to the chromophore of the molecule. In traditional $\mathrm{UV} / \mathrm{pH}$ titration two aliquots of typically $10-50 \mu \mathrm{M}$ solutions of a sample are prepared in either 0.01 (or 0.001 ) $\mathrm{M} \mathrm{HCl}$ or 0.01 (or 0.001 ) $\mathrm{M} \mathrm{NaOH}$, with the total ionic strength of $0.15 \mathrm{M}$. In one solution the molecule is fully ionized while in the other fully unionized. By mixing the two stock solutions under precise $\mathrm{pH}$ control, 5-6 solutions are prepared in a rather narrow $\mathrm{pH}$ range ( \pm 0.6 unit) around the expected $\mathrm{p} K_{\mathrm{a}}$. Their absorbance is measured at a wavelength where the difference in the absorbance between the ionized and unionized form is the largest. Recently, this time-consuming process has been automated (GLpKa with a D-PAS attachment). In a titration cell, the solution of the sample is titrated across a $\mathrm{pH}$ range that includes the $\mathrm{p} K_{\mathrm{a}}$ value(s) and multiwavelength UV spectra registered at each $\mathrm{pH}$ with the help of a fiber optics dip probe immersed into the titration cell $[60,61]$.

Calculation. In traditional $\mathrm{UV} / \mathrm{pH}$ titration, the $\mathrm{p} K_{\mathrm{a}}$ value can be calculated from the $\mathrm{pH}$ of the solution and the absorption data measured at a single wavelength using the $\mathrm{HH}$ Equations $1.1 \mathrm{c}-1.4 \mathrm{c}$. The $\mathrm{p} K_{\mathrm{a}}$ of a compound is obtained as an 
average value calculated from the solution series. This method is applicable for the determination of a single $\mathrm{p} K_{\mathrm{a}}$, or multiple $\mathrm{p} K_{\mathrm{a}}$ values if they are well separated $(>1.5 \mathrm{pH}$ units). In the D-PAS technique, target factor analysis (TFA) is used to deduce the $\mathrm{p} K_{\mathrm{a}}$ value(s) of a sample from an absorbance matrix [60]. This technique is able to handle multiprotic molecules with overlapping protonation.

Accuracy. The precision of $\mathrm{p} K_{\mathrm{a}}$ determination by traditional $\mathrm{UV} / \mathrm{pH}$ titration does not reach that of pH-metry, where the standard deviation can vary between $\pm 0.05-0.10$. However, according to a recent validation study, the D-PAS technique with a $S D= \pm 0.02$ has similar precision to potentiometry [62].

Advantages/drawbacks. The spectrophotometric method is usually more sensitive than potentiometry. The measurements can be performed at lower sample concentration allowing the $\mathrm{p} K_{\mathrm{a}}$ determination of less soluble compounds directly in aqueous medium, while for water-insoluble materials the co-solvent method can be easily applied. The D-PAS is a fast technique, one titration takes up $30 \mathrm{~min}$ and is sample conserving, usually $1-2 \mathrm{mg}$ of sample is enough for 3 parallel measurements. One limitation of spectrophotometry is that if the distance between the ionization and the chromophore center is greater than three sigma bonds then the pH-dependent spectral shift will be too small for measurement. Another limitation is if the absorption maxima of the compound occurs at a low wavelength $(<230 \mathrm{~nm})$ then background noise disruption increases considerably. Traditional $\mathrm{UV} / \mathrm{pH}$ titration is a very slow, timeconsuming process, while the capacity of the D-PAS technique is similar to potentiometry (10-12 compounds/day). UV/pH titration was used for determination of microconstants in several cases (e.g. repaglinide [63], moxifloxacin [64]) when the shift in the UV spectrum is due to the ionization of a given functional group.

\subsubsection{Other methods}

$N M R / p H$ titration. $\mathrm{NMR} / \mathrm{pH}$ titration can also be used for $\mathrm{p} K_{\mathrm{a}}$ measurement based on the fact that the chemical shift of NMR-active nuclei is governed (among other factors) by the protonation state of ionizable groups. Since protonation decreases the local electron density, a selected nucleus in the vicinity of the ionizable site exhibits a different shift in the ionized and unionized states. A plot $\delta^{\text {obs }} v s$. $\mathrm{pH}$ has a sigmoidal shape with an inflection point at $\mathrm{pH}=\mathrm{p} K_{\mathrm{a}}$.

Generally, NMR/pH titrations have been carried out in aqueous solutions using $\mathrm{D}_{2} \mathrm{O}$ as a solvent. Although glass electrodes operate properly in $\mathrm{D}_{2} \mathrm{O}$, a correction factor of 0.40 has to be added to the measured $\mathrm{pH}$ to get the true $\mathrm{pD}$ value. To avoid this correction, $\mathrm{NMR} / \mathrm{pH}$ titration may be conducted in a solvent mixture of $\mathrm{H}_{2} \mathrm{O} / \mathrm{D}_{2} \mathrm{O}(90 / 10 \mathrm{v} / \mathrm{v})$ and the water peak has to be suppressed by an appropriate method. Frequently, the whole titration is performed in a single NMR-tube and the $\mathrm{pH}$ is measured with a long, thin glass electrode. This method has been extended for the measurement of low $\mathrm{p} K_{\mathrm{a}}$ values (between 0 and 2), where potentiometry is no longer applicable. Since at such low pH a glass electrode has 
significant acidity error, dichloroacetic acid was proposed as an NMR "indicator molecule" for in situ monitoring of the $\mathrm{pH}$ in strong acidic solutions [55]. The $\mathrm{p} K_{\mathrm{a}}$ values of individual groups of large biopolymers have been reported as measured by NMR technique [65].

The main advantage of this technique compared to potentiometry is the capability of selective monitoring of ionization of a given functional group in multiprotic molecules with overlapping protonation. Thus, this methodology has become the chief approach of microspeciation as reviewed recently [34]. The acid/base profiling of imatinib [66] and cetirizine [33], measured by NMR/pH titration was reported.

Capillary Electrophoresis (CE). The application of CE for $\mathrm{p} K_{\mathrm{a}}$ determination has been intensively growing in the past decade as reviewed $[7,16,67,68]$. The method utilizes the change in electrophoretic mobility of a compound with change in $\mathrm{pH}$. The effective mobility ( $\left.\mu_{\text {eff }}\right)$ is measured at various $\mathrm{pH}$ values and $\mathrm{p} K_{\mathrm{a}}$ is obtained from the plot of $\mu_{\text {eff }} v S$. $\mathrm{pH}$. The experimental conditions effect the $\mathrm{p} K_{\mathrm{a}}$ determination such as buffer type and ionic strength, applied voltage, detection method, etc. are discussed as detailed by Henchoz et al. [16].

In this technique, the sample consumption is small (ng), and impure samples can be handled due to the separation upon the analysis. It is rather universal, since different detection methods can be coupled to CE [69]. The precision is good enough and agreement with other methods is acceptable, about $\pm 0.2 \mathrm{p} K_{\mathrm{a}}$ units in a range from 2 to 10 , but can be much weaker $( \pm 0.5)$ out of this $\mathrm{p} K_{\mathrm{a}}$ range. The method is sensitive for several factors, among them temperature which is cardinal.

Today, CE is a good tool for high throughput $\mathrm{p} K_{\mathrm{a}}$ measurement. The instrumentation is fully automated using a multiplex 96-channel CE with UV detection (CombiSep, Ames, USA) and more than 150 samples/day can be measured [70].

Spectral Gradient Analysis (SGA). To further increase the throughput of physicochemical profiling, a rapid $\mathrm{p} K_{\mathrm{a}}$ determination method was developed and reported first as "pH-gradient titration" [71]. Later, after the launch of a commercial instrument (Profiler SGA, Sirius) it is referred to in the literature as the SGA method. In this technique, a pH gradient flow - very linear in time - is created by mixing appropriate acidic and basic buffers. The sample is injected into this $\mathrm{pH}$ gradient flow which passes through a diode array UV spectrophotometer and the spectra are registered. The $\mathrm{pH}$ is not measured but estimated from the time elapsed since the start of the gradient generation. The $\mathrm{p} K_{\mathrm{a}}$ values are determined from changes in absorption as a function of $\mathrm{pH}$. The calculation is based on either the first derivative plot of the absorption spectrum for samples with only a single $\mathrm{p} K_{\mathrm{a}}$ (or well separated $\mathrm{p} K_{\mathrm{a}}$ values) or on the TFA approach for compounds with weak spectral change or overlapping ionization [60]. The precision of the method is evidently lower than that of other methods, but results of a comprehensive validation study show good agreement with literature data [72]. The SGA method allows $\mathrm{p} K_{\mathrm{a}}$ measurement within 4 min leading to high 
throughput capacity. The present available automated instrument (Sirius T3) containing an autoloader module (robotic arm) utilizes four 48-position vial trays for samples. It enables the measurement of 240 compounds/day. Low solubility and low molar absorptivity may be limitations of the SGA method.

\subsubsection{Co-solvent method}

Determination of $\mathrm{p} K_{\mathrm{a}}$ using the above discussed methods is often hindered by the low water solubility of the samples. It is a frequent problem today since the new molecules in drug research are less water-soluble and more lipophilic. For water insoluble compounds, the co-solvent method can be used. In this approach, the apparent ionization constants, $\mathrm{p}_{\mathrm{s}} K_{\mathrm{a}}$ values, are measured in different ratios of organic solvent/water mixtures. The aqueous $\mathrm{p} K_{\mathrm{a}}$ value is obtained by extrapolation to zero organic content. The co-solvent method is primarily used in $\mathrm{pH}$ metry, but it can be applied in UV-spectroscopy and CE techniques as well.

Many water miscible organic solvents have been used such as methanol $(\mathrm{MeOH})$, ethanol (EtOH), propanol, DMSO, dimehtylformamide (DMF), acetone, and tetrahydrofurane (THF). Since most literature data have been accumulated for a $\mathrm{MeOH} /$ water solvent mixture and it is generally accepted that $\mathrm{MeOH}$ shows a solvation effect closest to water, $\mathrm{MeOH}$ is normally chosen as an organic solvent of choice $[11,16,68]$.

Different extrapolation methods are known, but the Yasuda-Shedlovky (YS) extrapolation has proven to be the most reliable. Here, a linear correlation is established in a plot of $\mathrm{p}_{\mathrm{s}} K_{\mathrm{a}}+\log \left[\mathrm{H}_{2} \mathrm{O}\right] v s . a / \varepsilon+b$, where $\log \left[\mathrm{H}_{2} \mathrm{O}\right]$ is the molar water concentration of the given solvent mixture, $\varepsilon$ is the dielectric constant of the mixture, and $a$ and $b$ are the slope and intercept, respectively. The aqueous $\mathrm{p} K_{\mathrm{a}}$ values can be obtained for $\log 55.5$ and 1/78.3, the molar concentration and dielectric constant of pure water, correspondingly. The dielectric constant of $\mathrm{MeOH} /$ water mixtures is lower than that of water and the extent of ionization is suppressed, thus $\mathrm{p} K_{\mathrm{a}}$ values of acids are shifted higher while those of bases are toward lower values. The slope of the YS relationship is positive for acids and negative for bases. The YS procedure offers many benefits over the traditional plot of $\mathrm{p}_{\mathrm{s}} K_{\mathrm{a}} v s . R_{\mathrm{w}}$ (wt \% of organic solvent) which often shows a "hockey-stick" or "bow" shape, sometimes at $R_{\mathrm{w}}>60 \mathrm{wt} \%$ an S-shape curve. Proper electrode calibration using four parameter procedures in the solvent mixture is crucial [73].

According to a comprehensive validation study, the reproducibility and precision of the method, based on 431 separate titrations in the interval of 15-65 wt\% $\mathrm{MeOH}$ content using 25 model compounds, was found to be good $(S D= \pm 0.05)$. Extrapolation from a methanol-rich region $\left(R_{\mathrm{w}}\right.$ : 40-60 wt \%) gives an error in $\mathrm{p} K_{\mathrm{a}}$ not greater than \pm 0.2 for weak acids and \pm 0.1 for weak bases [74] .

Since not all compounds dissolve in a single organic solvent (e.g. methanol), a new multicomponent co-solvent system significantly improving the solubility of pharmaceutical compounds was recently developed for $\mathrm{p} K_{\mathrm{a}}$ determination $[75,76]$. The mixture consists of an equal volume of $\mathrm{MeOH}$, dioxane, and acetonitrile 
(referred to as MDM) diluted in water to obtain the required co-solvent system. This system enables $\mathrm{p} K_{\mathrm{a}}$ measurements by potentiometry (and also by $\mathrm{UV} / \mathrm{pH}$ titration) for a wide range of poorly soluble compounds. Since solubility considerably increases in the MDM system, measurements can be performed in a lower proportion of organic solvent, thus the long-distance extrapolation can be avoided. The linearity of the YS relationship is valid up to 55 wt \% MDM content. Validation based on 50 compounds showed good reproducibility $(S D= \pm 0.01-0.08)$ and the agreement of $\mathrm{p} K_{\mathrm{a}}$ values extrapolated by this method with values measured by other methods is very good $(<0.10$ unit).

The SGA method has been extended with measurements in 20 wt \% MDM content, and general calibration equations were set up for acids and bases $\left(\mathrm{p} K_{\mathrm{a} \text { (aqueous) }}=a \mathrm{p}_{\mathrm{s}} K_{\mathrm{a}}(20 \% \mathrm{MDM})+b\right)$, so a single point estimation may provide rapid aqueous $\mathrm{p} K_{\mathrm{a}}$ values for water-insoluble compounds in the early phase of drug research [76].

\subsubsection{Decision tree for method selection}

The selection of a suitable method must be based on the properties of the compound tested. Figure 1.12 shows a simple decision tree for method selection used in the laboratory of the author [4].

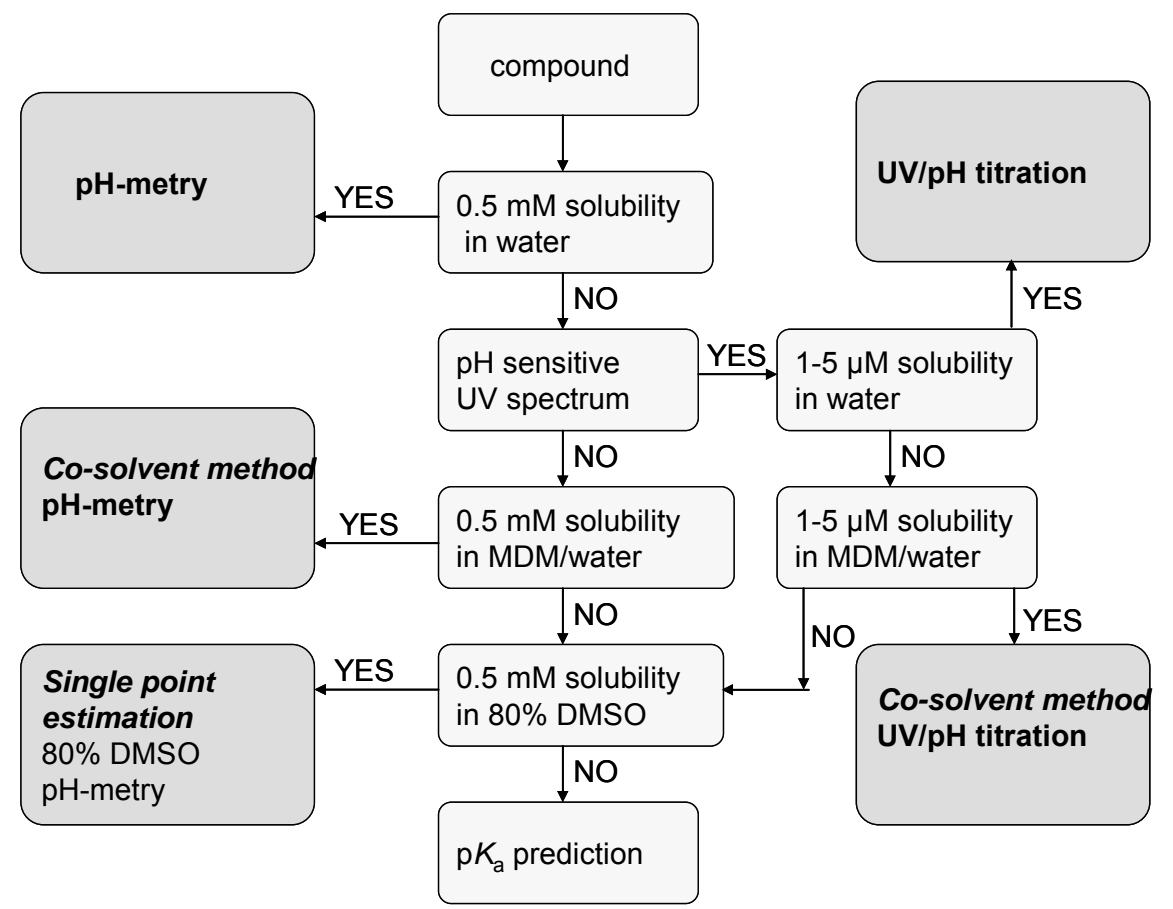

Figure 1.12. Decision tree for method selection of $\mathrm{p} K_{\mathrm{a}}$ measurement 
Table 1.4. Methods for $\mathrm{p} K_{\mathrm{a}}$ determination

\begin{tabular}{|c|c|c|c|c|c|c|c|}
\hline \multirow[b]{2}{*}{ Method } & \multicolumn{3}{|c|}{ Sample } & \multicolumn{2}{|c|}{ Throughput } & \multirow[b]{2}{*}{ Precision } & \multirow[b]{2}{*}{$\begin{array}{l}\text { Instrumen- } \\
\text { tation }\end{array}$} \\
\hline & $\begin{array}{l}\text { amount, } \\
\text { mg }\end{array}$ & $\begin{array}{c}\text { solu- } \\
\text { bility, } \\
\text { mM }\end{array}$ & $\begin{array}{l}\text { high } \\
\text { purity }\end{array}$ & speed $^{1}$ & $\begin{array}{l}\text { capa- } \\
\text { city }^{2}\end{array}$ & & \\
\hline potentiometry & $3-5$ & $>0.5$ & necessary & $20-30$ & $10-12$ & high & $\begin{array}{l}\text { GLpKa, SiriusT3 } \\
\text { (Sirius, UK) }\end{array}$ \\
\hline \multicolumn{8}{|l|}{$\begin{array}{l}\mathrm{UV} / \mathrm{pH} \\
\text { titration }\end{array}$} \\
\hline traditional & $1-2$ & $>0.01$ & necessary & $\begin{array}{c}\text { 6-8 } \\
\text { hours }\end{array}$ & 1 & medium & $\begin{array}{c}\mathrm{pH}-\text { meter }+ \\
\text { spectrophotometer }\end{array}$ \\
\hline automated & $1-2$ & $>0.01$ & necessary & 30 & $10-12$ & high & $\begin{array}{c}\text { GLpKa + D-PAS, } \\
\text { SiriusT3 (Sirius, UK) }\end{array}$ \\
\hline $\begin{array}{l}\mathrm{NMR} / \mathrm{pH} \\
\text { titration }\end{array}$ & $1-2$ & $>0.5$ & $\begin{array}{c}\text { not } \\
\text { necessary }\end{array}$ & $\begin{array}{c}2-3 \\
\text { hours }\end{array}$ & $2-3$ & high & NMR spectrometer \\
\hline \multicolumn{8}{|l|}{$\mathrm{CE}^{*}$} \\
\hline single channel & $<<1$ & $>0.01$ & $\begin{array}{c}\text { not } \\
\text { necessary }\end{array}$ & 30 & 20 & medium & $\mathrm{CE}$ \\
\hline multiplexed & $<<1$ & $>0.01$ & $\begin{array}{c}\text { not } \\
\text { necessary }\end{array}$ & 30 & 150 & acceptable & $\begin{array}{l}\text { CePro } 9600 \\
\text { (CombiSep) } \\
\end{array}$ \\
\hline $\mathrm{SGA}^{\dagger}$ & 1 & $>0.01$ & necessary & 4 & 240 & acceptable & $\begin{array}{c}\text { Profiler-SGA, } \\
\text { SiriusT3 (Sirius, UK) }\end{array}$ \\
\hline $\begin{array}{l}\text { * Capillary Electrc } \\
{ }^{+} \text {Spectral Gradien }\end{array}$ & $\begin{array}{l}\text { oresis } \\
\text { nalysis }\end{array}$ & & & $\begin{array}{l}{ }^{1} \mathrm{~min} / \\
{ }^{2} \mathrm{samp}\end{array}$ & omp. & & \\
\hline
\end{tabular}

\subsection{2. $\log S$ determination}

Several methods have been developed for the measurement of both equilibrium and kinetic solubility including traditional and high throughput techniques. Excellent reviews $[7,16,39,41]$ have surveyed the state-of-the-art techniques. Below, after a short summary of kinetic solubility methods, approaches for equilibrium solubility measurement are discussed focusing on good laboratory practice (GLP).

\subsubsection{Methods for determination of kinetic solubility}

Concerning the large number but small content, samples in the early phase of drug discovery are subjected to compound-saving and HT methods which are suitable for the measurement of kinetic solubility. In the turbidimetric method introduced by Lipinski et al. [77] small aliquots $(0.5 \mu \mathrm{l})$ of DMSO stock solution are added at $1 \mathrm{~min}$. intervals to aqueous buffers (originally, $2.5 \mathrm{ml}$ of pH 7 phosphate buffer) until the compound precipitates from the solution reaching the maximal (but not yet the equilibrium) solubility. The turbidity caused by the precipitation is measured by light scattering in the $620-820 \mathrm{~nm}$ range with a UV detector. In nephelometric [78], direct UV [79] and ultrafiltration-LC/MS [80] methods the above principle is adapted to 96-well plate using different detectors (nephelometer, diode array UV and MS, respectively). In the two later methods, 
the precipitate is separated from the solution by filtration (or centrifugation) before the concentration measurement. The ultrafiltration-LC/MS technique has the advantage of high sensitivity and the capability of handling impure samples. Commercially available instruments (Nephelostar, BMG; Nepheskan Ascent, Thermo Labsystem, $\mu$ SOL, $p$ ION) use fully automated liquid dispensing systems and provide high capacity (measurement of 200-300 compounds/day). The presence of DMSO in the kinetic solubility experiments may considerably affect the results in a highly compound-dependent way, thus it is practical to keep the DMSO at a minimum level (less than 0.5\%).

The main disadvantages of kinetic solubility measurements are the lack of standardization, poor reproducibility, and difficulties in the comparability of results.

\subsubsection{Methods for determination of equilibrium solubility}

\subsection{Saturation shake-flask method (SSF)}

The SSF method is the standard approach for the determination of equilibrium solubility which when properly performed provides high quality data. It is a simple but very time-consuming procedure and requires lots of manual work. The solution of the tested compound containing excess solid is prepared in aqueous buffer using a small $(2-5 \mathrm{ml})$ glass vial. The heterogeneous system is capped and vigorously stirred at a chosen temperature (usually $25^{\circ} \mathrm{C}$ or $37{ }^{\circ} \mathrm{C}$ ) for a specified time $(24,48 \mathrm{~h}$ or longer) until the equilibrium has been reached. After that, the two phases (solid and liquid) are separated by sedimentation, centrifugation, or filtration. Upon diluting sample aliquots with the solvent, if necessary, the concentration of the saturated solution is measured by an appropriate method, most frequently by UV spectroscopy or HPLC. Despite the longevity of SSF use, there in no accepted standard way to carry out this method. Published solubility studies show great differences in the experimental conditions used, particularly concerning the time of equilibration, the method of phase separation, and the control of $\mathrm{pH}$ during the measurement $[37,38,41]$.

Recently, in a comprehensive study published by Baka et al. [81] the most important experimental factors influencing the measured equilibrium solubility by the SSF were investigated (see some results in Section 1.4.2) and a standardized protocol was proposed for GLP [82]. The following conditions are suggested:

- the measurement must be carried out at controlled temperature with precision $\pm 0.1{ }^{\circ} \mathrm{C}$,

- Sörensen phosphate buffer can be used between pH 3-7, while Britton-Robinson buffer can be used in a wider $\mathrm{pH}$ range from 2.5 to 11.5 . $\mathrm{HCl}$ of appropriate concentration can be used below pH 2.5,

- the $\mathrm{pH}$ of the solution must be carefully controlled during the measurement, advisably before and after the equilibration,

- to avoid the difficulties in sampling, only a small ( 5-10 mg/5 ml) excess of solid should be present,

- a minimum of $24 \mathrm{~h}$ is necessary to reach the equilibrium, this time should consist of $6 \mathrm{~h}$ of stirring and $18 \mathrm{~h}$ of sedimentation, but in case of very sparingly soluble compounds longer stirring time may be necessary for equilibrium, so in the most rigorous 
application of SSF, the required time of equilibration must be determined from compound to compound,

- the safest technique of phase separation is sedimentation which assures a heterogeneous system until equilibrium has been achieved; if an opalescent solution is formed then the phase separation can be done by centrifugation while the most erroneous filtration should be avoided (see results in Section 1.4 .2 below),

- a compound existing in a meta-stable polymorph form can be transformed into a more stable one during the duration of solubility measurement, thus the analysis of the solid phase (by X-ray powder diffraction or thermo-gravimetric methods) at the end of the experiment is highly recommended.

Using the above listed conditions the equilibrium solubility of more than 50 compounds was determined with a standard deviation of less than $4 \%$ in our laboratory.

\subsection{Potentiometric methods}

The principle of the potentiometric methods is based on that characteristic shift of the titration curve caused by the precipitation of the unionized form of a compound from a solution. Potentiometric titration was introduced for equilibrium solubility measurement by Avdeef et al. [83-85]. The dissolution template titration (DTT) method uses $\mathrm{p} K_{\mathrm{a}}$ and $\log P$ values as input parameters. $\log P$ is used to estimate the intrinsic solubility based on a Hansch-Yalkowsky type equation $\left(\log S_{\mathrm{o}}=1.17-1.38 \log P\right)$. Using the $\mathrm{p} K_{\mathrm{a}}$ and the estimated intrinsic solubility, the DTT procedure simulates the entire titration curve before the assay begins. This curve serves as a titration template (the optimal quantity of the tested compound for the titration is suggested by the simulation) and also as a guide for the right titration protocol (how the instrument dispenses the titrant and collects the $\mathrm{pH}$ data) in the course of the titration. The titration starts at $\mathrm{pH}$ values, where the compound is unionized and forms a suspension (solid material is present in the solution). The titrant is dispensed accurately and slowly into the slurry, to drive the $\mathrm{pH}$ of the solution in the direction of dissolution. Typically, a 3-10 $\mathrm{h}$ (sometimes longer) time frame is required for the entire equilibrium solubility data collection (20-50 pH points) [41]. The method, when performed with the pSOL titrator (pION, US), provides a precise solubility-pH profile without assuming a HH relationship and is much faster than the SSF method but still has a very low throughput.

The novel potentiometric procedure (CheqSol) has been developed recently for rapid measurement of solubility using the instrument called the GLpKa-D-PAS (Sirius, UK). In this method, the equilibrium solubility is actively sought by changing the concentration of the neutral (unionized) form of a compound by adding acid or base titrants and monitoring the rate of the change of $\mathrm{pH}$, due to precipitation or dissolution in a process called "Chasing Equilibrium". In this method, the titration is started at $\mathrm{pH}$ value, where the compound is fully ionized and dissolved and performed toward the direction of $\mathrm{pH}$ where the unionized form precipitates. The turbidity of the solution caused by the precipitation is detected with a fiber optic dip probe. With this method both the kinetic solubility and the equilibrium solubility can be determined. The kinetic solubility value is 
obtained from the concentration when the first precipitation of the unionized form appears in the solution, while the equilibrium solubility is obtained from actively seeking the equilibrium $\mathrm{pH}$ where an equal amount of the sample is precipitating and dissolving per unit of time [86]. The CheqSol method is faster (typically 30-60 min/compound) because the intrinsic solubility is determined instead of the entire solubility-pH profile. Then $\mathrm{HH}$ equation is used for the calculation of the approximate $\log S / \mathrm{pH}$ profile. It was validated against the SSF method and excellent agreement of solubility results was found [87].

\subsubsection{3. $\mu$ DISS method}

A miniaturized rotating disk dissolution instrument, called $\mu$ DISS ProfilerPLUS (pION, US) has been developed for characterizing the intrinsic dissolution rate in early preformulation. This apparatus is also suitable for the measurement of equilibrium solubility of sparingly soluble compounds, provided enough material is used to maintain the saturation $[41,88,89]$. In this procedure, $5 \mathrm{mg}$ of drug are compressed into pellets and inserted into a rotating disk carrier containing an embedded magnetic stir bar at its bottom. This assembly is placed into a glass vial filled with a small volume (1-3 ml) of aqueous buffer as the dissolution medium. The concentration is measured with a rapid in situ fiber optic UV (diode array) detector. The instrument employs six parallel dissolution vessels and eight channels of UV detectors which provide better capacity above the SSF method. Over the high precision, further advantages of this method are: (i) any polymorph changes during dissolution can be recognized and (ii) the longer incubation time needed to establish the true equilibrium of the most stable form of a solid may be evident in the dissolution curve [39].

\subsection{High throughput methods}

Some methods suitable for medium or high throughput determination of $\log S$ were also described. The miniaturised shake-flask (MSF) method developed by Glomme et al. $[90,91]$ is a compound saving and fast method, thus it is frequently used in pharmaceutical companies. Typically, 0.1-0.2 mg solid powder is introduced to a specially designed filter chamber and a small (e.g. $2 \mathrm{ml}$ ) volume of aqueous buffer is added. Purpose-built filter caps are firmly attached and the vials are shaken at constant temperature for $24 \mathrm{~h}$. The filter-containing cap compartments are then depressed to effect separation of the solid and the top compartment solutions are analyzed by fast gradient RP-HPLC. The throughput is just medium, as 20 compounds/week can be measured. The MSF method was further developed for HT measurements by Zhou et al. [92] where a 96-well plate is used as the source of the samples and DMSO stocks were evaporated via a GeneVac evaporator.

Those 96-well plate based HT methods (originally developed for kinetic solubility measurement), where the incubation time is long enough (e.g. $\mu$ SOL method, [39]) and the effect of DMSO content is eliminated, are also suitable for equilibrium solubility determination. Generally, in these modified-microplate methods the $24 \mathrm{~h}$ incubation time is adequate to reach the solubility equilibrium [39]. 
However, due to small volumes, the precise $\mathrm{pH}$ control during the measurement may be problematic. In the lyophilized solubility assay (LYSA) the sample is dispensed into a microtiter plate along with $10 \mathrm{mM}$ DMSO solution then the organic solvent is removed by lyophilization and aqueous buffer is added. During a $24 \mathrm{~h}$ incubation period the plate is agitated by a shaking mechanism, then filtrated and the concentration is measured using a UV plate reader [93]. Another promising HT procedure is the PASS (Partially Automated Solubility Screening) method, where the compounds are suspended in heptane and dispensed into the plate wells, then heptane is evaporated before buffer is added [94].

\subsubsection{Special applications}

The methods described above have been applied for special purposes. Potentiometric titration, according to the CheqSol approach, has been reported to study the solubility of polymorphs. A new method named "potentiometric cycling for polymorph creation" (PC) ${ }^{2}$, was developed to generate the most stable polymorph in aqueous solution [95]. It was applied to sulindac producing two polymorphs including a new, more stable one. It was found that their intrinsic solubility differ by a factor of seven, which is much larger than that of any earlier measured difference between polymorphs.

Table 1.5. Methods for $\log S$ determination

\begin{tabular}{|c|c|c|c|c|c|c|}
\hline \multirow[b]{2}{*}{ Method } & \multirow[b]{2}{*}{ Detection } & \multirow{2}{*}{$\begin{array}{l}\text { LOD, } \\
\mu \mathrm{g} / \mathrm{ml}\end{array}$} & \multicolumn{2}{|c|}{ Throughput } & \multirow[b]{2}{*}{ Precision } & \multirow{2}{*}{$\begin{array}{l}\text { Instrumen- } \\
\text { tation }\end{array}$} \\
\hline & & & $\begin{array}{c}\text { speed, } \\
\text { min/comp. }\end{array}$ & $\begin{array}{c}\text { capacity, } \\
\text { samp./day }\end{array}$ & & \\
\hline \multicolumn{7}{|c|}{ for kinetic solubility } \\
\hline turbidimetric & UV & 5 & 15 & 50 & low & \\
\hline nephelometric & $\begin{array}{l}\text { laser nephe- } \\
\text { lometer }\end{array}$ & 5 & 4 & 300 & low & $\begin{array}{l}\text { Nephelostar, } \\
\text { Nepheloscan }\end{array}$ \\
\hline direct-UV & UV & $2 \cdot 10^{-3}$ & 4 & 300 & medium & $\mu \mathrm{SOL}$ \\
\hline $\begin{array}{l}\text { ultafiltration- } \\
\text { LC/MS }\end{array}$ & MS & 0.1 & 6 & 200 & medium & LC/MS \\
\hline \multicolumn{7}{|c|}{ for equilibrium solubility } \\
\hline SSF & UV; HPLC & 1 & 36 hours & $<1$ & high & \\
\hline \multicolumn{7}{|l|}{ Potentiometric } \\
\hline DTT & pH-metry & $5 \cdot 10^{-3}$ & 3-10 hours & $1-5$ & high & pSOL \\
\hline CheqSol & pH-metry & 0.1 & $30-60$ & $10-15$ & high & GLpKa; SiriusT3 \\
\hline$\mu \mathrm{DISS}$ & UV & 1 & 24 hours & 6 & high & $\begin{array}{c}\mu \text { DISS } \\
\text { ProfilerPLUS }\end{array}$ \\
\hline \multicolumn{7}{|l|}{$\begin{array}{l}\text { modified-plate } \\
\text { HT }\end{array}$} \\
\hline MSF & UV; LC/MS & 1 & 24 hours & $3-100$ & medium & \\
\hline$\mu \mathrm{SOL}$ & UV & 0.1 & $\begin{array}{l}18-24 \\
\text { hours }\end{array}$ & 100 & acceptable & $\mu \mathrm{SOL}$ \\
\hline LYSA & UV & 1 & 24 hours & 100 & acceptable & \\
\hline PASS & UPLC & $10^{3}$ & 24 hours & 100 & acceptable & \\
\hline
\end{tabular}


The biorelevant solubility values are more and more required in drug discovery and development (DD\&D). An optimized 96-well HT UV solubility method was adapted to measure solubility of drugs in biorelevant media such as FaSSIF and FeSSIF solutions [96]. The method provides reliable data using a very small amount of sample and small volumes of the expensive FaSSIF/FeSSIF components. The $\mu$ DISS method was also found useful for measurement in biorelevant media and temperature [97]. The study has revealed that the majority of the tested drugs exhibited higher solubility in these media than in pure buffers.

\subsection{3. $\log P$ determination}

Since $\log P$ is the oldest parameter in physicochemical profiling, several wellestablished experimental methods are available for its determination. Vast amounts of literature have described the theory and practice of the used methods [e.g. 11,46,98-101]. Aspects from the GLP guide for $\log P$ measurements have also been published [98,101,102]. The recent reviews provide a comprehensive survey about the latest developments in HT techniques [6,9,14-16].

Two types of methods can be distinguished for $\log P$ determination: $(i)$ the direct approaches, where $\log P$ is directly obtained from the measured data (shake-flask, stir-flask, filter chamber, dual-phase potentiometric, etc.) and (ii) indirect (chromatographic, CE) techniques, where the measured parameter has a linear relationship with $\log P$ and $\log P$ is calculated using calibration equations. In this chapter, the direct methods are overviewed, out of the indirect methods only TLC is presented, while others like HPLC, MECK, etc. used for log $P$ measurement are discussed elsewhere in the book.

In order to facilitate the comparison of their capacity, Table 1.6 summarizes both types of methods.

\subsubsection{Shake-flask (SF) method}

The traditional SF method is the reference and most widely used approach of $\log P$ determination.

Procedure. In advance, the two phases (n-octanol or other useful partition organic solvent that is immiscible with water and aqueous buffer) must be mutually saturated with vigorous agitation then filtered or centrifuged. The tested substance is dissolved in the aqueous phase and introduced into an appropriate glass vial. Octanol (or other organic solvent) is added in a required volume and the system is shaken at a constant temperature for a period long enough for equilibrium to be achieved (generally $1 \mathrm{~h}$ ). After separation of the phases by centrifugation, the concentration is measured using an appropriate method, mostly UV spectroscopy. Concerning the difficulties of the precise analytical work with octanol, it is a common practice to measure the concentration decrease in the aqueous phase by detecting the absorbance before and after the partition.

Accuracy, sources of the experimental error. The SF method is suitable for $\log P$ measurement in the range from -2 to 5 having a $S D<0.05$, provided that optimal 
experimental conditions are maintained. Many factors can affect the reliability of the measured $\log P$ values increasing the experimental error. One of them is undoubtedly the applied extreme phase ratio necessary in the case of lipophilic compounds $(\log P>3)$. According to our experiences, the highest phase ratio that can be used without a considerable increase in error is $R=500$ (e.g. $50 \mathrm{ml}$ aqueous buffer: $0.1 \mathrm{ml}$ octanol). However, in the opposite case with hydrophilic compounds, when more octanol has to be used, the sampling from the lower aqueous phase may be problematic, thus it is advisable to remove the upper octanol layer before aliquots are taken. Glass and surface adsorption, formation of stable emulsions, and the presence of impurities in the sample have often influenced the results.

Advantages/drawbacks. The main advantage of the SF method is its simplicity, sufficient accuracy, and applicability to non-ionizable compounds. But it has some well-known shortcomings, such as being tedious and time-consuming, difficulties with maintaining a constant temperature during the whole procedure, requiring relatively high amounts of sample and solvent. The SF method cannot be used for UV inactive compounds unless alternative detection methods are employed, and so on.

\subsubsection{Potentiometric method}

Dual phase potentiometric titration using automated instruments has become the "gold standard" of $\log P$ determination (for ionizable compounds) in the past ten years $[11,60,100]$. It consists of two titrations of the tested compound. One is performed without the partition solvent and provides the aqueous $\mathrm{p} K_{\mathrm{a}}$ value. The second is done using the same conditions but in the presence of a partition solvent (e.g. octanol) with intensive stirring upon titrant addition, while stopping it when the $\mathrm{pH}$ is measured. If the unionized form of the compound partitions into octanol then the two titration curves will be different, due to a shift (similar to what was discussed in the co-solvent $\mathrm{p} K_{\mathrm{a}}$ method). From the dual-phase titration, the apparent $\mathrm{p}_{0} K_{\mathrm{a}}$ value is obtained. $\log P$ is calculated from the differences in $\mathrm{p} K_{\mathrm{a}}$ values and the phase ratio. A large shift indicates high lipophilicity (see also in Section 1.4.3).

This method allows the $\log P$ determination in a range from -2 to 6 , with very high precision $(S D= \pm 0.01)$. The agreement with the SF method is excellent according to validation studies $[103,104]$. However, it has limited capacity and cannot be used for compounds with $\mathrm{p} K_{\mathrm{a}}$ out of the established measurable $\mathrm{pH}$ range. A further drawback is that only a limited phase ratio can be applied (in our practice with GLpKa: $20 \mathrm{ml}$ water : $0.05 \mathrm{ml}$ octanol for lipophilic compounds and $5 \mathrm{ml}$ of water : $15 \mathrm{ml}$ of octanol for hydrophilic compounds). A newly developed instrument (SiriusT3) has further increased efficacy and measurement is possible in as low as $1 \mathrm{ml}$ aqueous phase. 


\subsubsection{Indirect $\log P$ measurement methods}

Because of the drawbacks and limitations of direct methods, numerous alternative procedures have been developed and applied. Several micellar, microemulsion, vesicle electrokinetic chromatographic systems, and reversedphase chromatographic methods (RP-TLC, RP-HPLC) can be used to estimate lipophilicity. Some excellent reviews on the use of separation methods for indirect $\log P$ determination have been published [e.g. 105-106].

Although RP-HPLC is more widely used technique for $\log P$ estimation [105], RPTLC undoubtedly has some unique advantages, including use of less expensive laboratory equipment and being easy to perform. Simultaneous running of 15-20 compounds on one plate can significantly reduce the analysis time per compound. The method is based on the linear relationship between $\log P$ measured by the SF method and the logarithm of chromatographic retention expressed as the $R_{\mathrm{M}}$ value. RP-TLC has been successfully applied for $\log P$ measurement of highly lipophilic molecules using calibration equations obtained with structurally related compounds [e.g. 107-109]. Recently, a validated RP-TLC method was proposed for parallel estimation of the lipophilicity of chemically diverse neutral compounds or weak acids and bases [110]. To cover a wide range of lipophilicity, two optimized RP-TLC systems were used: one for moderate lipophilic compounds $(\log P=0-3)$ and another for highly lipophilic molecules ( $\log P=3-6)$. Two chemically diverse sets of compounds were selected to set up the general calibration equations. The method was tested with 20 randomly selected drugs and good agreement with SF results were found $(S D<0.15)$. With automated sampling and imaging detection of the compounds the method can be regarded as a possible alternative for rapid and acceptable accurate estimation of lipophilicity of drug candidates in the early phase of DD\&D.

\subsubsection{High throughput methods}

Attempts have been done to miniaturize the traditional SF method into a microtiter plate platform with robotic liquid handling and HPLC/UV [111] or LC/MS [112] detection. In these techniques the partitioning process is transferred to 96-deep well plates and after equilibration, the detector signal produced by a sample from the octanol phase is divided by the signal from the aqueous phase. In a review by Kerns [7], the critical elements of these methods are discussed. A commercially available automated plate based instrument for HT $\log P$ determination is called the AlogP (Analiza, US).

Regarding indirect (HPLC and MECK) $\log P$ methods, additional successful strategies were applied to increase the throughput and speed up the determination time [16]. For example, the use of short columns and a high flow rate in HPLC, usage of UPLC, and multiplexed MECK have been reported. These methods are surveyed in the Chapter 2 of this book. 


\subsubsection{Decision tree for method selection}

The method selection strategy followed in the laboratory of the author is shown in Figure 1.13.

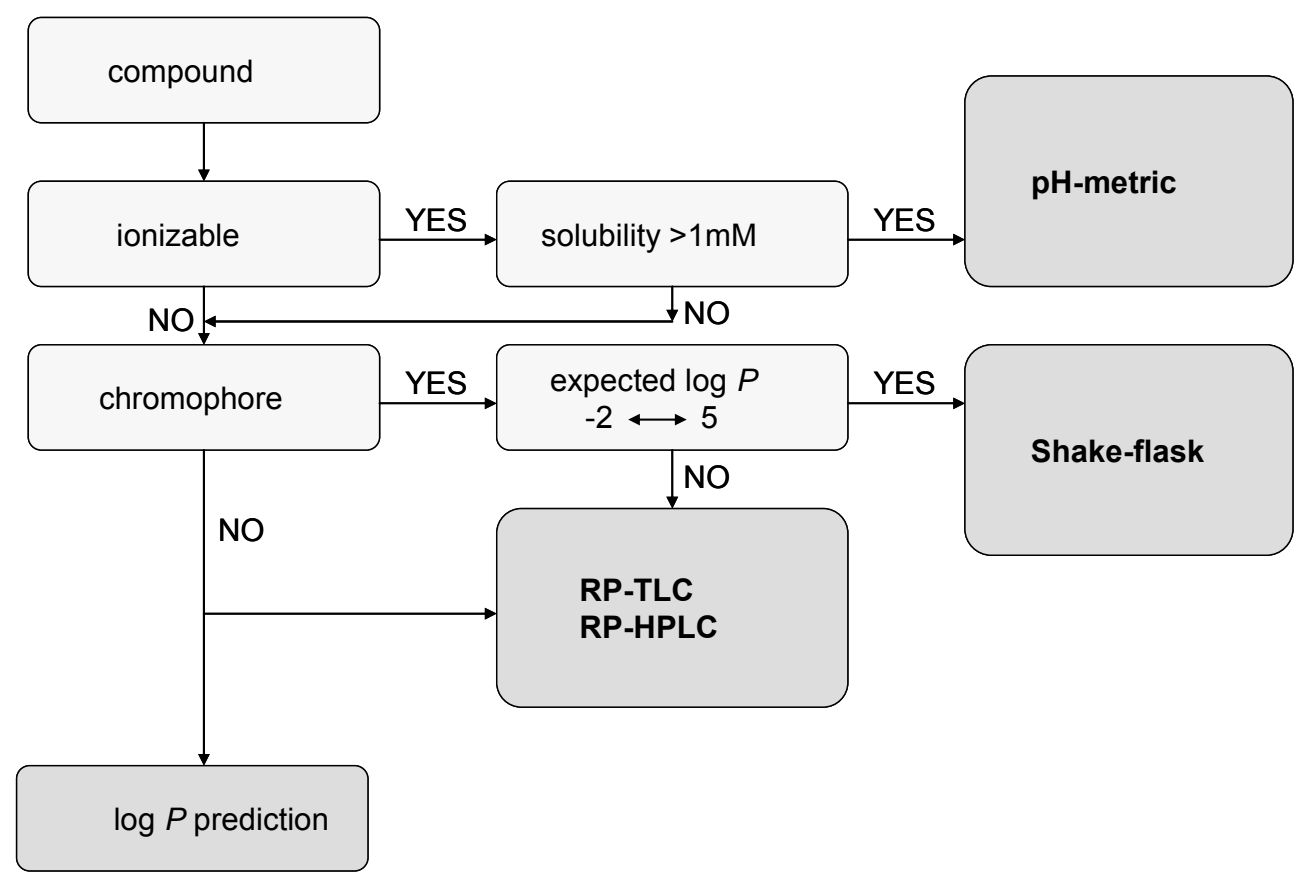

Figure 1.13. Decision tree for method selection of $\log P$ measurement

Table 1.6. Methods for $\log P$ determination

\begin{tabular}{|c|c|c|c|c|c|c|}
\hline \multirow[b]{2}{*}{ Method } & \multirow{2}{*}{$\begin{array}{l}\log P \\
\text { range }\end{array}$} & \multirow{2}{*}{$\begin{array}{c}\text { sample } \\
\text { amount, } \\
\text { mg }\end{array}$} & \multicolumn{2}{|c|}{ Throughput } & \multirow[b]{2}{*}{ Precision } & \multirow[b]{2}{*}{ Instrumentation } \\
\hline & & & $\begin{array}{c}\text { speed, } \\
\text { min/comp. }\end{array}$ & $\begin{array}{l}\text { capacity, } \\
\text { samp./day }\end{array}$ & & \\
\hline \multicolumn{7}{|c|}{ direct methods } \\
\hline \multicolumn{7}{|l|}{ shake-flask } \\
\hline traditional & $-2 \leftrightarrow 5$ & $2-10$ & $180-360$ & 2 & high & \\
\hline $\begin{array}{c}\text { automated } \\
\text { (96-well plate } \\
\text { platform) }\end{array}$ & $-2 \leftrightarrow 5$ & $1-5$ & 10 & 100 & acceptable & $\begin{array}{c}\text { AlogP } \\
\text { (Analiza Inc.) }\end{array}$ \\
\hline potentiometric & $-2 \leftrightarrow 6$ & $1-5$ & 60 & 20 & high & GLp $K_{\mathrm{a}}$, SiriusT3 \\
\hline \multicolumn{7}{|c|}{ indirect methods } \\
\hline RP-TLC & $0 \leftrightarrow 6$ & $1-3$ & 120 & 50 & medium & \\
\hline RP-HPLC & $-1 \leftrightarrow 6$ & 0.01 & 15 & 100 & acceptable & \\
\hline MEEKC & $-1 \leftrightarrow 7$ & $<<1$ & 15 & 150 & acceptable & $\begin{array}{l}\text { CePro } 9600, \\
\text { MCE } 2000\end{array}$ \\
\hline
\end{tabular}




\subsection{CASE STUDIES}

In this chapter we present some useful examples of physicochemical profiling for the illustration of methods discussed above. Mainly, such problematic compounds have been selected where the routine measurement is difficult or hindered by certain reasons. The most frequent difficulties in the $\mathrm{p} K_{\mathrm{a}}, \log S$, and $\log P$ determination are the low solubility, instability, lack of UV activity and polymorph transition of the compound. The case studies introduced below can provide a possible template for the measurement of "difficult to measure" molecules.

\subsection{1. $\mathrm{p} K_{\mathrm{a}}$ determination}

Case 1.

Sample:

RG-1503

Method: $\quad$ co-solvent method; potentiometric titration in methanol/water system

Instrumentation: GLpKa (Sirius, UK)

The compound is a multiprotic molecule containing four ionizable groups (Figure 1.14a: A-D). The two piperazine $\mathrm{N}$ atoms and the pyridine $\mathrm{N}$ are proton accepting basic centers, while the arylsulfonamide moiety represents a proton releasing acidic group. The aqueous solubility of the compound is less than $0.5 \mathrm{mM}$ and it has no useful pH-dependent UV spectrum in the $\mathrm{pH}$ range 3-10, thus neither potentiometry nor $\mathrm{UV} / \mathrm{pH}$ titration in an aqueous medium can be used.

(a)

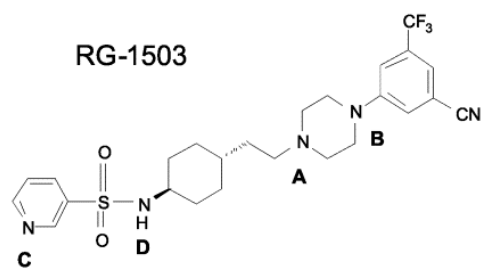

(c)

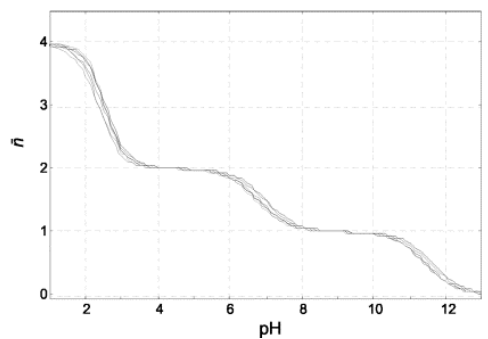

(b)

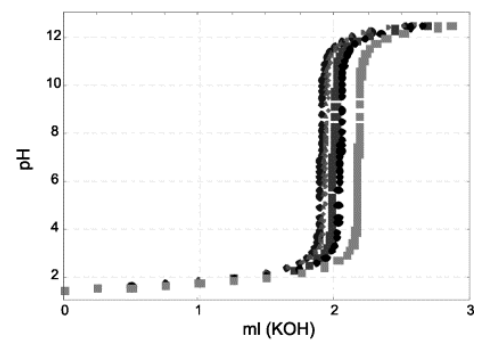

(d)

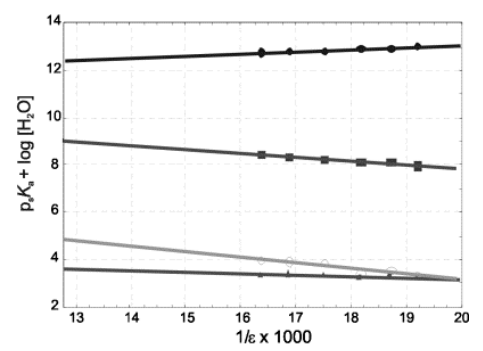

Figure 1.14. Co-solvent $\mathrm{pH}$-metry for $\mathrm{pKa}$ determination:

(a) structure of the sample (RG-1503), (b) titration curves in different methanol/water mixtures, (c) Bjerrum plots, (d) YS extrapolation curves 
The $\mathrm{p} K_{\mathrm{a}}$ values were measured by potentiometry using the co-solvent method (see Section 1.3.1.4). Six titrations were performed in methanol/water mixtures (40-60 wt\%) between pH $1.5-12.5 \mathrm{in} \sim 1 \mathrm{mM}$ concentration of the sample, at $0.15 \mathrm{M}(\mathrm{KCl})$ ionic strength, at $25.0 \pm 0.1{ }^{\circ} \mathrm{C}$ temperature, under $\mathrm{N}_{2}$ atmosphere (Figure 1.14.b). From the obtained $\mathrm{p}_{\mathrm{s}} K_{\mathrm{a}}$ values, the aqueous $\mathrm{p} K_{\mathrm{a}}$ values were calculated by YS extrapolation (Figure 1.14d).

Results: $\mathrm{p} K_{\mathrm{a} 1}=2.02 \pm 0.22$ (B group); $\mathrm{p} K_{\mathrm{a} 2}=3.03 \pm 0.09$ (C group);

$$
\mathrm{p} K_{\mathrm{a} 3}=7.35 \pm 0.03 \text { (A group); } \mathrm{p} K_{\mathrm{a} 4}=11.40 \pm 0.09 \text { (D group). }
$$

Case 2.

Sample:

Method:

nitrofurantoin

Instrumentation: GLpKa + D-PAS (Sirius, UK)

Nitrofurantoin is a water-insoluble compound which has one acidic group and exhibits a pH-dependent UV spectrum. The $\mathrm{p} K_{\mathrm{a}}$ value was measured in an $\mathrm{MDM} /$ water system because its solubility is high enough in this solvent mixture for the spectroscopic determination. A stock solution was prepared in $10 \mathrm{mM}$ concentration with MDM, $50 \mu$ l of this stock solution was used for the titration in $15 \mathrm{ml}$ of $20-50 \mathrm{wt} \% \mathrm{MDM} /$ water mixtures between $\mathrm{pH} 3-10$, at $0.15 \mathrm{M} \mathrm{(KCl)} \mathrm{ionic}$ strength, at $25.0 \pm 0.1{ }^{\circ} \mathrm{C}$ temperature, under $\mathrm{N}_{2}$ atmosphere. Figure 1.15.c shows the $\mathrm{p}_{\mathrm{s}} K_{\mathrm{a}}$ values used for YS extrapolation. The extrapolated aqueous $\mathrm{p} K_{\mathrm{a}}$ value is: $6.87 \pm 0.01\left(R^{2}=0.9958\right)$, which is in good agreement with literature data measured by other methods [76].

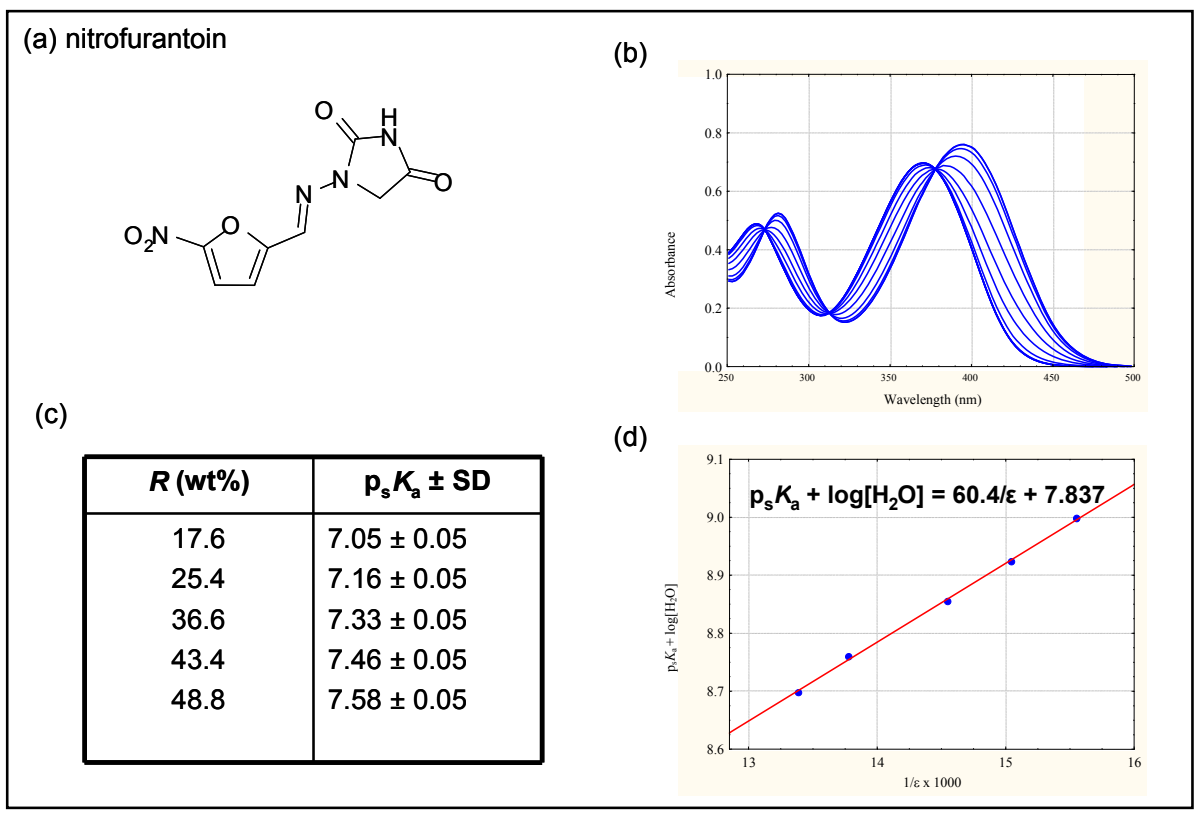

Figure 1.15. Co-solvent $\mathrm{UV} / \mathrm{pH}$ titration for $\mathrm{p} K_{\mathrm{a}}$ determination:

(a) structure of the sample (nitrofurantoin), (b) pH-dependent UV spectra, (c) apparent $\mathrm{p} K_{\mathrm{a}}$ values in different MDM/water mixtures, (d) YS extrapolation 
Case 3.

Sample:

Method:

\section{lisinopril}

potentiometric titration in aqueous solution and in methanol/water system; NMR/pH titration

Instrumentation: GLpKa + D-PAS (Sirius, UK); Varian Inova $600 \mathrm{MHz}$ spectrometer (Palo Alto, CA)

Lisinopril is a tetraprotic compound having two acidic (carboxyl) and two basic (a primary and a secondary amine) groups. Figure 1.16a shows the ionization processes of the molecule. The dissociation of the two carboxyl groups is highly overlapping. The solubility of lisinopril $(0.22 \mathrm{M})$ allows the determination of $\mathrm{p} K_{\mathrm{a}}$ values by the standard potentiometric method in aqueous medium. However, the first dissociation constant falls into the low $\mathrm{pH}$ range which may cause uncertainty of the measurement.

For the characterization of the acid/base property of the molecule, three independent methods were applied: potentiometry in aqueous solution and in a methanol/water system, as well as $\mathrm{NMR} / \mathrm{pH}$ titration. In aqueous medium, three titrations were carried out in a $2 \mathrm{mM}$ concentration solution, between $\mathrm{pH} 1.8-12$, at $0.15 \mathrm{M}(\mathrm{KCl})$ ionic strength, at $25.0 \pm 0.1{ }^{\circ} \mathrm{C}$ temperatures, under $\mathrm{N}_{2}$ atmosphere. Since $\mathrm{p} K_{\mathrm{a} 1}$ value falls below the lower applicability limit $(<2) \mathrm{of} \mathrm{pH}$ metric titration, the $\mathrm{p} K_{\mathrm{a}}$ values were also measured using the co-solvent method.

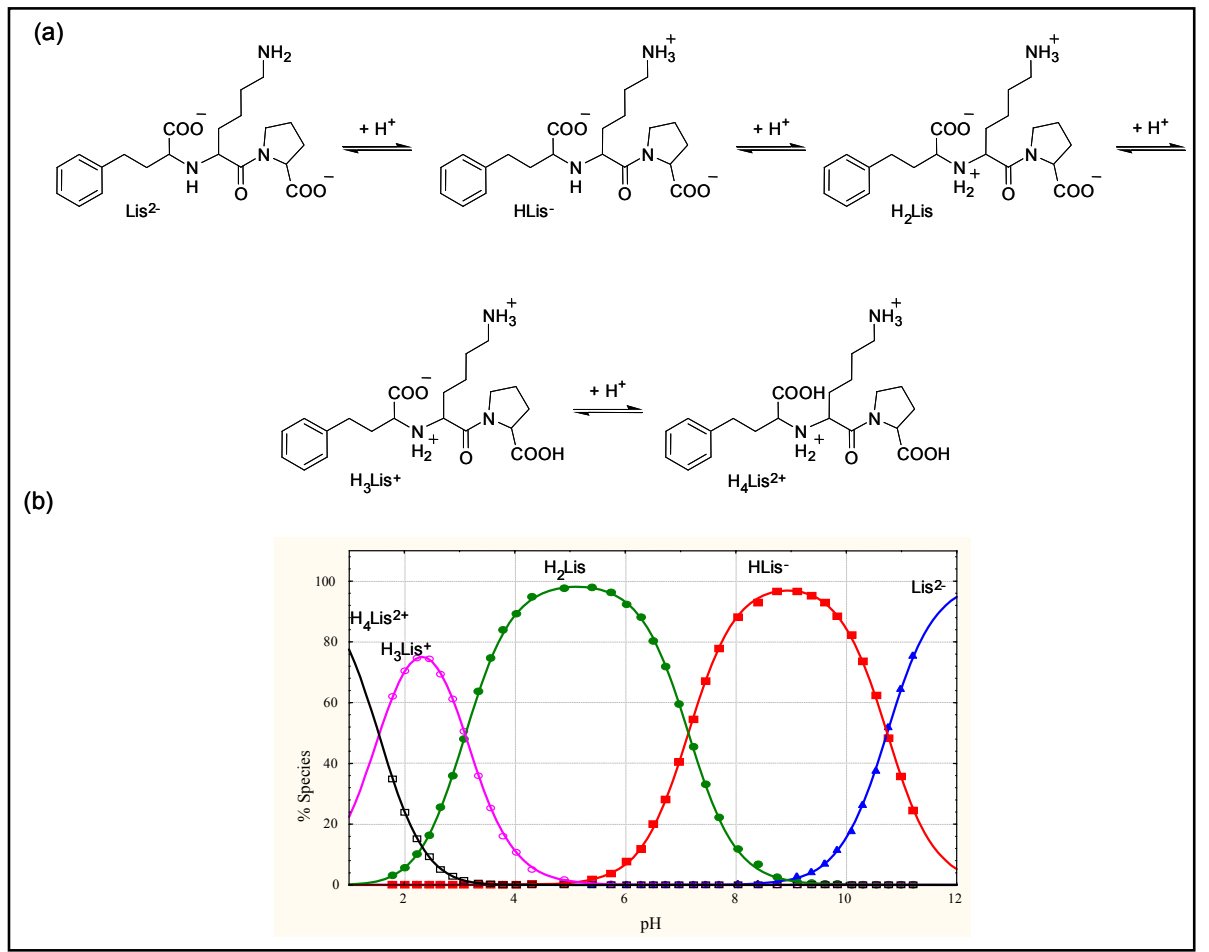

Figure 1.16. Protonation scheme of (a) tetraprotic lisinopril,

(b) distribution of macrospecies 
The apparent $\mathrm{p} K_{\mathrm{a}}$ values of the $\mathrm{COOH}$ groups obtained in 14-44 wt\% methanol/water mixtures shifted up to the established measurable $\mathrm{pH}$ range, and a reliable aqueous $\mathrm{p} K_{\mathrm{a} 1}$ value could be obtained by YS extrapolation.

For the exact proton speciation of lisinopril, ${ }^{1} \mathrm{H} \mathrm{NMR} / \mathrm{pH}$ titrations with in situ $\mathrm{pH}$ measurements were carried out, using the most similar experimental conditions as possible in potentiometry. This method was useful to assign the constants to the functional groups: $\mathrm{p} K_{\mathrm{a} 1}$ and $\mathrm{p} K_{\mathrm{a} 2}$ belong to the $\mathrm{COOH}$ groups, $\mathrm{p} K_{\mathrm{a} 3}$ refers to the secondary amine $(-\mathrm{NH}-)$, and $\mathrm{p} K_{\mathrm{a} 4}$ shows the basicity of the primary amine $\left(-\mathrm{NH}_{2}\right)$ function.

The highly precise $\mathrm{p} K_{\mathrm{a}}$ values were calculated as an average of the best two values obtained by independent methods (Table 1.7). These values were used to calculate the distribution curve of different protonated species of lisinopril against the $\mathrm{pH}$ (Figure 1.16b).

Table 1.7. The $\mathrm{p} K_{\mathrm{a}}$ values of lisinopril measured by different methods

\begin{tabular}{lcccc}
\hline \multirow{2}{*}{ method } & \multicolumn{4}{c}{ ionization constants } \\
\cline { 2 - 5 } & $\mathbf{p} \boldsymbol{K}_{\mathrm{a} 1} \pm \boldsymbol{S D}$ & $\mathbf{p} \boldsymbol{K}_{\mathrm{a} 2} \pm \boldsymbol{S D}$ & $\mathbf{p} \boldsymbol{K}_{\mathrm{a} 3} \pm \boldsymbol{S D}$ & $\mathbf{p} \boldsymbol{K}_{\mathrm{a} 4} \pm \boldsymbol{S D}$ \\
\hline potentiometry & $1.54 \pm 0.05$ & $3.10 \pm 0.01$ & $7.14 \pm 0.01$ & $10.74 \pm 0.01$ \\
\hline potentiometry in solvent mixtures & $1.62 \pm 0.01$ & $3.21 \pm 0.02$ & $7.22 \pm 0.03$ & $10.75 \pm 0.01$ \\
\hline NMR/pH titration & $1.63 \pm 0.01$ & $3.15 \pm 0.01$ & $7.12 \pm 0.01$ & $10.53 \pm 0.03$ \\
\hline average of the best two values & $1.63 \pm 0.01$ & $3.13 \pm 0.01$ & $7.13 \pm 0.01$ & $10.75 \pm 0.01$ \\
\hline
\end{tabular}

\subsection{2. $\log S$ determination}

Case 4.

Sample: $\quad$ hydrochlorothiazide

Method: SSF

Instrumentation: Radiometer PH220 pH meter; LAUDA M20S thermostat; Heidolph MR 1000 magnetic stirrer; JASCO V-550 UV/VIS spectrophotometer

Hydrochlorothiazide is a bivalent acid with $\mathrm{p} K_{\mathrm{a}}$ values: 8.75 and 9.88. Its intrinsic solubility $\left(S_{0}\right)$ value was measured at pH 6.0 using the SSF method [81].

First the $S_{0}$ of the sample was measured according to a standard (literature) protocol with the following conditions. Buffer: Britton-Robinson (BR); solid excess: small amount; temperature: $25.0 \pm 0.1^{\circ} \mathrm{C}$; equilibration time: $48 \mathrm{~h}$ stirring plus $24 \mathrm{~h}$ sedimentation; phase separation technique: sedimentation; concentration measurement: UV spectroscopy $\left(\lambda=271 \mathrm{~nm}, A^{1 \%} 1 \mathrm{~cm}\right.$ : 696); number of parallels: 6. Result: $S_{\mathrm{o}}=556 \pm 13.2 \mu \mathrm{g} / \mathrm{ml}$.

Next, different parameters of this protocol were examined, always one of the six parameters (buffer choice, amount of solid excess, temperature, time of stirring, time of sedimentation, phase separation technique) was varied while the other conditions were kept unchanged. 
Effect of buffer solution. Three buffer solutions were used at $\mathrm{pH}$ 6.0. The results are shown in Figure 1.17a. The statistical analysis has indicated that $S_{0}$ values in BR and Sörensen phosphate (I) buffers are in accordance, but the solubility in Sörensen citrate (II) buffer deviates significantly. The ionic strength of this later buffer is four times higher than that of BR or Sörensen I.

Effect of phase separation. Alternative techniques to sedimentation such as centrifugation and filtration were studied. 12 samples were centrifuged after $48 \mathrm{~h}$ stirring at $2000 \mathrm{rpm}$ for $10 \mathrm{~min}$, while 12 samples were filtered through $0.45 \mu \mathrm{m}$ membrane filters. Results shown in Figure $1.17 \mathrm{~b}$ are significantly different. The highest deviation is caused by filtration.

Effect of equilibration time. Figure 1.17c shows the experimental results obtained when (i) stirring time was changed from 30 min to $48 \mathrm{~h}$ followed by a $24 \mathrm{~h}$ sedimentation; and (ii) sedimentation time was changed from $1 \mathrm{~h}$ to $24 \mathrm{~h}$, keeping the stirring time constant ( $48 \mathrm{~h}$ ). From the results it can be concluded that the time of sedimentation plays a greater role in the development of equilibrium than the time of intensive agitation.

Effect of temperature. The solubility of hydrochlorothiazide increases with the temperature (Figure $1.17 \mathrm{~d}$ ). It is almost double at $37{ }^{\circ} \mathrm{C}$ than at $25{ }^{\circ} \mathrm{C}$, which underlines the need for solubility determination at biomimetic temperature as well.

(a)

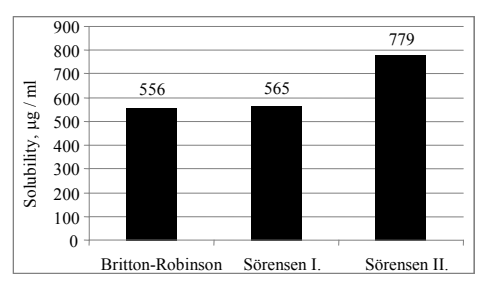

(c)

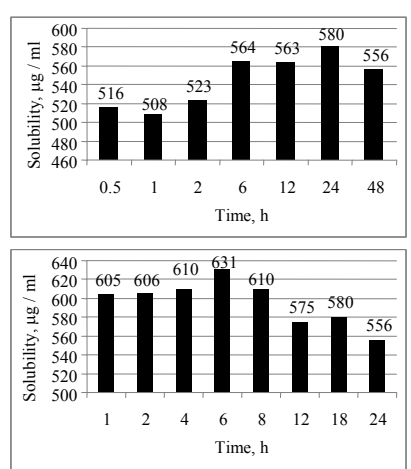

(b)

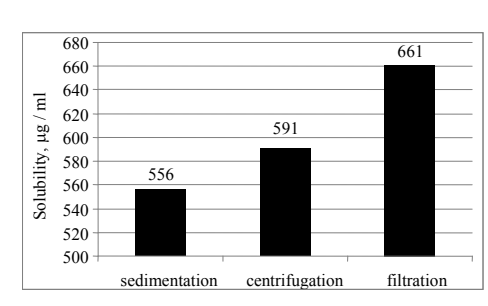

(d)

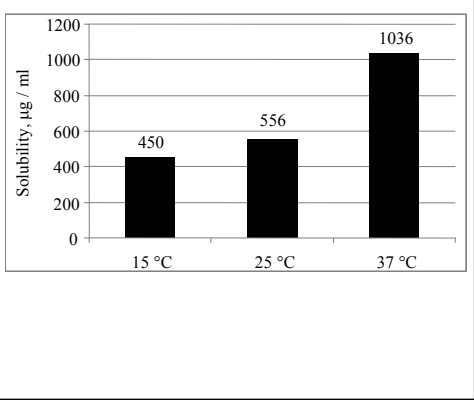

Figure 1.17. Effect of experimental conditions on the intrinsic equilibrium solubility of hydrochlorothiazide: (a) buffer solution, (b) phase separation technique,

(c) stirring time (upper graph) sedimentation time (lower graph), (d) temperature 


\section{Case 5.}

Sample: papaverine hydrochloride

Method: SSF

Instrumentation: Radiometer PH220 pH meter; LAUDA M20S thermostat; Heidolph MR 1000 magnetic stirrer; JASCO V-550 UV/VIS spectrophotometer

The solubility-pH profile of papaverine hydrochloride was determined in a wide $\mathrm{pH}$ range using a new (shorter) protocol derived from the SSF method: BR buffer, small solid excess, $25.0 \pm 0.1^{\circ} \mathrm{C}, 6 \mathrm{~h}$ stirring and $18 \mathrm{~h}$ sedimentation [42].

First, the intrinsic solubility of the sample was measured at high pH (11.71) and found $17 \mu \mathrm{g} / \mathrm{ml}\left(\log S_{\mathrm{o}}=1.70[\log \mu \mathrm{M}]\right)$. Then the equilibrium solubility $\left(S_{\mathrm{pH}}\right)$ values at twelve different $\mathrm{pH}$ values between 0.06 and 8.02 were determined.

From $\log S_{\mathrm{o}}$ and $\mathrm{p} K_{\mathrm{a}}(6.36)$ values the theoretical $\log S_{\mathrm{pH}} / \mathrm{pH}$ profil was generated by the $\mathrm{HH}$ equation. Figure 1.18 shows the excellent agreement between the experimental data points and the predicted $\mathrm{HH}$ curve. This shape is typical for a monovalent base, where the solubility increases with a decrease of the $\mathrm{pH}$, as the free base starts to convert to the protonated form. At around $\mathrm{pH} 3$, the solubility of the papaverine hydrochloride salt reaches the maximum $\left(\mathrm{pH}_{\max }\right)$, which is limited by the solubility product. Between $\mathrm{pH} 2$ and 3 there is a constant value for the salt solubility. Below pH 2 the solubility of the salt decreases due to the common ion effect, caused by chloride ions from $\mathrm{HCl}$ used to adjust the $\mathrm{pH}$.

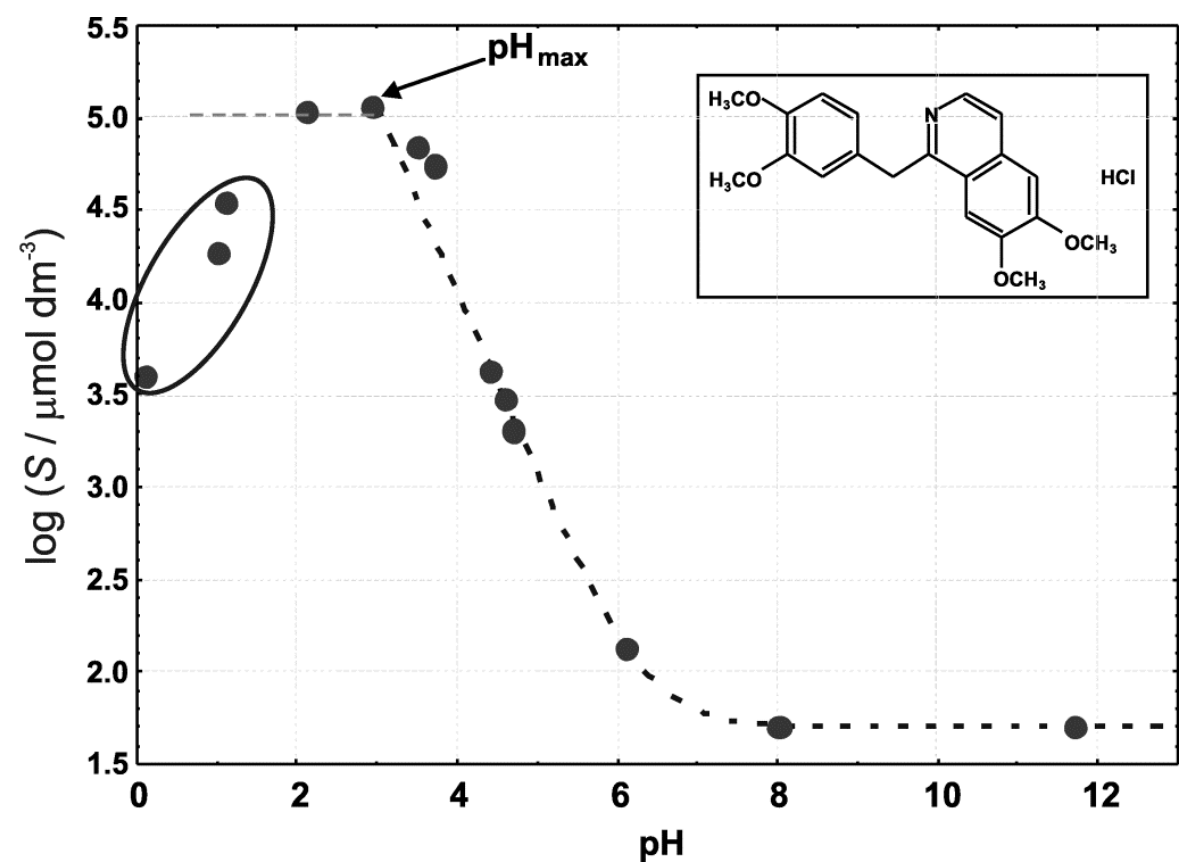

Figure 1.18. Solubility-pH profile of papaverine hydrochloride 
This example proves that the $\mathrm{HH}$ equation can be used for the calculation of solubility at physiological important $\mathrm{pH}$ values once the intrinsic solubility and the $\mathrm{p} K_{\mathrm{a}}$ value have been preciously determined [42].

Case 6.

$\begin{array}{ll}\text { Sample: } & \text { telmisartan } \\ \text { Method: } & \text { SSF } \\ \text { Instrumentation: } & \text { Radiometer PH220 pH meter; LAUDA thermostat; Heidolph } \\ & \text { MR } 1000 \text { magnetic stirrer; JASCO V-550 UV/VIS } \\ & \text { spectrophotometer }\end{array}$

The solubility of telmisartan was measured in distilled water (ordinarily $\mathrm{pH} \sim 6$ ) and at $37 \pm 0.1^{\circ} \mathrm{C}$ temperature (one of the conditions where solubility is required by the registration authorities). Solid material at $0.01 \mathrm{~g}$ was added to $20 \mathrm{ml}$ freshly boiled and cooled water and then the new (shorter) protocol derived from the SSF method was followed. Aliquots were taken out from the supernatant and the absorbance was measured without dilution at $\lambda=295 \mathrm{~nm}$, in a cell with a $5 \mathrm{~cm}$ pathlength. The concentration was calculated using $A^{1 \%}{ }_{1 \mathrm{~cm}}=510$ measured separately prior to solubility measurement. From three parallel experiments, the solubility of telmisartan was found as low as $S_{\mathrm{pH}}=0.50 \pm 0.09 \mu \mathrm{g} / \mathrm{ml}$. The relatively high error $(S D= \pm 18 \%)$ is due to the very low solubility (the lowest value we could ever measure by the SSF method) and the occasionally formed supersaturated solution, from which small (invisible) particles precipitated in the cell upon absorbance measurement.

Case 7.

$\begin{array}{ll}\text { Sample: } & \text { maprotiline } \\ \text { Method: } & \text { SSF and CheqSol } \\ \text { Instrumentation: } & \text { Radiometer PH220 pH meter; LAUDA thermostat; Heidolph } \\ & \text { MR } 1000 \text { magnetic stirrer; JASCO V-550 UV/VIS } \\ & \text { spectrophotometer and GLpKa + D-PAS }\end{array}$

The precise intrinsic solubility of maprotiline base $\left(\mathrm{p} K_{\mathrm{a}}=10.33\right)$ - another very sparingly soluble compound - could not be determined by the SSF method. The result obtained from three separate measurements in BR buffer at $\mathrm{pH} 11.5$ was $S_{0}=8.05 \pm 3 \mu \mathrm{g} / \mathrm{ml}$. The reason for the extremely high experimental error $(S D= \pm 37 \%)$ is that a colloid, slightly opalescent solution (perhaps due to recrystallization or supersaturation) was formed upon equilibration. This opalescence could be eliminated by neither filtration nor centrifugation. So, the SSF solubility result must be considered as an approximate value. Thus, the potentiometric method, namely the Chasing Equilibrium Solubility (CheqSol) was also applied. Maprotiline was added (2 $\mathrm{mg}$ ) to $10 \mathrm{ml}$ of $0.15 \mathrm{M} \mathrm{KCl}$ solution then preacidified with $0.5 \mathrm{M} \mathrm{HCl}$ to $\mathrm{pH} 2$ where the compound was fully dissolved. This solution was titrated with $0.5 \mathrm{M} \mathrm{KOH}$ until the solution became cloudy, which indicated the precipitation of the free base form. The occurrence of precipitation was detected using a spectroscopic dip probe then the solution was quickly 
brought close to equilibrium by adding very small amounts of acidic or basic titrants alternatively resulting in an oscillation between supersaturation and subsaturation. The Bjerrum plot of titration is shown in Figure 1.19. While the sample is fully dissolved, the experimental data fit well to the nonprecipitation theoretical curve (a). After precipitation, the points lie close to the precipitation theoretical curve (b). The precipitation point is used to calculate the kinetic solubility value. The intrinsic equilibrium solubility was determined from 40 data points with 8 zero $\mathrm{pH}$ gradient crossings.

The intrinsic solubility was obtained as average of 6 separate titrations, $S_{0}=5.8 \pm 0.3 \mu \mathrm{g} / \mathrm{ml}$. The low $S D$ indicates the higher precision of the data and the advantage of the CheqSol method in this case.

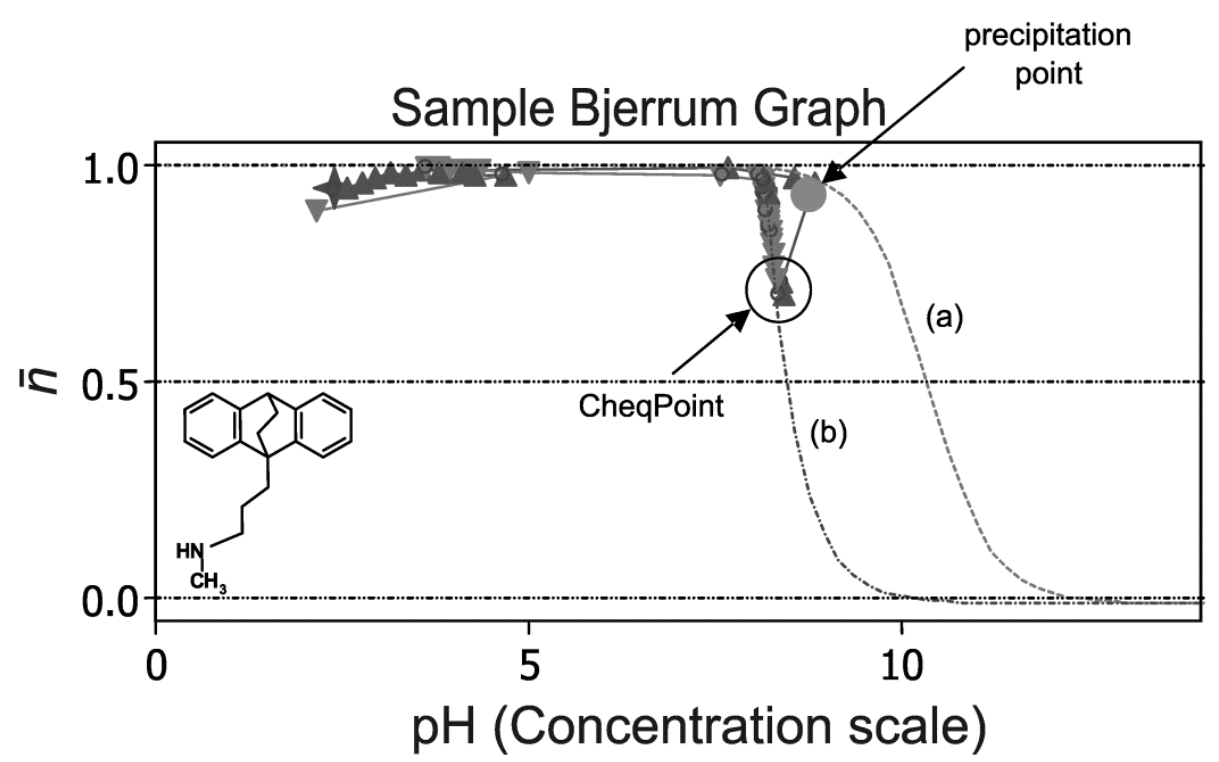

Figure 1.19. Bjerrum plot of solubility determination of maprotiline by CheqSol method. (a) nonprecipitation theoretical curve, (b) precipitation theoretical curve

Case 8.

Sample: $\quad$ venlafaxine $\mathrm{HCl}$

Method: SSF

Instrumentation: Radiometer PH220 pH meter; LAUDA M20S thermostat; Heidolph MR 1000 magnetic stirrer; JASCO V-550 UV/VIS spectrophotometer

Venlafaxine is a monovalent base $\left(\mathrm{p} K_{\mathrm{a}}=9.6\right)$, its hydrochloride salt can form different polymorphs. The solubility of two polymorph forms (I and II) was investigated at three $\mathrm{pH}$ values: 4.9 (unadjusted $\mathrm{pH}$ in distilled water), 8.9 (BR buffer), and $12(0.001 \mathrm{M} \mathrm{NaOH})$ at $37 \pm 0.1^{\circ} \mathrm{C}$ temperature using the SSF method. The results are summarized in Table 1.8. The salt solubility is higher than $50 \%$ $(\mathrm{g} / 100 \mathrm{ml})$ in the case of both polymorphs. The intrinsic solubility of venlafaxine 
measured at $\mathrm{pH} 12$ was also found to be the same for both I and II forms $\left(S_{\mathrm{o}}=460 \pm 10 \mu \mathrm{g} / \mathrm{ml}\right)$.

The diffraction analysis of the solid phase filtered out at the end of the solubility measurement revealed that polymorphs I and II equally converted to the same crystal form of free base venlafaxine. This experience underscores the need for analysis of the solid phase after the equilibrium state has been reached.

Table 1.8. Solubility (g/100 ml) of two polymorph forms of venlafaxine hydrochloride at three $\mathrm{pH}$ values and at $37^{\circ} \mathrm{C}$ temperature

\begin{tabular}{lccc}
\hline venlafaxine hydrochloride & $\boldsymbol{S}_{\mathbf{p H}}(\mathbf{p H} 4.9)$ & $\boldsymbol{S}_{\mathbf{p H}}(\mathbf{p H ~ 8 . 9 )}$ & $\boldsymbol{S}_{\mathbf{0}}(\mathbf{p H ~ 1 2 . 0 )}$ \\
\hline Form I & $>50$ & 0.180 & 0.046 \\
\hline Form II & $>50$ & 0.208 & 0.046 \\
\hline
\end{tabular}

\subsection{3. $\log P$ determination}

Case 9.

Sample: $\quad$ chlorpromazine

Method: SSF

Instrumentation: LAUDA M20S thermostat; Hawlett-Packard 8452A UV/VIS spectro-photometer

Chlorpromazine is a very lipophilic monovalent base ( $\left.\mathrm{p} K_{\mathrm{a}}: 9.24\right)$. The true $\log P$ value cannot be measured at high $\mathrm{pH}$ values $(>11.5)$ directly by the SF method because of the low solubility of the free base form of the compound at high $\mathrm{pH}$. In such cases (which is typical among drugs), the $\log \mathrm{D}^{\mathrm{pH}}$ is measured at different $\mathrm{pH}$ values at which the molecule partially ionizes and dissolves better and then it is converted to the true $\log P$ using Equation $1.30 \mathrm{~b}$. The $\log D^{\mathrm{pH}}$ values of chlorpromazine were measured at three $\mathrm{pH}$ values $(7.4,8.0$ and 8.5$)$ in BR buffer as the aqueous phase, using an $\mathrm{R}=200$ and 100 phase ratios (50 ml buffer : 0.25 $\mathrm{ml}$ octanol and $25 \mathrm{ml}$ buffer : $0.25 \mathrm{ml}$ octanol). We followed the standard protocol of the SF method: $1 \mathrm{~h}$ intensive shaking in a shaking thermostat; phase separation by centrifugation (730 $\mathrm{g}$ for $10 \mathrm{~min}$ ). The absorbance of the aqueous phase before $\left(A_{0}\right)$ and after $\left(A_{1}\right)$ the partition was measured by spectroscopy at $\lambda=254 \mathrm{~nm}$. The apparent partition coefficient is calculated according to $D^{\mathrm{pH}}=\left[\left(A_{0}-A_{1}\right) / A_{1}\right] R$ [104]. The lipopilicity-pH profile is shown in Figure 1.20.

Result: $\log P=5.13 \pm 0.10(n=18)$ 


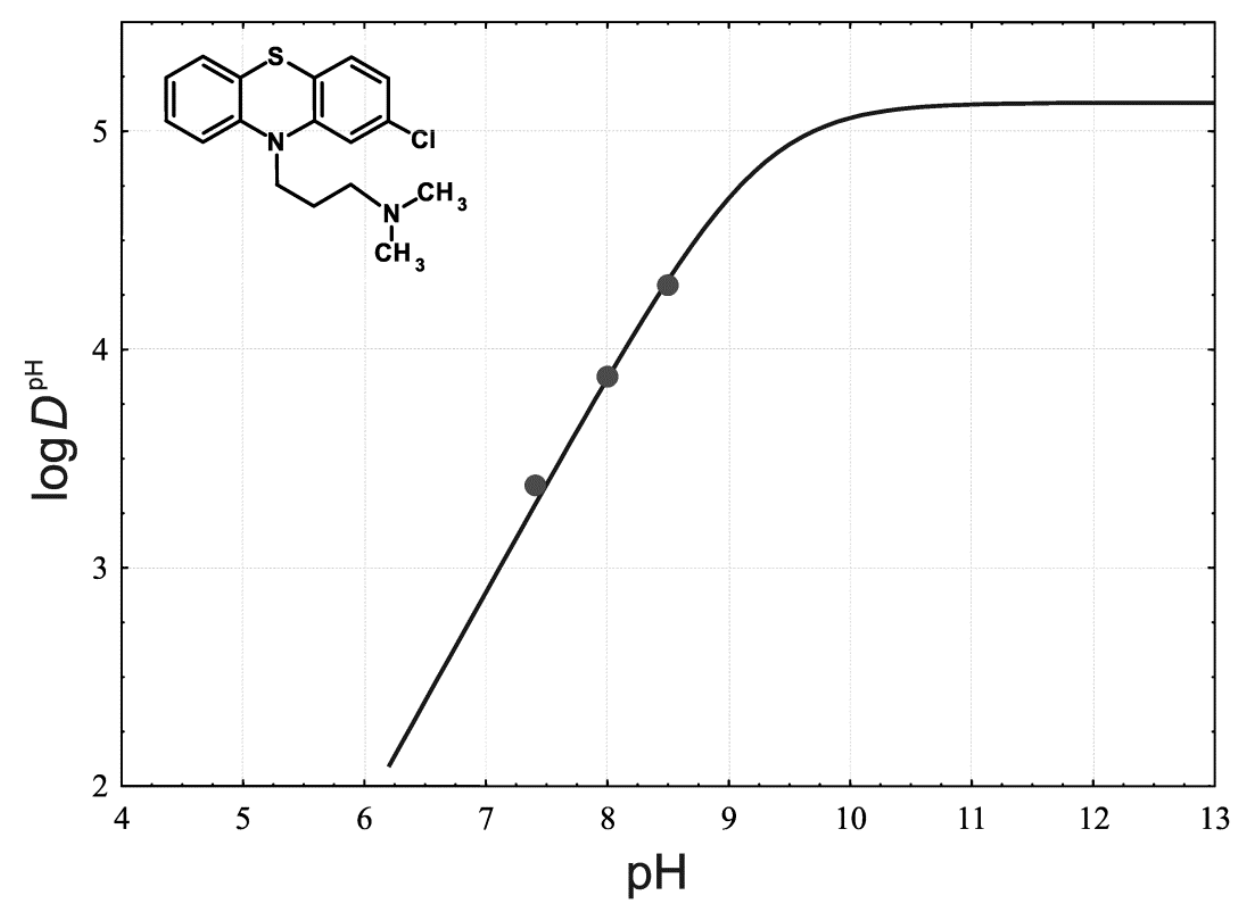

Figure 1.20. Lipophilicity-pH profile of chlorpromazine (points represent the experimentally measured log $D^{\mathrm{pH}}$ values)

Case 10.

Sample: deramciclane

Method: $\quad$ potentiometric method

Instrumentation: PCA 101 (Sirius, UK)

Deramciclane was an original anxiolytic molecule developed by EGIS (Hungary) in the late '90s, which unfortunately failed from clinical phase III. It is a sparingly soluble monovalent base $\left(\mathrm{p} K_{\mathrm{a}}=9.61\right)$. It has a very weak UV absorption (low specific absorptivity) thus lipophilicity determination by the SF method (as done in Case 9 ) is hindered. The $\log P$ value was measured by dual-phase potentiometric titration at $25.0 \pm 0.1{ }^{\circ} \mathrm{C}$ temperature, under $\mathrm{N}_{2}$ atmosphere. Six titrations were performed between $\mathrm{pH} 3$ and 12, in a $1 \mathrm{mM}$ concentration solution of the sample using $15 \mathrm{ml}$ water and $0.05 \mathrm{ml}$ octanol phase (Figure 1.21a). From these titrations the apparent $\mathrm{p} K_{\mathrm{a}}$ values (measured in the presence of octanol, $\mathrm{p}_{\mathrm{o}} K_{\mathrm{a}}$ ) were obtained. The Bjerrum plot (Figure 1.21b) shows big shift toward lower $\mathrm{pH}$ values (typical for bases) which indicates high lipophilicity of the sample. The log $P$ value is calculated according to the equation: $\log P=(10$ (pKa- poKa) -1$) / r$. The extreme (octanol/water) phase ratio $(r=0.0033)$ used here allowed lipophilicity measurement as high as $\log P=5.90 \pm 0.02(n=6)$. According to our experiences, this represents the upper limit of the $\mathrm{pH}$-metric $\log P$ determination method [113]. 
(a)

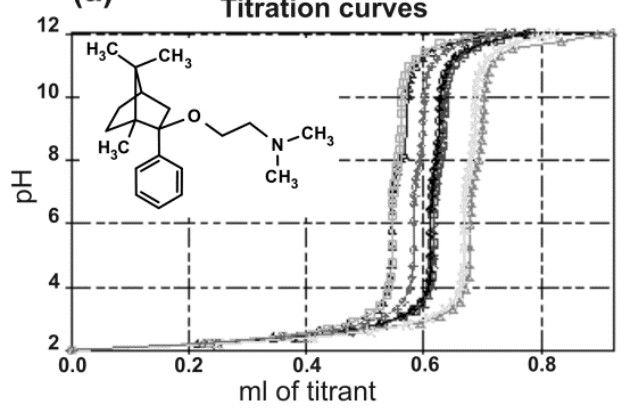

(b)

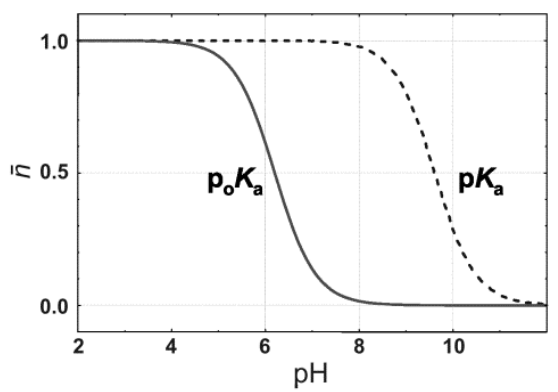

Figure 1.21. $\mathrm{pH}$-metric $\log P$ determination of deramciclane:

(a) titration curves in the presence of different amounts of octanol, (b) Bjerrum plot

Case 11.

Sample: $\quad$ prostaglandin $\mathrm{E}_{1}$-ethylester (PGEE)

Method: $\quad$ RP-TLC

Instrumentation: $\mathrm{RP}-\mathrm{diC}_{1}$ silanized plates, Merck \#5747; Camag

microsampler; Shimadzu CS-9301CP densitometer

PGEE is an example for molecules where classical, standard methods cannot be applied. Due to the lack of useful UV absorption (above $\lambda>230 \mathrm{~nm}$ ) or an ionizable group, neither the SF nor pH-metry can be used. Log $P$ was determined by a validated RP-TLC method.<smiles>CCCCCCCCC[C@H]1C(=O)C[C@@H](O)[C@@H]1/C=C/[C@H](O)CCCCC(=O)OCC</smiles>

Measurement was performed on $20 \mathrm{~cm}$ x $20 \mathrm{~cm}$ plates precoated with silanized silica gel $\mathrm{GF}_{254}$ as the stationary phase and methanol/water (55:45) as the mobile phase. Before use, the plates were washed with methanol (ascending development), then dried and heated at $160^{\circ} \mathrm{C}$ for $1 \mathrm{~h}$. The samples (PGEE and calibration set) were dissolved in a $1: 1$ methanol/chloroform mixture $(2 \mathrm{mg} / \mathrm{ml})$ and $2 \mu \mathrm{l}$ was spotted on the plate. The chamber was saturated with the mobile phase for $30 \mathrm{~min}$ before use. After development the plates were dried and evaluated by densitometry.

The calibration curve was set up using seven compounds [114] and obtained from three parallel runs: $\log P=3.508 R_{\mathrm{M}}+0.968(r=0.995, n=21)$. The $\log P$ of PGEE was calculated with the help of this equation.

Result: $\log P_{\mathrm{TLC}}=4.02 \pm 0.05(n=3)$. 


\subsection{OUTLOOK}

Concerning the role of physicochemical profiling in the future, we can certainly predict that it remains an integrated part of drug research providing a simple, cheap, and fast tool for the estimation of ADMET parameters in the early stage of DD\&D.

A higher level of automation (e.g. integration of several robotic platforms) and higher sensitivity of detection methods can be expected leading to the increase of the HT feature of the applied methods, but it must be synchronous with the improvement of the reliability of the data determined. Next to this, the costeffectiveness will be the critical factor in the selection between methods having the same capacity.

We can anticipate the increasing application of biorelevant experimental conditions in physicochemical profiling. Standardization and validation of these biomimetic systems are obviously necessary in the near future.

The use of in silico methods will be growing if further development of computational approaches results in even more reliable data. For the in silico methods based on big databases the quality of the input of experimental values must be further improved.

Finally, more effective usage of physicochemical profiling in drug research can be promoted by including informative courses or seminars, for example, in higher education to strengthen this special field of medicinal chemistry in academia.

\section{Acknowledgement}

I would like to thank my colleague Gergely Völgyi, PhD for his experimental work, valuable suggestions, and help in preparing the figures. I also thank the Hungarian National Science Foundation (Grant No.: OTKA K 78102) for financial support.

\section{REFERENCES}

1. J. Wang, L. Urban. The impact of early ADME profiling on drug discovery and development strategy. Drug Discovery World Fall (2004) 73-86.

2. C. Hansch, P.P. Maloney, T. Fujita, R. Muir. Correlation of biological activity of phenoxyacetic acids with Hammett substituent constants and partition coefficients. Nature 194 (1962) 178-180.

3. G.K. Dixon, J.P. Major, M.J. Rice., High Throughput Screening: The Next Generation Bios, Oxford, 2000.

4. K. Takács-Novák, G. Völgyi. Physicochemical profiling in drug research. Magyar Kémiai Folyóirat 111 (2005) 169-176 (Hungrian).

5. B. Testa, H. van de Waterbeemd, G. Folkers, R. Guy. , Pharmacokinetic Optimization in Drug Research. Biological, Physicochemical, and Computational Strategies, WileyVHCA, Zürich, 2001. 
6. L. Di, E.H. Kerns, G.T. Carter. Drug-like property concepts in pharmaceutical design. Current Pharmaceutical Design 15 (2009) 2184-2194.

7. E.H. Kerns. High throughput physicochemical profiling for drug discovery. Journal of Pharmaceutical Sciences 90 (2001) 1838-1858.

8. L. Di, E.H. Kerns. Application of pharmaceutical profiling assays for optimization of drug-like properties. Current Opinion in Drug Discovery and Development 8 (2005) 495-504.

9. E.H. Kerns, L. Di. Automation in pharmaceutical profiling. Journal of the Association for Laboratory Automation 10 (2005) 114-123.

10. P.J. Taylor. Hydrophobic properties of drugs. In C. Hansch, P.G. Sammes, J.B. Taylor, H. Lennernäs. (Eds.), Comprehensive Medicinal Chemistry Vol. 4, Pergamon, Oxford, 1990, pp 241-294.

11. A. Avdeef. Absorption and Drug Development: Solubility, Permeability and Charge State. Wiley, New York, 2003.

12. A. Avdeef, B. Testa. Physicochemical profiling in drug research: a brief survey of the state-of-the-art of experimental techniques. Cellular and Molecular Life Sciences 59 (2002) 1681-1689.

13. E.H. Kerns, L. Di. Physicochemical profiling: overview of the screens. Drug Discovery Today: Technologies 1 (2004) 343-348.

14. H. Wan, A.G. Holmén. High throughput screening of physicochemical properties and in vitro ADME profiling in drug discovery. Combinatorial Chemistry and High Throughput Screening 12 (2009) 315-329.

15. J. Wang, S. Skolnik. Recent advances in physicochemical and ADMET profiling in drug discovery. Chemistry and Biodiversity 6 (2009) 1887-1899.

16. Y. Henchoz, B. Bard, D. Guillarme, P-A. Carrupt, J-L. Veuthey, S. Martel. Analytical tools for the physicochemical profiling of drug candidates to predict absorption/distribution. Analytical and Bioanalytical Chemistry 394 (2009) 707729.

17. A. Pagliara, M. Reist, S. Geinoz, P-A. Carrupt, B. Testa. Evaluation and prediction of drug permeation. Journal of Pharmacy and Pharmacology 51 (1999) 1339-1357.

18. E. Kerns, L. Li. Drug-like properties: concepts, structure design and methods: from ADME to toxicity optimization. Elsevier, San Diego, 2008.

19. J.K. Seydel, M. Wiese. Drug-membrane interactions. Analysis, drug distribution, modeling. In: R. Mannhold, H. Kubinyi, G. Folkers. (Eds), Methods and Principles in Medicinal Chemistry. Wiley-VCH, Weinheim, 2002.

20. P.A. Shore, B.B. Brodie, C.A.M. Hogben. The gastric secretion of drugs: a $\mathrm{pH}$ partition hypothesis. Journal of Pharmacology and Experimental Therapeutics 119 (1957) 361-369.

21. R.P. Austin, A.M. Davis, C.N. Manners. Partitioning of ionizing molecules between aqueous buffers and phospholipid vesicles. Journal of Pharmaceutical Sciences $\mathbf{8 4}$ (1995) 1180-1183.

22. A. Avdeef, K. Box, J.E. Comer, C. Hibbert, K.Y. Tam. pH-metric logP. 10. Determination of vesicle membrane-water partition coefficients of ionizable drugs. Pharmaceutical Research 15 (1998) 209-215. 
23. S.D. Krämer, D. Lombardi, A. Primorac, A.V. Thomae, H. Wunderli-Allenspach. Lipid bilayer permeation of drug-like compounds. Chemistry and Biodiversity 6 (2009) 1900-1916.

24. Y. Sai, A. Tsuji. Transporter-mediated drug delivery: recent progress and experimental approaches. Drug Discovery Today 9 (2004) 712-720.

25. R. Didziapertis, P. Japertas, A. Avdeef, A. Petrauskas. Classification analysis of Pglycoprotein substrate specificity. Journal of Drug Targeting 11 (2003) 391-406.

26. A. Albert, E.P. Serjeant. The Determination of Ionization Constants. $3^{\text {rd }}$ ed. Chapman \& Hall, London, 1984.

27. B. Noszál. Acid-base properties of bioligands. In K. Burger, (Ed): Biocoordination Equilibria in Biologically Active Systems. Ellis Horwood, Chichester, 1990, pp 18-55.

28. K. Takács-Novák, B. Noszál, I. Hermecz, G. Keresztúri, B. Podányi, G. Szász. Protonation equilibria of quinolone antibacterials. Journal of Pharmaceutical Sciences 79 (1990) 1023-1028.

29. K. Mazák, S. Hosztafi, Á. Rácz, B. Noszál. Structural and physicochemical profiling of morphine and related compounds of therapeutic interest. Mini-Reviews in Medicinal Chemistry 9 (2009) 984-995.

30. K. Kóczián, G. Völgyi, J. Kökösi, B. Noszál. Site-specific acid-base properties of tenoxicam. Helvetica Chimica Acta 90 (2007) 1681-1690.

31. A. Dogan, E. Kilic. Tautomeric and microscopic protonation equilibria of some $\alpha$ amino acids. Analytical Biochemistry 365 (2007) 7-13.

32. K. Takács-Novák, B. Noszál, M. Tőkés-Kövesdi, G. Szász. Acid-base properties of terbutaline in terms of protonation macro- and microconstants. Journal of Pharmacy and Pharmacology 47 (1995) 431-435.

33. A. Marosi, Z. Kovács, S. Béni, J. Kökösi, B. Noszál. Triprotic acid-base microequilibria and pharmacokinetic sequelae of cetirizine. European Journal of Pharmaceutical Sciences 37 (2009) 321-328.

34. Z. Szakács, M. Kraszni, B. Noszál. Determination of microscopic acid-base parameters from NMR-pH titrations. Analytical and Bioanalytical Chemistry $\mathbf{3 7 8}$ (2004) 1428-1448.

35. N. Sum, A. Avdeef. Biorelevant $\mathrm{pK}_{\mathrm{a}}\left(37^{\circ} \mathrm{C}\right)$ predicted from the $2 \mathrm{D}$ structure of the molecule and its $\mathrm{pK}_{\mathrm{a}}$ at $25^{\circ} \mathrm{C}$. Journal of Pharmaceutical and Biomedical Analysis $\mathbf{5 6}$ (2011) 173-182.

36. H.H. Cocolas. Antiarrhythmic drugs. In J.N. Delgado, W.A. Remers. (Eds), Wilson and Gisvold's Textbook of Organic Medicinal and Pharmaceutical Chemistry. $9^{\text {th }}$ edition, Lippincott, New York, 1991 pp. 546-555.

37. S.H. Yalkowsky, S. Banerjee. Aqueous Solubility: Methods of Estimation for Organic Compounds. Marcel Dekker, New York, 1992.

38. D.J.W. Gant, T. Higuchi. Solubility Behavior of Organic Compounds. Wiley, New York, 1990.

39. A. Avdeef. Solubility of sparingly-soluble ionizable drugs. Advanced Drug Delivery Reviews 59 (2007) 568-590.

40. C.A.S. Bergström, K. Luthman, P. Artursson. Accuracy of calculated pH-dependent aqueous drug solubility. European Journal of Pharmaceutical Sciences 22 (2004) 387-398. 
41. A. Avdeef, D. Voloboy, A. Foreman. Dissolution-solubility: pH, buffer, salt, dualsolid, and aggregation effects. In B.Testa, H. van de Waterbeemd. (Eds): Comprehensive Medicinal Chemistry II. Vol. 5. ADME-TOX Approaches, Elsevier, Oxford, 2007 pp. 399-423.

42. G. Völgyi, E. Baka, K. Box, J.E. Comer, K. Takács-Novák. Study of pH-dependent solubility of organic bases. Revisit of Henderson-Hasselbalch relationship. Analytica Chimica Acta 673 (2010) 40-46.

43. G.L. Amidon, H. Lennernäs, V.P. Shah, J.R. Crison. A theoretical bases for a biopharmaceutic drug classification: The correlation of in vitro drug product dissolution and in vivo bioavailability. Pharmaceutical Research 12 (1995) 413420.

44. J.B. Dressmann, M. Vertzoni, K. Goumas, C. Reppas. Estimating drug solubility in the gastrointestinal tract. Advanced Drug Delivery Reviews 59 (2007) 591-602.

45. A. Leo, C. Hansch, D. Elkins. The partition coefficients and their uses. Chemical Reviews 71 (1971) 525-616.

46. A. Avdeef. Assessment of distribution-pH profiles. In V. Pliska, B. Testa, H. van de Waterbeemd. (Eds), Methods and Principles in Medicinal Chemistry. Vol. 4. CVH, Weinheim, 1996 pp. 109-139.

47. K. Takács-Novák, M. Józan, G. Szász. Lipophilicity of amphoteric molecules expressed by the true partition coefficient. International Journal of Pharmaceutics 113 (1995) 47-55.

48. N.P. Franks, M.H. Abraham, W.R. Lieb. Molecular organization of liquid n-octanol: An X-ray diffraction analysis. Journal of Pharmaceutical Sciences 82 (1993) 466470.

49. D.E. Leahy, P.J. Taylor, A.R. Wait. Model solvent systems for QSAR. 1. Propylene glycol dipelargonate (PGDP). A new standard for use in partition coefficient determination. Quantitative Structure-Activity Relationships 8 (1989) 17-31.

50. G.P.van Balen, C.A.M. Martinet, G. Caron, G. Bouchard, M. Reist, P-A. Carrupt, R. Fruttero, A. Gasco, B. Testa. Liposome/water lipophilicity: Methods, information content, and pharmaceutical application. Medical Research Reviews 24 (2004) 299324.

51. S. Krämer. Liposome/water partitioning: theory and applications. In B. Testa, H. van de Waterbeemd, G. Folkers, R. Guy. (Eds), Pharmacokinetic Optimization in Drug Research. Biological, Physicochemical, and Computational Strategies, WileyVHCA, Zürich, 2001.

52. C.A. Lipinski, F. Lombardo B.W. Dominy, P.J. Feeney. Experimental and computational approaches to estimate solubility and permeability in drug discovery and development settings. Advanced Drug Delivery Reviews 23 (1997) 325.

53. C. Hansch, J.P. Björkroth, A. Leo. Hydrophobicity and central nervous system agents: On the principle of minimal hydrophobicity in drug design. Journal of Pharmaceutical Sciences 76 (1987) 663-687.

54. G. Ferenczy, G.M. Keserű. Thermodynamics guided lead discovery and optimization. Drug Discovery Today 15 (2010) 919-932.

55. Z. Szakács, G. Hägele. Accurate determination of low $\mathrm{pK}$ values by $1^{\mathrm{H}} \mathrm{NMR}$ titration. Talanta, 62 (2004) 819-825. 
56. H. Hegedűs, A. Gergely, P. Horváth, B. Noszál. Acid-base properties of biological phenyl-alkyl-amines, characterized by CD-pH titration. Journal of Chemical Research Synopses (1999) 306-307.

57. F.Z. Oumada, C. Ràfols, M. Rosés, E. Bosch. Chromatographic determination of aqueous dissociation constants of some water-insoluble nonsteroidal antiinflammatory drugs. Journal of Pharmaceutial Sciences 91 (2002) 991-999.

58. K. Box, J.E. Comer. Using measured $\mathrm{pK}_{\mathrm{a}}, \log \mathrm{P}$ and solubility to investigate supersaturation and predict BCS class. Current Drug Metabolism 9 (2008) 869-878.

59. A. Avdeef, J.J. Bucher. Accurate measurement of the concentration of hydrogen ions with a glass electrode: Calibrations using the Prideaux and other universal buffer solutions and a computer-controlled automatic titrator. Analytical Chemistry $\mathbf{5 0}$ (1978) 2137-2142.

60. J.E.Comer. High-throughput measurement of $\log \mathrm{D}$ and $\mathrm{pK}_{\mathrm{a}}$. In P. Artursson, $\mathrm{H}$. Lennernäs, H. van de Warterbeemd. (Eds), Methods and Principles in Medicinal Chemistry. Vol. 18. Wiley-CVH, Weinheim, 2003 pp. 21-45.

61. R.I. Allen, K. Box, J.E. Comer, C. Peake, K.Y. Tam. Multiwavelength spectrophotometric determination of acid dissociation constants of ionisable drugs. Journal of Pharmaceutical and Biomedical Analysis 17 (1998) 699-712.

62. K.Y. Tam, K. Takács-Novák. Multiwavelength spectrophotometric determination of acid dissociation constants: a validation study. Analytica Chimica Acta 434 (2001) 157-167.

63. Z. Mandić, V. Gabelica. Ionization, lipophilicity and solubility properties of repaglinide. Journal of Pharmaceutical and Biomedical Analysis 41 (2006) 866-871.

64. M-H. Langlois, M. Montagut, J-P. Dubost, J. Grellet, M-C. Saux. Protonation equilibrium and lipophilicity of moxifloxacin. Journal of Pharmaceutical and Biomedical Analysis 37 (2005) 389-393.

65. M. Tollinger, J.D. Forman-Kay, L.E. Kay. Measurement of side-chain carboxyl $\mathrm{pK}_{\mathrm{a}}$ values of glutamate and aspartate residues in an unfolded protein by multinuclear NMR spectroscopy. Journal of American Chemical Society 124 (2002) 5714- 5717.

66. Z. Szakács, S. Béni, Z. Varga, L. Őrfi, G. Kéri, B. Noszál. Acid-base profiling of imatinib and its fragments. Journal of Medicinal Chemistry 48 (2005) 249-255.

67. Z. Jia. Physicochemical profiling by capillary electrophoresis. Current Pharmaceutical Analysis 1 (2005) 41-56.

68. S. Babić, A.J.M. Horvat, D. Mutavdžić Pavlović, M. Kaštelan-Macan. Determination of $\mathrm{pK}_{\mathrm{a}}$ values of active pharmaceutical ingredients. Trends in Analytical Chemistry $\mathbf{2 6}$ (2007) 1043-1061.

69. S.K. Poole, S. Patel, K. Dehring, H. Workman, C.F. Poole. Determination of acid dissociation constants by capillary electrophoresis. Journal of Chromatography A 1037 (2004) 445-454.

70. S. Pang, J. Kenseth, S. Coldiron. High throughput multiplexed capillary electrophoresis in drug discovery. Drug Discovery Today 9 (2004) 1072-1080.

71. K. Box, J.E. Comer, P. Hosking, K.Y. Tam, L. Trowbridge, A. Hill. Rapid physicochemical profiling as an aid to drug candidate selection. In G.K. Dixon, J.S. Major, M.J. Rice (Eds), High Throughput Screening: The Next Generation. Bios, Oxford, 2000, pp. 67-74. 
72. K. Box, C. Bevan, J.E. Comer, A. Hill, R. Allen, D. Reynolds. High-throughput measurement of $\mathrm{pK}_{\mathrm{a}}$ values in a mixed-buffer linear $\mathrm{pH}$ gradient system. Analytical Chemistry 75 (2003) 883-892.

73. A. Avdeef, J.E. Comer, S.J. Thomson. pH-metric logP. 3. Glass electrode calibration in methanol/water, applied to $\mathrm{pK}_{\mathrm{a}}$ determination of water-insoluble substances. Analytical Chemistry 65 (1993) 42-49.

74. K. Takács-Novák, K.Box, A. Avdeef. Potentiometric $\mathrm{pK}_{\mathrm{a}}$ determination of waterinsoluble compounds: validation study in methanol/water mixtures. International Journal of Pharmaceutics 151 (1997) 235-248.

75. K. Box, G. Völgyi, R. Ruiz, J.E. Comer, K. Takács-Novák, E. Bosch, C. Ràfols, M. Rosés. Physicochemical properties of a new multicomponent cosolvent system for the $\mathrm{pK}_{\mathrm{a}}$ determination of poorly soluble pharmaceutical compounds. Helvetica Chimica Acta 90 (2007) 1538-1553.

76. G. Völgyi, R. Ruiz, K. Box, J.E. Comer, E. Bosch, K. Takács-Novák. Potentiometric and spectrophotometric $\mathrm{pK}_{\mathrm{a}}$ determination of water-insoluble compounds: Validation study in a new cosolvent system. Analytica Chimica Acta 583 (2007) 418-428.

77. C. Lipinski. Computational and experimental approaches to avoiding solubility and oral absorption problems in early discovery. In R. Borchard (Ed), Designing Drugs with Optimal in Vivo Activity after Oral administration. Drew University Residential School on Medicinal Chemistry, Madison, NJ. 2000.

78. C. Bevan, R.S. Lloyd. A high throughput screening method for the determination of aqueous solubility by laser nephelometry in microtitre plates. Analytical Chemistry 72 (2000) 1781-1787.

79. A. Avdeef. High-throughput measurements of solubility profiles. In B. Testa, H. van de Waterbeemd, G. Folkers, R. Guy (Eds), Pharmacokinetic Optimization in Drug Research. Biological, Physicochemical, and Computational Strategies, Wiley-VHCA, Zürich, 2001. pp. 305-326.

80. T. Yamashita, Y. Dohta, T. Nakamura, T. Fukami. High-speed solubility screening assay using ultra-performance liquid chromatography/mass spectrometry in drug discovery. Journal of Chromatography A 1182 (2008) 72-76.

81. E. Baka, J.E. Comer, K. Takács-Novák. Study of equilibrium solubility measured by saturation shake-flask method using hydrochlorothiazide as model compound. Journal of Pharmaceutical and Biomedical Analysis 46 (2008) 335-341.

82. E. Baka. Good laboratory practice of equilibrium solubility measurements. Acta Pharmaceutica Hungarica 81 (2011) 18-28 (Hungarian).

83. A. Avdeef. pH-metric solubility. 1. Solubility $\mathrm{pH}$ profiles from Bjerrum plots. Gibbs buffer and $\mathrm{pK}_{\mathrm{a}}$ in the solid state. Pharmacy and Pharmacology Communications 4 (1998) 165-178.

84. A. Avdeef, C.M. Berger, C. Brownell. pH-metric solubility. 2. Correlation between the acid-base titration and the saturation shake-flask solubility-pH methods. Pharmaceutical Research 17 (2000) 85-89.

85. A. Avdeef, C.M. Berger. pH-metric solubility. 3. Dissolution titration template method for solubility determination. European Journal of Pharmaceutical Sciences 14 (2001) 281-291.

86. M. Stuart, K. Box. Chasing equilibrium: measuring of the intrinsic solubility of weak acids and bases. Analytical Chemistry 77 (2005) 983-990. 
87. K. Box, G. Völgyi, E. Baka, M. Stuart, K. Takács-Novák, J.E. Comer. Equilibrium versus kinetic measurements of aqueous solubility and the ability of compounds to supersaturate in solution. A validation study. Journal of Pharmaceutical Sciences 95 (2006) 1298-1307.

88. A. Avdeef, 0. Tsinman. Miniaturized rotating disk intrinsic dissolution rate measurement: Effect of buffer capacity in comparisons to traditional Wood's apparatus. Pharmaceutical Research 25 (2008) 2613-2627.

89. K. Tsinman, A. Avdeef , 0. Tsinman, D. Voloboy. Powder dissolution method for estimating rotating disk intrinsic dissolution rates of low solubility drugs. Pharmaceutical Research 26 (2009) 2093-2100.

90. A. Glomme, J. März, J.B. Dressman. Comparison of a miniaturized shake-flask solubility method with automated potentiometric acid/base titrations and calculated solubilities. Journal of Pharmaceutical Sciences 94 (2005) 1-16.

91. A. Glomme, J. März, J.B. Dressman. Predicting the intestinal solubility of poorly soluble molecules. In B. Testa, S.D. Krämer, H. Wunderli-Allenspach, G. Folkers (Eds), Pharmacokinetic Profiling in Drug Research: Biological, Physicochemical and Computational Strategies, Wiley-VCH, Weinheim, 2006. pp 259-280.

92. L. Zhou, L. Yang, L., S. Tilton, J. Wang. Development of a high throughput equilibrium solubility assay using miniaturized shake-flask method in early drug discovery. Journal of Pharmaceutical Sciences 96 (2007) 3052-3071.

93. A.T. Serajuddin. Salt formation to improve drug solubility. Advanced Drug Delivery Reviews 59 (2007) 603-616.

94. J. Alsenz, E. Meister, E. Haenel. Development of a partially automated solubility screening (PASS) assay for early drug development. Journal of Pharmaceutical Sciences 96 (2007) 1748-1762.

95. A. Llinàs, K. Box, J. Burley, R. Glen, J. Goodman. A new method for the reproducible generation of polymorphs: two forms of sulindac with very different solubilities. Journal of Applied Crystallography 40 (2007) 379-381.

96. B. Bard, S. Martel, P-A. Carrupt. High throughput UV method for the estimation of thermodynamic solubility and the determination of the solubility in biorelevant media. European Journal of Pharmaceutical Sciences 33 (2008) 230-240.

97. J. Fagenberg, O. Tsinman, N. Sun, K. Tsinman, A. Avdeef, C. Bergström. Dissolution rate and apparent solubility of poorly soluble drugs in biorelevant dissolution media. Molecular Pharmaceutics 7 (2010) 1419-1430.

98. A. Hersey, A. Hill, R. Hyde, D. Livingstone. Principles of method selection in partition studies. Quantitative Structure-Activity Relationships 8 (1989) 288-296.

99. L-G. Danielsson, Y-H. Zhang. Methods for determining $n$-octanol-water partition constants. Trends in Analytical Chemistry 15 (1996) 188-196.

100. J.E. Comer, K. Tam. Lipophilicity profiles: theory and measurement. In B. Testa, B., H. van de Waterbeemd, G. Folkers, R. Guy (Eds), Pharmacokinetic Optimization in Drug Research. Biological, Physicochemical, and Computational Strategies, WileyVHCA, Zürich, 2001. pp. 275-304.

101. J.C. Dearden, G.M. Bresnen. The measurement of partition coefficient. Quantitative Structure-Activity Relationships 7 (1988) 133-144. 
102. K. Takács-Novák. Practical aspects of determination of partition coefficient according to GLP rules. Acta Pharmaceutica Hungarica 67 (1997) 179-191 (Hungarian).

103. B. Slater, A. McCormack, A. Avdeef, J.E. Comer. pH-metric logP. 4. Comparison of partition coefficients determined by shake-flask, HPLC and potentiometric methods. Journal of Pharmaceutical Sciences 83 (1994) 1280-1283.

104. K. Takács-Novák, A. Avdeef. Interlaboratory study of logP determination by shakeflask and potentiometric methods. Journal of Pharmaceutical and Biomedical Analysis 14 (1996) 1405-1413.

105. K. Valkó. Application of high-performance liquid chromatography based measurements of lipophilicity to model biological distribution. Journal of Chromatography A 1037 (2004) 299-310.

106. R. Kaliszan. QSRR: Quantitative structure-(chromatographic) retention relationships. Chemical Reviews 107 (2007) 3212-3246.

107. G.L. Biagi, A.M. Barbaro, A. Sapone, M. Recenatini. Determination of lipophilicity by means of reversed-phase thin-layer chromatography. I. Basic aspects and relationship between slope and intercept in TLC equations. Journal of Chromatography A 662 (1994) 341-361.

108. A. Pyka, M. Babuska. Lipophilicity of selected steroid compounds. I. Investigations on RP18W stationary phase by RP-HPTLC. Journal of Liquid Chromatography and Related Technologies 29 (2006) 1891-1903.

109. Z. Rozmer, P. Perjési, K. Takács-Novák. Use of RP-TLC for logP determination of isomeric chalcones and cyclic chalcone analogues. Journal of Planar Chromatography 19 (2006) 124-128.

110. G. Völgyi, K. Deák, J. Vámos, K. Valkó, K. Takács-Novák. RPTLC determination of $\log$ P of structurally diverse neutral compounds. Journal of Planar Chromatography 21 (2008) 143-149.

111. L. Hitzel, A.P. Watt, K.L. Locker. An increased throughput method for the determination of partition coefficients. Pharmaceutical Research 17 (2000) 13891395.

112. D.M. Wilson, X. Wang, E. Walsh, R.A. Rourick. High throughput logD determination using liquid chromatography-mass spectrometry. Combinatorial Chemistry and High Throughput Screening 4 (2001) 511-519.

113. K. Takács-Novák. Investigation of physicochemical properties of deramciclane (EGIS-3886), a new anxiolytic compound. Acta Pharmaceutica Hungarica 69 (1999) 123-127 (Hungarian).

114. K. Takács-Novák, P. Perjési, J. Vámos. Determination of logP for biologically active chalcones and chalcone analogs by RPTLC. Journal of Planar Chromatography 14 (2001) 42-46. 